UNIVERSIDADE DE SĀO PAULO

INSTITUTO DE GEOCIENCIAS

\title{
REVISÃO SISTEMÁTICA DOS CONULATAE COLLINS ET AL. 2000, FORMAÇÃO PONTA GROSSA, DEVONIANO (?LOCHKOVIANO-FRASNIANO), BACIA DO PARANÁ, BRASIL: IMPLICAÇÕES PALEOBIOGEOGRÁFICAS E COMENTÁRIOS SOBRE AS RELAÇŌES FILOGENÉTICAS ENTRE OS CONULATAE
}

Juliana de Moraes Leme

Orientador: Prof. Dr. Marcello Guimarães Simões

DISSERTAÇÃO DE MESTRADO

Programa de Pós-Graduação em Geologia Sedimentar 
UNIVERSIDADE DE SÃO PAULO

INSTITUTO DE GEOCIÊNCIAS

REVISÃO SISTEMÁTICA DOS CONULATAE COLLINS ET AL. 2000, FORMAÇÃO PONTA GROSSA, DEVONIANO (?LOCHKOVIANOFRASNIANO), BACIA DO PARANÁ, BRASIL: IMPLICAÇÕES PALEOBIOGEOGRÁFICAS E COMENTÁRIOS SOBRE AS RELAÇÕES FILOGENÉTICAS ENTRE OS CONULATAE

\author{
JULIANA DE MORAES LEME
}

Orientador: Prof. Dr. Marcello Guimarães Simões

DISSERTAÇÃO DE MESTRADO

COMISSÃO JULGADORA

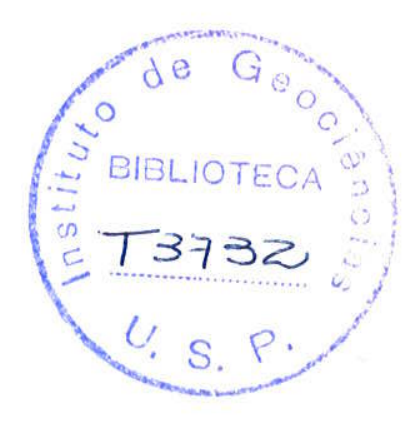

\begin{abstract}
Nome
Presidente: $\quad$ Prof. Dr. Marcelo Guimarães Simões

Examinadores: Prof. Dr. Nelson Bernardi
\end{abstract}

Prof. Dr. Setembrino Petri

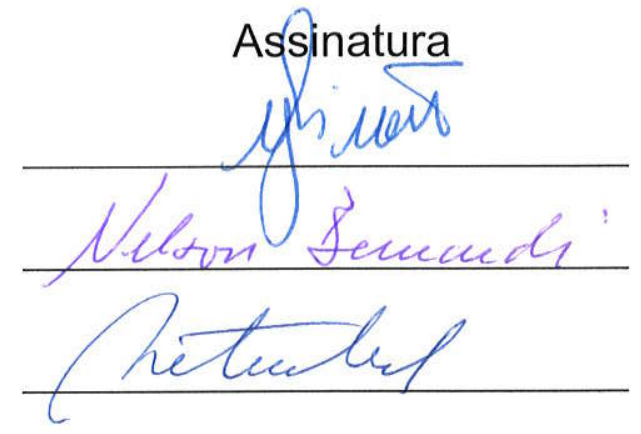

SÃO PAULO

2002 


\section{UNIVERSIDADE DE SÃO PAULO INSTITUTO DE GEOCIÊNCIAS}

REVISÃO SISTEMÁTICA DOS CONULATAE COLLINS ET AL. 2000, FORMAÇÃO PONTA GROSSA, DEVONIANO (?LOCHKOVIANOFRASNIANO), BACIA DO PARANÁ, BRASIL: IMPLICAÇÕES PALEOBIOGEOGRÁFICAS E COMENTÁRIOS SOBRE AS RELAÇÕES FILOGENÉTICAS ENTRE OS CONULATAE

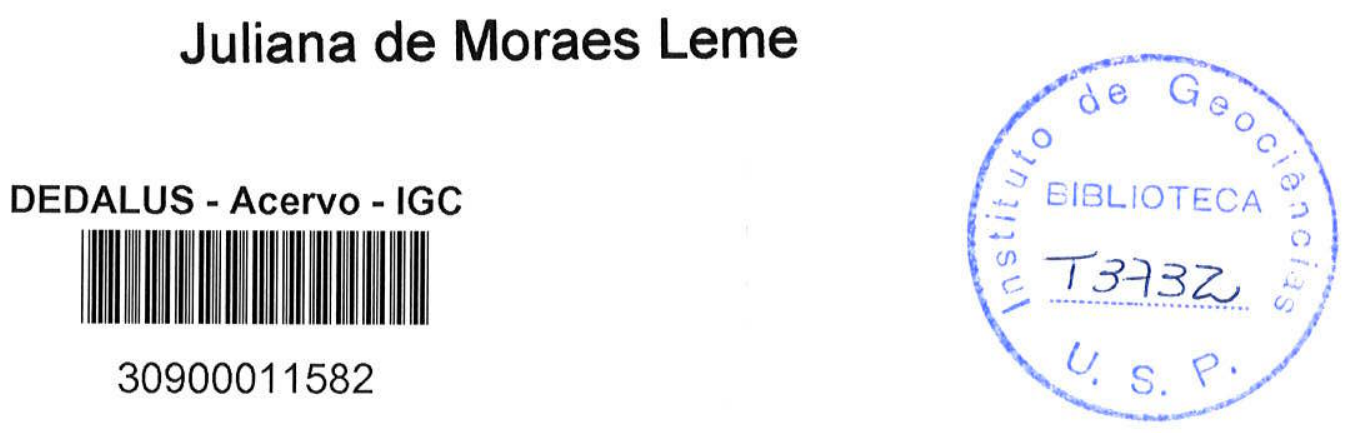

Orientador: Prof. Dr. Marcello Guimarães Simões

DISSERTAÇÃO DE MESTRADO

Programa de Pós-Graduação em Geologia Sedimentar 


\section{SUMÁRIO}

I. LISTA DE FIGURAS

II. LISTA DE QUADROS

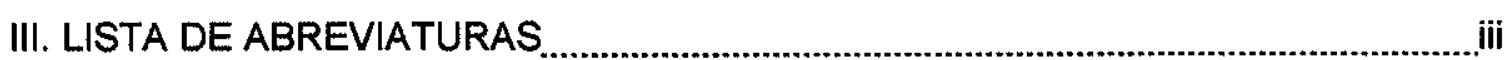

IV. AGRADECIMENTOS

V. RESUMO

VI. ABSTRACT

1. INTRODUÇÃO

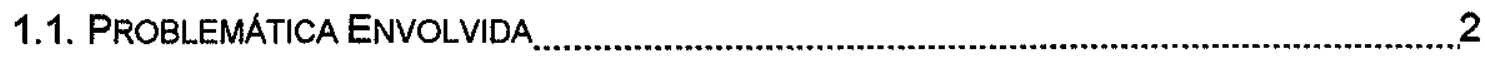

1.2. JUSTIFICATIVA

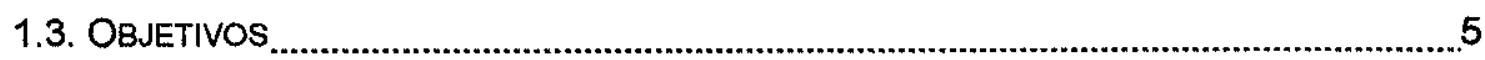

1.4. REVISÃO CRITICA DA LITERATURA

2. MATERIAL E MÉTODOS

2.1. ARCABOUÇO CONCEITUAL E METODOLOGgICO ADOTADO

2.2. PROCEDENCIA DAS AMOSTRAS

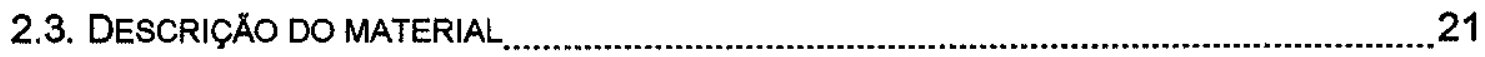

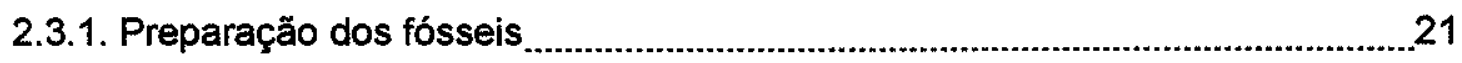

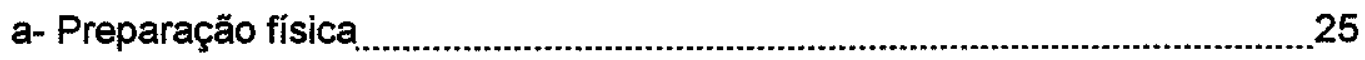

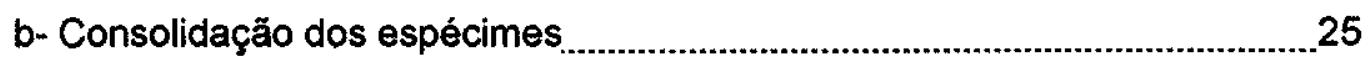

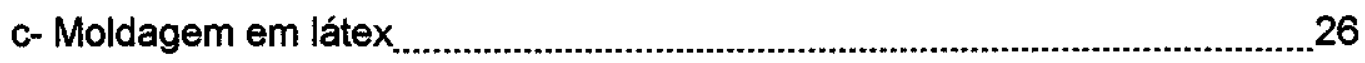

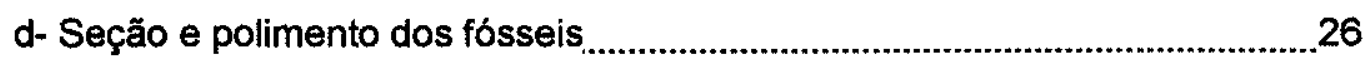

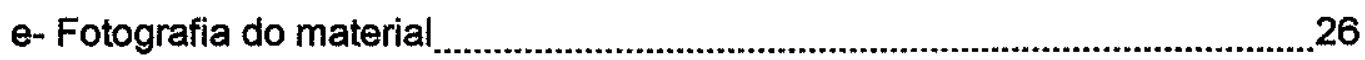

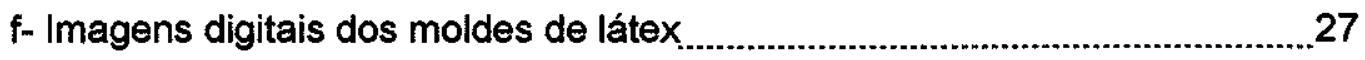

3. RESULTADOS

3.1. PALEONTOLOGIA SISTEMÁTICA

4. DISCUSSÃO

4.1. ATRIBUTOS E TERMOS MORFOLOGICOS

4.2. AFINIDADES DA FAUNA DE CONULARIOS DA FORMAÇÃO PONTA GROSSA ................... 51

4.3. DISTRIBUIÇÃO ESTRATIGRÁFICA DOS CONULÁRIOS DA FORMAÇÃO PONTA GROSSA .. 57

5. CONSIDERAÇŐES FINAIS

5.1. CONCLUSÕES

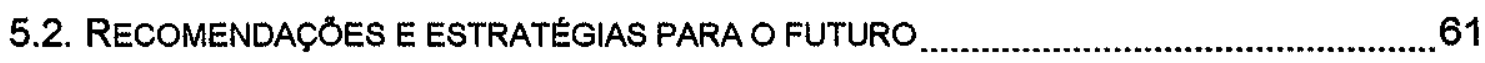

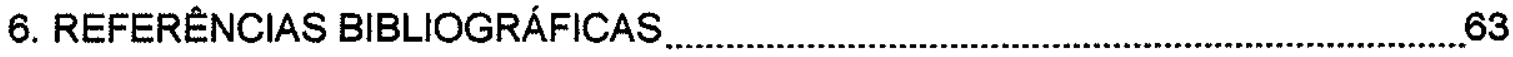


APENDICE

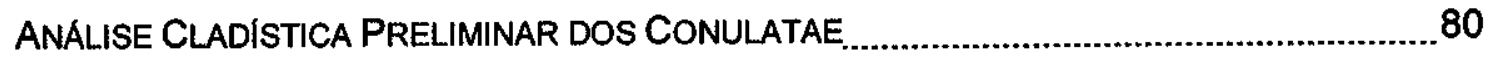

ANEXO

I. QUADRO DE RELAÇÃO DE ESPECIMES DE CONULÁRIOS EXAMINADOS, DEPOSITADOS NAS COLEÇOES CIENTIFICAS DA UNESP, USP, UNG E UEPG. 


\section{LISTA DE FIGURAS}

FIGURA 1- Mapa de localização dos afloramentos da Formaçăo Ponta Grossa 18

FIGURA 2- Diagrama espaço-tempo para o intervalo "Furnas-Ponta Grossa", na subbacia de Apucarana 19

FIGURA 3- Seção colunar do afloramento situado na estrada de ferro JaguariaivaArapoti, Jaguariaíva, PR, Formação Ponta Grossa, Seqüência B. 20

FIGURA 4- Morfologia geral dos conulários 22

FIGURA 5- Comparação entre estruturas internas de Conulatae e Stauromedusae.......23

FIGURA 6- Comparação entre estruturas internas de Conulatae e Coronatae. 23

FIGURA 7- Conularia quichua, agrupamento e cinco faces. 39

FIGURA 8- Esfoliação da teca de conulários 46

FIGURA 9- Conularia quichua com leve achatamento ântero-posterior 49

FIGURA 10- Mapas paleobiogeográficos devonianos 52

ESTAMPA 1- Conularia quichua, estruturas internas 34

ESTAMPA 2- Conularia quichua, morfologia geral 36

ESTAMPA 3- Paraconularia africana, morfologia geral e estruturas internas .43 APÉNDICE

FIGURA 1- Caráter 1. Ornamentação no sulco da aresta 85

FIGURA 2- Caráter 2. Ornamentação da teca. 85

FIGURA 3- Caráter 3. Ornamentação no cordão. 87

FIGURA 4- Caráter 4. Dobra externa na linha mediana 87

FIGURA 5- Caráter 5. Espessamento interno da teca.. 88

FIGURA 6- Caráter 6. Espaçamento da ornamentação da teca. .88

FIGURA 7- Caráter 7. Flexão adapertural dos cordöes na região da linha mediana $\ldots . . . . .88$

FIGURA 8- Cladograma resultante de análise de consenso estrito de 89 cladogramas 91 


\section{LISTA DE QUADROS}

QUADRO 1- Composição taxonômica das faunas de conulários das principais áreas do Domínio Malvinocáfrico 54

APENDICE

QUADRO 1- Subfamílias e gêneros da família Conulariidae e Conulariellidae 83

QUADRO 2- Matriz de caracteres morfológicos. 89 


\section{LISTA DE ABREVIATURAS}

IBB/UNESP. Instituto de Biociências, Universidade Estadual Paulista, Câmpus de Botucatu;

IGc/USP- Instituto de Geociências, Universidade de São Paulo, Câmpus de São Paulo;

UNG- Universidade de Guarulhos;

UEPG- Universidade Estadual de Ponta Grossa;

DZP. Departamento de Zoologia, Paleontologia. Sigla da Coleção Científica de Paleontologia do Departamento de Zoologia, IBB/UNESP;

GPIE-Sigla da Coleção de Entrada do Departamento de Paleontologia e Estratigrafia, IGc/USP;

CuPg-Sigla de controle interno da Coleção Científica de Paleontologia do Laboratório de Geociências, UNG;

D-058- Sigla da Coleção Científica de Paleontologia do Departamento de Geociências, UEPG; 


\section{AGRADECIMENTOS}

Gostaria de expressar os meus mais sinceros agradecimentos à diversas pessoas e instituições que contribuíram para a realização dessa pesquisa, dentre esses:

Ao Prof. Dr. Marcello Guimarães Simões pela orientação, estímulo constante $\Theta$ confiança na elaboração desta dissertação, pelo exemplo profissional, pela aprendizagem acadêmica e pessoal, além da oportunidade oferecida;

À Fundação de Amparo à Pesquisa do Estado de São Paulo (FAPESP), pelos financiamentos concedidos na forma de Bolsa de Iniciação Científica (Proc. 99/10824-1) e Bolsa de Mestrado (Proc. 00/14904-9);

Ao Instituto de Geociências, e ao Departamento de Geologia Sedimentar e Ambiental, pela infraestrutura oferecida;

Ao Departamento de Zoologia do IBB/UNESP, especialmente ao Laboratório de Paleozoologia Evolutiva, por facultar o uso de suas instalações, equipamentos e coleções;

À Profa. Dra. Maria Lucia Negreiros Fransozo (Depto. Zoologia, IBB-UNESP), por facultar o uso de equipamentos ópticos, obtidos através do projeto FAPESP (Proc. 98/03134-6), para obtenção das imagens digitais.

Ao Prof. Dr. Heyo Van Iten (Hanover College, Indiana), pelo envio de várias separatas importantes e de difícil acesso, além das longas discussões e comentários que ajudaram a enriquecer esse documento;

Ao Prof. Dr. Antonio Carios Marques (Depto. de Zoologia, Instituto de Biociências, USP, campus de São Paulo), pelo auxílio nas discussões e elaboração da matriz de caracteres morfológico de Conulatae; 
Aos Profs. Élvio Bosseti (UEPG), Luis Eduardo Anelli (USP), Maria Judite Garcia (UNG) e Rita de Cássia Tardin Cassab (CPRM), pela gentileza em permitir o exame das coleções cientificas das instituições, acima, além do empréstimo do material de conulários e Sphenothallus;

Ao Prof. Dr. Nelson Bernardi, pelas traduções dos textos em alemão e comentários sobre o uso de termos morfológicos empregados, bem como outras discussões;

Ao Prof. Dr. Fábio Lang da Silveira (IB/USP) e Ms. André Camarra Morandini, pela doação de espécimes de coronados e pelo auxílio na obtenção de separatas;

Ao Prof. Dr. Antônio Carlos Sequeira Fernandes (Museu Nacional, UFRJ), pelo auxílio na obtenção de separatas de difícil acesso;

Ao Prof. Dr. Fernando Portela Marques e ao Ms. Luiz Henrique Cruz de Mello, pela colaboração no uso dos programas computacionais;

Aos estudantes de Pós-graduação (IGc/USP) Biol. Sabrina Coelho Rodrigues, Ms. Renato Pirani Ghilardi, Ms. Alexandre Magno Feitosa Sales, Ms. Luiz Henrique Cruz de Mello, Ms. Fernanda de Freitas Torello e aos estudantes de graduação (IBB-UNESP) Marcos César Bissaro Jr., Fawaz Ali Jamal Filho, pela ajuda nos trabalhos de campo;

Ao técnico do Departamento de Zoologia (IB/UNESP) Sr. Hamilton Antônio Rodrigues pelo auxílio e disposição nos trabalhos de campo;

A Sra. Lígia Barrozo Simões, pelo trabalho fotográfico;

A Sra. Maria Antonieta Caricati Silva, pela confecção dos desenhos;

Aos estudantes do Laboratório de Paleozoologia Evolutiva, pela amizade estabelecida; 
A Sabrina Coelho Rodrigues, pelo companheirismo profissional, pela paciência e ajuda nas horas dificeis, por compartilhar experiências de vida, mas, principalmente, pela nossa grande amizade;

Ao Sr. Renato Pirani Ghilardi, pela colaboração em todos os momentos, pela amizade e companheirismo;

Ao Alexandre Magno F. Sales, pela amizade e apoio em São Paulo, SP;

À família Miyamoto, por me receber como filha em sua casa, durante minha estada em São Paulo e também pelo carinho, apoio e amizade;

A minha mãe, pela minha formação, pelo exemplo de vida, pelo amparo $e$, principalmente, pelo amor e carinho que nunca me faltaram;

Ao Rafael, meu companheiro, por toda a compreensão e paciência, pelo apoio e por tudo que sente por mim. 


\section{RESUMO}

Este estudo compreende a primeira revisão sistemática dos Conulatae Collins et al. 2000 (Cnidaria) da Formação Ponta Grossa, Devoniano (?Lochkoviano-Frasniano), Bacia do Paraná, desde 1913. O exame de 133 espécimes de conulários, provenientes das regiões de Jaguariaiva e Ponta Grossa, Estado do Paraná, indica que, pelo menos, duas espécies estão presentes na Formação Ponta Grossa, ou seja: Conularia quichua Ulrich e Paraconularia africana (Sharpe). Uma terceira espécie, Paraconularia ulrichana (Clarke), identificada por Clarke (1913), não foi identificada nas coleções examinadas. Constatou-se ainda que os espécimes atribuídos por Clarke (1913) à $P$. africana não pertencem a essa espécie. Desse modo, os espécimes aqui descritos como Paraconularia africana são os primeiros identificados e ilustrados para a Formação Ponta Grossa.

Notavelmente, espécimes de C. quichua e P. africana da Formação Ponta Grossa têm caracteres morfológicos internos da teca preservados. A teca de $C$. quichua, por exemplo, exibe espessamentos internos nas arestas, bem como uma estrutura mineralizada na base, à moda de um "pilar central". Tais feições são também, pela primeira vez, descritas para essas espécies. Entretanto, a estrutura denominada de "pilar central" é referida, pela primeira vez, para os Conulatae. Em decorrência das observações acima, a diagnose especifica de $C$. quichua e $P$. africana foi emendada.

Indivíduos da espécie C. quichua ocorrem isolados ou formando agrupamentos com dois ou três exemplares. Anteriormente, agrupamentos de indivíduos do gênero Conularia estavam restritos às espécies C. splendida Billing, C. tenuicosta Ruedemann e C. congregata Hall, que ocorrem América do Norte.

C. quichua e $P$. africana são duas espécies de ampla ocorrência no Devoniano, sendo especialmente comuns no Emsiano. Ambas têm ampla distribuição 
paleobiogeográfica no Domínio Malvinocáfrico, ocorrendo nos terrenos devonianos do Peru, da Bolívia, do Chile, da Argentina, do Paraguai, do Uruguai, do Brasil até a África do Sul. Entretanto, a ocorrência de C. quichua no Devoniano africano carece ainda de comprovação.

Em adição à revisão sistemática realizada, uma análise cladistica preliminar para os Conulatae é apresentada. Para tal, foram utilizados somente os caracteres e táxons sugeridos por R. C. Moore e H. J. Harrington em 1956, no clássico volume do "Treatise on Invertebrate Paleontology", Part F, Coelenterata, Conulata, a fim de comprovar a consistência dos grupos taxonômicos (famílias e subfamílias) propostos por esses autores. Os resultados mostram que, com exceçăo de Conularinae, os outros agrupamentos sugeridos pelos autores acima não foram reconhecidos. Desse modo, os dados derivados de uma análise ainda muito preliminar, sugerem urgência nos estudos de revisão sistemática dos Conulatae, englobando uma revisão crítica dos caracteres e seus estados, além do emprego da metodologia cladística.

Finalmente, fundamentados nos resultados obtidos e nas discussões apresentadas, algumas recomendações e estratégias para estudos futuros são sugeridas: a- a utilização de caracteres biométricos (e.g., ângulo basal, espaçamento entre cordões) deve ser evitada, em decorrência da ampla variação desses em função do tipo de preservação apresentado pelos espécimes; b- técnicas de computação (e.g., software MATLAB versão 6.0, Release 12, The MathWorks Inc.) poderiam ser empregadas nas reconstruções tridimensionais de tecas achatadas, possibilitando resgatar a morfologia original dos conulários e, a partir de então, recuperar valores biométricos para alguns caracteres, tais como, o ângulo basal e o espaçamento entre cordões; c- o estudo da sistemática dos Conulatae deve estar fundamentado na teoria cladística, procurando esclarecer as relações de parentesco dentro desse grupo e seu escopo, bem como a identificação das autapomorfias de Conulatae e o 
reconhecimento de subgrupos monofiléticos. Para viabilizar essa análise, entretanto, estudos morfológicos minuciosos deverão ser realizados, incluindo não apenas a descrição de feições morfológicas extemas, mas também intemas da teca $e$, $\alpha-$ revisões amplas deverão obrigatoriamente estar fundamentadas também no reexame dos espécimes de coleções previamente estudadas. Isso porque muitos dados morfológicos (e.g., morfologia de arestas; estruturas internas da teca) não são passíveis de resgate, apenas a partir dos dados de literatura. Esses poderiam ser úteis no reconhecimento de gêneros e espécies e para traçar as afinidades dos conulários com outros grupos de cnidários (Scyphozoa). 


\section{ABSTRACT}

The present study is the first, since 1913, to revise the conulariids (Conulatae Collins et al. 2000, Cnidaria) from the Ponta Grossa Formation, Devonian (?Lochkovian-Frasnian), Parana Basin. Bulk sample included the exam of 133 specimens found in Devonian rocks from Jaguariaiva and Ponta Grossa region, Paraná State. The results indicate that, at least, two conulariid species are present in the Ponta Grossa Formation, including Conularia quichua Ulrich and Paraconularia africana (Sharpe). A third species, Paraconularia ulrichana (Clarke), identified by Clarke (1913), was not recognized among the examined specimens. Yet, the detailed analyses of Clarke's specimens of $P$. africana indicate that they do not belong to this species. Therefore, the Paraconularia africana specimens herein described are the first one of this species identified and illustrated for the conulariid fauna of the Ponta Grossa Formation.

Notably the internal characters of $C$. quichua and $P$. africana thecae are preserved. The theca of $C$. quichua, for example, has internal thickening at the corners, as well as a mineralized structure (central pillar) at the base. Such features are also described by the first time to these species. However, the "central pillar" has never been found in other conulariids. Consequently the specific diagnosis of $C$. quichua e $P$. africana was emended.

Specimens of $C$. quichua are found as solitary or forming clusters with two or three individuals. Before this study, clusters of Conularia were restricted to the following species: $C$. splendida Billing, C. tenuicosta Ruedemann and C. congregata Hall.

C. quichua and $P$. africana show wide paleobiogeographic distribution in the Devonian, particularly during the Emsian. Both species are distributed in the Malvinokaffrick Realm, being found in terrains of Peru, Bolivia, Chile, Argentina, 
Paraguay, Uruguay, Brazil and South Africa. However, the occurrence of C. quichua in the South African Devonian needs further confirmation.

In addition to the systematic study done, a preliminary cladistic analysis for Conulatae is also presented. The cladistic analysis was based on the taxa and characters proposed by R. C. Moore and H. J. Harrington, in 1956, in the classical volume of the "Treatise on Invertebrate Paleontology", Part F, Coelenterata, Conulata. The goal here was to test the consistency of some groups (families and subfamilies) recognized by these authors. The results indicate that, with exception of Ctenoconulariinae, the groups suggested by those authors are not valid. Even considering the very preliminary nature of the presented cladistic analysis that could mar our results, seems urgent a systematic review of Conulatae using the cladistic methodology.

Finally based on the obtained results and the discussions presented, the following recommendations and strategies for future researches are suggested: aavoid the use of biometric characters (e.g., apical angles, spacing of rods), because of the wide range of values that could be obtained from specimens with different taphonomic histories; b- computational techniques (e.g., software MATLAB 6.0, Release 12, The MathWorks Inc.) could be employed in the three-dimensional reconstructions of colapsed thecae. By using this approach the values of the biometric characters could be determined; $c$ - the study of Conulatae systematics must be based on the cladistic theory, trying to establish the relationships within the group and its scope. However, in order to ensure this, detailed morphological studies must be done in the coming years, and $d$ - exhaustive reviews must be based on the reexamination of specimens deposited in previously studied type collections. This is because some morphological data (e.g., corner morphology; internal structures) cannot be adequately studied from the information amassed in the literature. These may be useful in the 
recognizance of genera and species within Conulatae, also helping the interpretation of conulariid affinities with other groups of cnidarians (Scyphozoa). 


\section{INTRODUÇÃO}

O termo conulário (=Conulatae Collins et al., 2000) foi, por muito tempo, aplicado para um número expressivo de fósseis, com teca relativamente simples, de formato piramidal, tubular ou cónico, de composição mineralógica variada (e.g., fosfáticos, quitinosos, quitinofosfáticos, calcários) (Feldmann \& Babcock, 1986; Babcock, 1991). Dessa forma, o termo passou a ser empregado para denominar fósseis de organismos que não, necessariamente, representavam grupos monofiléticos. Corresponderia, assim, a uma espécie de "lixeira taxonômica", para a qual eram enviados elementos de afinidades desconhecidas ou dificeis de serem estabelecidas, à luz do conhecimento da fauna marinha vivente. De fato, uma revisão crítica da literatura mostra que a maior parte das primeiras inferências sobre as relações filogenéticas dos Conulatae foi estabelecida com base em organismos que diferem substancialmente do conceito atual de Conularia Sowerby (vide item 3.1), gerando muita confusão.

Análises morfológicas mais recentes de elementos atribuidos aos gêneros Conularia Sowerby e Paraconularia Sinclair (Babcock \& Feldmann, 1984, 1986a; Feldmann \& Babcock, 1986; Babcock et al., 1987a, b, Babcock, 1990, 1991; Van Iten et al., em preparação), além de estudos tafonômicos (Simões et al., 2000a) e da microestrutura da teca ( Van Iten, 1992b), permitem agora uma definição mais precisa do termo conulário, isso é: fósseis de cnidários marinhos, extintos, bentônicos, sésseis de epifauna, com teca fosfática, piramidal, alongada e, na maioria das vezes, com 4 faces, (Babcock, 1991; Van Iten, 1991a; Van Iten et al., em preparação).

A despeito disso, porém, existe ainda hoje enorme conflito na literatura especializada no que tange às afinidades dos conulários. Diversos autores (Termier \& Termier, 1949, 1953; Kozlowski, 1968; Oliver, 1984; Steul, 1984; Mortin, 1985; Feldmann \& Babcock, 1986; Babcock \& Feldmann, 1986a; Babcock, 1991) rejeitaram a possibilidade de tais invertebrados serem filogeneticamente aparentados aos 
Scyphozoa, idéia amplamente aceita por outro grupo de pesquisadores (Bischoff, 1978; Van Iten, 1987, 1991a, b, 1992a, b; Jerre, 1994; McKinney et al., 1995). A partir do exame tafonômico de alta resolução das ocorrências do Membro Jaguariaiva ou Seqüência B (Bergamaschi, 1999), Formação Ponta Grossa (?LochkovianoFrasniano), da Bacia do Paraná, ficou comprovado que os conulários são organismos bentônicos, sésseis (Simões et al., 1999; Simões et al., 2000a, b, c; Rodrigues et al., 2000a, b), idéia já compartilhada por autores brasileiros (veja Petri \& Fúlfaro, 1983, p. 86) estrangeiros (Cooper, 1977, p. 180). Esse fato, associado aos dados filogenéticos, moleculares e morfológicos de grupos de cnidários aparentados, especialmente os Coronatae e Stauromedusae (Marques, 1997; Collins, 1999), demonstrou que os conulários são um grupo irmão de Stauromedusae (Collins et al., 2000; Marques \& Collins, 2000). Desse modo, os conulários são hoje interpretados como parte de um grande grupo de cnidários sésseis, que divergiram cedo na história do grupo, dos quais os únicos representantes conhecidos são os Stauromedusae (Collins et al., 2000; Marques \& Collins, 2000; Simőes et al., 2000b).

\subsection{Problemática Envolvida}

Os braquiópodes, os bivalves, os trilobitas e os conulários preservados nos estratos devonianos dos continentes austrais (exceto Austrália) apresentam notável endemismo (e.g., Clarke, 1913; Boucot, 1971; Richter \& Richter, 1942; Eldredge \& Ormiston, 1979; Melo, 1985; Kotzian, 1995; Machado, 1999). No Brasil, os melhores registros da chamada fauna do domínio Malvinocáfrico (Boucot, 1971; Cooper, 1977; Eldredge \& Ormiston, 1979) são encontrados na Formação Ponta Grossa, no Estado do Paraná (Lange \& Petri, 1967; Petri \& Fúlfaro, 1983; Melo, 1985, 1986, 1988; Assine et al., 1994). 
Os estudos sobre conulários devonianos do domínio Malvinocáfrico são numerosos, incluindo os trabalhos de Sharpe (1856), Bernard (1895), Kayser (1897), Reed (1904, 1925), Thomas (1905), Schwarz (1906), Knod (1908), Clarke (1913), Kozlowski (1913, 1923), Douglas (1920), Sinclair (1948), Branisa \& Vanek (1973), Feldmann \& Babcock (1986) e Babcock et al. (1987a, b). Em adição, conulários de outras áreas austrais, tais como a Austrália, foram descritos por Parfrey (1982) e Waterhouse (1986).

No caso dos conulários do Devoniano da Bacia do Paraná, até o momento, nenhum estudo taxonômico formal foi publicado, desde Clarke (1913). Contrariamente a outros grupos de invertebrados, comuns na Formação Ponta Grossa, tais como, os trilobitas (Popp, 1985; Carvalho \& Quadros, 1987; Carvalho \& Edgecombe 1991), os braquiópodes (Quadros, 1987; Bosetti, 1989a, b, c), os bivalves (Morsch, 1984a, b, 1986 e 1987; Kotzian, 1995; Machado, 1999) e os tentaculites (Ciguel, 1989; AzevedoSoares, 1999) que, nas duas últimas décadas, foram alvo de revisões importantes, os conulários permaneceram praticamente ignorados e inadequadamente descritos, face ao avanço ocorrido na sistemática do grupo, particularmente a partir de meados da década de 1980 .

Mais recentemente, entretanto, Leme et al. (2000a, b) apresentaram os dados preliminares de uma revisão sistemática dos conulários da Formação Ponta Grossa, com base em espécimes provenientes, única e exclusivamente, dos afloramentos de Jaguariaiva, PR. Embora esses dados tenham colaborado para um melhor entendimento da sistemática do grupo, havia a necessidade ainda de um estudo mais aprofundado da morfologia da teca dos conulários devonianos da Bacia do Paraná, com óbvias implicações sistemáticas, bem como, um exame mais abrangente, envolvendo outras ocorrências conhecidas e material adicional, depositado em coleçőes científicas diversas (e.g., Departamento de Geociências da UEPG, 
Laboratório de Geociências da UNG; Departamento de Geologia Sedimentar e Ambiental do (Gc/USP). Os aspectos acima constituem, o escopo principal da presente dissertação.

\subsection{JUSTIFICATIVA}

Os seguintes aspectos justificam o estudo realizado:

a- Estudos modernos, enfocando especialmente as estruturas internas das tecas (vide Van Iten, 1992b; Van Iten et al., em preparação) dos conulários do Devoniano da Bacia do Paraná, não existem, sendo importantes para o entendimento da sistemática do grupo;

b- Dados preliminares de literatura estão concentrados nas ocorrência do município de Jaguariaíva, PR, mas outras ocorrências são conhecidas no âmbito da Formação Ponta Grossa, no Estado do Paraná. Essas não foram objeto de nenhum estudo, nos últimos 89 anos, isso é, desde Clarke (1913). Por outro lado, nos últimos anos, houve um enorme avanço no conhecimento morfológico do grupo e, portanto, as descrições fornecidas por Clarke (1913) não estão, obviamente, atualizadas;

c- Conulários devonianos dos continentes austrais são bem conhecidos através de estudos, especialmente gerados a partir da década de 1980 e uma comparação com os da Bacia do Paraná, seria muito interessante, para o entendimento das afinidades paleobiogeográficas da fauna. 


\subsection{OBjetivos}

Conforme acima demonstrado, até o presente momento, o único estudo taxonômico disponivel para os conulários da Bacia do Paraná é o de Clarke (1913). Esse autor identificou as espécies Paraconularia africana (Sharpe 1856), Paraconularia ulrichana (Clarke 1913) e Conularia quichua Ulrich 1890, para sedimentitos da Formação Ponta Grossa, regiôes de Tibagi, Jaguariaíva e Ponta Grossa. Obviamente, como já comentado, o estudo de Clarke (1913) necessita de atualização, ou seja, os espécimes examinados pelo autor precisariam ser reexaminados. Isso porque não é possível redescrevê-los a partir das ilustrações disponíveis. Além disso, algumas formas, como Conularia quichua Ulirich, 1890, não foram llustradas, dada a sua péssima qualidade de preservação (Clarke, 1913). Embora nenhum estudo formal tenha sido realizado após Clarke (1913), espécies de conulários foram citadas por outros autores ou aparecem em listas taxonômicas (e.g. Oliveira \& Leonardos, 1943; Cooper 1977, Petri \& Fúlfaro 1983, Lima 1989). Dessa forma, o presente estudo tem por objetivos:

a- revisão sistemática dos conulários (Cnidaria) da Formação Ponta Grossa, Devoniano (?Lochkoviano-Frasniano), a partir do minucioso estudo morfológico de tecas provenientes da Formaçăo Ponta Grossa, dos municípios de Jaguariaíva e Ponta Grossa;

b- reexame dos atributos e termos morfológicos utilizados no estudo sistemático dos Conulatae, especialmente os propostos por Babcock \& Feldmann (1986a);

c- verificaçăo da existência de variaçăo na composição da fauna de conulários, segundo sua posição estratigráfica e,

d- comparação da fauna de conulários da Formação Ponta Grossa, com outras do Domínio Malvinocáfrico, discutindo o seu caráter paleobiogeográfico. 
Em adição aos objetivos acima, durante o desenvolvimento do presente estudo foi possivel travar um contato estreito com aspectos mais amplos da Paleobiologia dos Conulatae. Em especial, a partir da revisão sistemática e estudos tafonômicos (Rodrigues, 2002) foi notado que muitos dos táxons de Conulatae e seus atributos morfológicos diagnósticos não são consistentes (veja item 4.1; Rodrigues, 2002). Obviamente, um amplo estudo cladístico dos Conulatae não faz parte do escopo original do presente projeto de mestrado. De qualquer modo, como um exercício de raciocinio e um treinamento inicial, são apresentadas também, no apêndice desse documento, algumas considerações referentes à análise cladística preliminar dos Conulatae (vide apêndice).

\subsection{REVISÃo CRITICA DA LITERATURA}

Em decorrência do escopo da pesquisa realizada, nesse item foram revisados os dados de literatura referentes às questões de afinidades dos conulários (vide Simões et al.,2001a). Há cerca de 181 anos, estudiosos dos Conulatae vêm reunindo um volume substancial de dados a respeito da sistemática, anatomia, paleoecologia, tafonomia e distribuição ambiental e temporal desse controverso grupo de invertebrados marinhos, extintos. Recentes descobertas sobre a morfologia interna e externa, a constituição da teca de conulários e espécimes preservados in situ, juntamente com a aplicação da teoria cladística na análise de afinidades dos conulários, têm, em parte, contribuído para reviver as idéias propostas por Kiderien (1937). Segundo esse autor, os conulários foram afins aos cifozoários.

A detalhada revisão crítica da literatura dos Conulatae mostra que, historicamente, é possivel reconhecer fases distintas de estudo, com enfoque variável ao longo das diferentes décadas, refletindo o desenvolvimento das pesquisas. No periodo de 1821-1979, por exemplo, as pesquisas a respeito dos conulários estiveram 
fortemente concentradas na descrição e proposta de novas espécies. Esses estudos foram responsáveis pelo estabelecimento do escopo taxonómico do grupo, com o reconhecimento de vários subgrupos, fundamentados em critérios fenéticos. Nos anos 80, o enfoque muda e vários artigos importantes foram publicados sobre a paleoecologia dos conulários (Babcock \& Feldmann, 1986a, b; Babcock et al., 1987a, b; Harland \& Pickerill, 1987; Van Iten, 1989). Já na década de 90 , o problema das afinidades dos Conulatae foi mais intensamente debatido (Bergström, 1995; Brood, 1995a, b; Hughes et al, 2000; Jerre, 1993, 1994; McKinney et al., 1995; Van Iten 1991a, b, 1992a, b; Van Iten \& Cox, 1992; Van Iten et al., 1996, 2000). Dessa forma, uma ampla revisão da literatura é apresentada a seguir, procurando estabelecer criticamente as diferentes fases históricas da construção do arcabouço teórico/conceitual referente aos Conulatae.

Século 19 e início do século 20: de Moluscos a Vertebrados. Inicialmente, até os anos 30 , os conulários foram aceitos como moluscos pelos maiores especialistas da época. As primeiras interpretações presentes na literatura sugeriam que conulários eram afins aos cefalópodes. Essas interpretações estavam apoiadas, mormente, nas semelhanças entre as conchas dos nautilóides, ortocônicos e a presença de parede basal na teca dos conulários (Eichwald, 1840; Vanuxem, 1842). Posteriormente, Lindström (1884) relacionou-os aos pterópodes, fundamentado na similaridade entre a morfologia externa das conchas de algumas espécies de pterópodes viventes e de Conularia (Babcock, 1991).

Em 1896, conulários foram atribuídos a outro filo de invertebrados, Annelida, por R. Ruedemann, com base em material do Ordoviciano de Nova lorque. Esses espécimes foram, posteriormente, referidos ao gênero Sphenothallus (Feldmann et al., 
1986; Bodenbender et al., 1989), cujas afinidades são desconhecidas, possivelmente um Cnidaria (Van Iten et al., 1992).

Finalmente, as interpretaçōes de que pertenceriam aos Chordata (Termier \& Termier, 1949, 1953) estão fundamentadas em evidências não consistentes, tais como, uma suposta segmentação do esqueleto e presença de órgãos fotossensíveis (Babcock, 1991, Termier \& Termier, 1949, 1953; Steul, 1984).

Dos anos 30 aos 90: afinidades com Cnidaria. Kiderlen (1937) foi o primeiro autor a considerar conulários como afins aos cifozoários. Suas interpretações foram fundamentadas nas ilustrações de Wiman (1895), onde a simetria radial da teca dos conulários está bem representada. Em sua reconstrução do modo de vida dos conulários, esses aparecem com tentáculos, apresentando ciclo de vida consistindo de uma fase inicial fixa, polipóide, seguida do desenvolvimento de uma fase medusóide, livre natante (Kiderlen, 1937).

Desde Kiderlen (1937), muitos autores (Knight, 1937; Moore \& Harrington, 1956a, b; Werner, 1966; 1967; 1969; 1973; Bischoff, 1978; Van Iten, 1991a, b; 1992a, b; Van Iten \& Cox, 1992; Van Iten et al., 1996, 2000; Jerre 1993, 1994; McKinney et al., 1995; Hughes et al., 2000) obtiveram novas evidências que reforçaram, conclusivamente, a idéia de que conulários são afins aos Cnidaria (Van Iten 1991a, b, 1992a, b; Hughes et al., 2000), tais como: a- morfologia da teca com cordões, cristas, espessamentos internos nas arestas e linhas medianas; b- teca composta por duas camadas distintas, uma interna mineralizada e outra externa, não mineralizada, ambas constituídas de lamelas; c- provável modo de reprodução assexuada por brotamento; d- modo de reparo de injúrias caracterizada por deposição de lamelas não mineralizadas na superfície da camada interna da teca; e- crescimento da teca 
caracterizado por extensão da camada externa e espessamento da camada interna mineralizada e, f- modo de vida séssil, com indivíduos isolados ou agrupados.

A morfologia e a microestrutura das feições internas presentes na região das arestas e linhas medianas (vide Fig. 5 e 6, mais adiante) dos conulários apresentam similaridades em número, arranjo, tamanho e forma aos septos gástricos e estruturas da teca dos cifozoários, Coronatae Haeckel e Stauromedusae Haeckel, sendo consideradas estruturas homólogas (Jerre, 1994; McKinney et al., 1995; Van Iten 1991a, b; 1992a, b; Van Iten \& Cox, 1992; Van Iten et al., 1996, 2000). A hipótese de que as linhas medianas de conulários foram regiōes de inserção dos septos gástricos, homólogos aos de cifozoários, está fundamentada em comparações com a anatomia interna de Eoconularia loculata (Wiman) e Craterolophus tethys Clarke. De fato, conulários e estauromedusas, em questão, apresentam seus septos bifurcados e similares em número, arranjo e forma, sugerindo uma disposição semelhante a dos tecidos moles dos conulários, em vida (Van Iten, 1991a; Jerre, 1994). Adicionalmente, as tecas de conulários e coronados (Coronatae, uma ordem da Classe Scyphozoa Götte) exibem similaridades na construção e no crescimento da teca, na ornamentação externa com corrugações longitudinais e transversais e no modo de reparo de injúrias, por formação de parede basal. Embora certos detalhes da anatomia e crescimento da teca de conulários ainda não sejam completamente compreendidos (Van Iten, 1991a), a comparação entre projeções internas perradiais e inter-radiais da teca de coronados com, respectivamente, carenas e septos da teca de conulários, indica que ambas são muito similares (Van Iten 1991a, 1992a, b; Jerre, 1994; Van Iten et al., 1996; Hughes et al., 2000).

Outros fatores, tais como, corpo com seção transversal quadrada e simetria radial tetrâmera, além de análises filogenéticas apoiadas em dados paleontológicos, morfológicos e moleculares indicam que Conulatae é grupo irmão de Stauromedusae 
(Collins et al., 2000; Marques \& Collins, 2000). Um fator significante para esse resultado foi a determinação de Conulatae como animais sésseis, a partir de observações dos conulários em depósitos de sufocamento (obrution deposits) no Devoniano da Bacia do Paraná (Simões et al., 2000b). Além disso, Conulatae e Stauromedusae não formam um grupo monofilético com cifozoários. Dados de seqüências moleculares também indicam que Stauromedusae não faz parte da Classe Scyphozoa (Collins et al., 2000; Marques \& Collins, 2000).

Conulariida: um novo filo de invertebrados marinhos, extintos. Em uma série de artigos ao longo dos anos 80 e 90, L. E. Babcock e R. Feldmann apresentaram uma visão distinta a respeito da anatomia e relações filogenéticas dos organismos atribuídos aos conulários. Essa visão é derivada de uma interpretação particular sobre a anatomia de partes moles e duras dos conulários (vide discussão no item 4.1). Para Babcock \& Feldmann (1986a), conulários são animais que geralmente apresentam quatro faces; teca piramidal; simetria bilateral; integumento multilaminado, moderadamente flexivel, composto de fosfato de cálcio e proteina; teca formada por cordões de fosfato de cálcio arranjados transversalmente através da face; base afilada, terminando num pedúnculo, possivelmente quitinoso, fosfático ou quitinofosfático; nenhuma estrutura interna mineralizada (dura) conhecida; partes moles internas compreendem um tubo alongado que se estende ao longo do corpo e uma ou mais estruturas globulares, todas com função desconhecida.

Fundamentados em evidências morfológicas e mineralógicas, tais como, a estrutura e a constituição da teca (fosfato de cálcio e proteína) e a simetria bilateral, como mostrado acima, Babcock \& Feldmann (1986a, c) propuseram o Filo Conulariida. Os autores argumentaram que os conulários apresentam morfologia distinta de todos os demais grupos de animais conhecidos, podendo ser, dessa forma, atribuídos a um 
filo à parte. Nesse contexto, os caracteres morfológicos que suportam a afinidade com Cnidaria são interpretados apenas como homoplasias (Babcock et al., 1995).

Para Babcock \& Feldmann (1986a, c), o novo filo compreenderia, aproximadamente, 40 gêneros, definidos por: a- o espaçamento relativo entre os cordões; b- a proporção de cordões opostos e alternados na linha mediana; c- o ângulo basal; d- a presença e a ausência de nodos e espinhos (cristas) e, e- o espaçamento entre nodos e espinhos (cristas). Além desses, o padrão da articulação dos cordões e o ângulo dos cordões, foram usados para definir espécies. As limitações dessas interpretações serão comentadas no item 4.1.

Sistemática dos conulários: da fenética a cladística. Inicialmente, as pesquisas a respeito da sistemática dos conulários, englobaram uma abordagem envolvendo a chamada sistemática tradicional, fenética (Amorim, 1994, p.126; Amorim, 1997, p.106). A maioria das publicações do período de 1821 a 1979 são descrições de novas espécies e novos gêneros, fundamentados, como dito acima, apenas em critérios fenéticos. Nesse período, somente alguns autores, tais como, Kiderlen (1937), Finks (1955), Moore \& Harrington (1956a, b) e Bischoff (1978), enfocaram os problemas relacionados à paleobiologia e afinidades dos Conulatae.

Até 1939, pouca atenção havia sido dispensada à classificação dos Conulatae (Sinclair, 1952). Em 1939, Boucek formalizou a classificação previamente proposta para os conulários da Boêmia. O autor apresentou três famílias (Conularidae Walcott, Conulariellidae Kiderlen e Serpulitidae Boucek) na Ordem Conularida Miller \& Gurley, reunindo um total de cinco gêneros e quatro subgêneros (Boucek, 1939). Posteriormente, Sugiyama (1940) propôs uma emenda para essa classificação, incluindo a Família Conulariopsidae. Acrescentou três gêneros e um subgênero aos demais válidos. 
Durante as décadas de 1940 e 1950, G.W. Sinclair elegeu novos gêneros e espécies do Paleozóico médio, tais como: Paraconularia Sinclair 1940, Climacoconus Sinclair 1942; Conularina Sinclair 1942; Eoconularia Sinclair 1943; Glyptoconularia Sinclair 1948; Anaconularia Sinclair 1952; Calloconularia Sinclair 1952; Ctenoconularia Sinclair 1952; Diconularia Sinclair 1952; Exoconularia Sinclair 1952.

Uma nova proposta para a Família Conularidae Walcott foi apresentada por Sinclair (1952). Esse autor reagrupou os conulários em três novas subfamílias (Conulariinae, Paraconulariinae e Ctenoconulariinae), dentro de Conularidae, mantendo as demais famílias anteriormente propostas por Boucek (1939). Entretanto, Sinclair (1952) reconheceu que os membros da Família Serpulitidae não eram conulários. Porém, é interessante notar que nas propostas de classificações, acima relatadas, não foram discutidas as relações em categorias taxonômicas superiores. No entanto, esse autor contribuiu enormemente para o entendimento da sistemática dos conulários tentando estabelecer as relações entre gêneros e espécies.

A abordagem filogenética dos conulários foi somente tratada quatro anos mais tarde, por Moore \& Harrington (1956a, b), no volume da clássica série "Treatise on Invertebrate Paleontology", Part F, Coelenterata, Conulata, embora as idéias de parentesco já estivessem na literatura desde Kiderlen (1937). De acordo com esses autores, conulários foram incluídos no Filo Coelenterata, Classe Scyphozoa e Subclasse Conulata Moore \& Harrington. Isso devido à simetria tretâmera e à presença de quatro septos mineralizados interradiais. Em adição, Moore \& Harrington $(1956 a, b)$ reconheceram duas subordens entre os conulários (Conchopeltina Moore \& Harrington e Conulariina Miller \& Gurley). Uma nova família Conchopeltidae foi também proposta por (Moore \& Harrington, 1956a, b). As outras famílias (Conularidae e Conulariellidae) já reconhecidas por Sinclair (1940) foram consideradas como válidas. 
A ocorrência de conulários com teca mostrando seção transversal circular foi reportada pela primeira vez no Siluriano da Austrália, por Bischoff (1978). Também nesse estudo, Bischoff (1978) apresentou uma descrição detalhada dos caracteres internos da teca dos conulários, observando diferentes tipos de septos, isso é, espessamentos internos ao longo da teca, na região da linha mediana. Seguindo Kiderlen (1937), o autor propôs um significado funcional para as mesmas, isto é, os septos seriam estruturas de fixação dos músculos longitudinais que suportariam os mesentérios, fundamentados na similaridade entre a disposição interna e o desenvolvimento dos septos dos conulários e mesentérios de cifomedusas viventes (e.g., Craterolophus sp.). Os conulários descritos por Bischoff (1978) foram atribuídos a nova subordem Circonulariina. A classificação de Moore \& Harrington (1956a, b) foi novamente ampliada, com a inclusão da Família Circonularidae e as subfamílias Austraconulariina e Circonulariinae (Bishoff, 1978).

Durante o período de 1970 a 2000 , novos gêneros e espécies foram propostos (Méndez-Alzola \& Sprechmann, 1973; Waterhouse, 1979, 1986; Lammers \& Young, 1984; Hergarten, 1985; Qian et al., 1997 e Hughes et al., 2000). Esses autores seguiram a classificação de Moore \& Harrington (1956b), mas outros, (e.g., Mariñelarena, 1970; Jerre, 1993) não atribuíram os novos gêneros e espécies a nenhuma categoria taxonômica supragenética.

Somente 44 anos depois de Moore \& Harrington (1956b), as afinidades filogenéticas dos Conulatae foram discutidas novamente. Collins et al. (2000) apresentaram argumentos consistentes a favor da hipótese de que conulários estão relacionados aos cnidários, em particular aos cifozoários, fundamentados em similaridades a dois grupos de Scyphozoa, Coronatae e Stauromedusae. Esses autores realizaram análises filogenéticas, incluindo dados paleontológicos e neontológicos, indicando que Conulatae é grupo irmão de Stauromedusae, um grupo 
de cnidários polipóides, sésseis, tradicionalmente classificados dentro de Scyphozoa. Assim, os conulários pertenceriam à nova Classe Stauromedusae e Subclasse Conulatae, Filo Cnidaria (Collins et al., 2000).

Em relação às contribuições acima, nota-se que o estudo das relações filogenéticas dos conulários, a partir de análises cladísticas, constitui um importante desafio à Paleontologia dos invertebrados marinhos paleozóicos. Nesse sentido, é nítida a urgência de aplicação desse, procurando esclarecer as relações entre os gêneros que compõem o grupo interno e a determinação de seu escopo (vide apêndice). 


\section{MATERIAL E MÉTODOS}

\subsection{ARCABOUÇO CONCEITUAL E Metodológico Adotado}

A partir de dados filogenéticos, moleculares e morfológicos de grupos de cnidários aparentados, os conulários foram interpretados como pertencentes a uma nova classe de Cnidaria, Classe Stauromedusae Haekel, Subclasse Conulatae Collins et al. 2000 (conforme visto no item 1.4). Desse modo, os conulários são hoje interpretados como um grupo irmão de Stauromedusae e parte de um grande grupo de cnidários sésseis (Collins et al., 2000; Marques \& Collins, 2000; Simões et al., 2000b). Portanto, o termo Conulatae está sendo empregado no presente documento no contexto sugerido por Collins et al. (2000).

Durante o estudo preliminar realizado (Leme, 2000, Proc. FAPESP 99/10824-1), foi notado que as feições internas (septos e carenas) da teca estão preservadas. Tais feições são comumente citadas na discussão da morfologia funcional e afinidades filogenéticas dos conulários (e.g., Kiderlen, 1937; Kozlowski, 1968; Moore \& Harrington, 1956a, b; Werner, 1966, 1967; Bischoff, 1978; Van Iten, 1991a, b; 1992a, b; Jerre, 1994; Van Iten et al., 1996). Nesse sentido, a terminologia e mesmo as feições internas utilizadas por Sinclair (1940, 1942, 1948, 1952), Moore \& Harrington (1956a, b), Bischoff (1978) e Van Iten (1991a, b), Van Iten et al. (1996), além de alguns termos referidos por Babcock \& Feldmann (1986a) (e.g., articulação dos cordões), foram utilizados na redescrição dos espécimes da Bacia do Paraná, disponiveis para estudo.

Deve ser lembrado aqui que apesar do estudo de Babcock \& Feldmann (1986a) ser o único que procurou sistematizar a terminologia para a descrição morfológica de conulários e que os termos sugeridos são de fácil emprego, ao menos no nível operacional (veja, por exemplo, Simões et al. 1999, Rodrigues et al., 2000a, b), sua utilização não pode ser desprovida de uma prévia, crítica e minuciosa análise 
tafonômica. Isso porque, conforme discutido no item 4.1, estão fundamentados na utilização de caracteres biométricos, passíveis de alterações, segundo o modo de preservação dos exemplares.

Sendo assim, no presente estudo, foram seguidas as recomendações sugeridas por Leme et al. (2000a, b) e Rodrigues et al. (2000b), isto é: a- o estudo taxonômico dos Conulatae deve estar fundamentado em coleções numerosas, para que o maior espectro possível de variações tafonômicas e morfológicas decorrentes sejam identificadas; b- o estudo deve priorizar o exame de espécimes pouco deformados (bem preservados), no caso de estarem disponíveis; c- a proposição de novos táxons (gêneros e espécies) não deve ser feita com base em exemplares fragmentados ou incompletos, uma vez que muitas das características externas (e.g., padrão de articulação) variam ao longo do exoesqueleto do animal e, d- comparações fundamentadas em caracteres biométricos só deverão ser realizadas com base em espécimes mostrando o mesmo tipo de preservação.

A partir das recomendações referidas acima e dos resultados obtidos, as feições biométricas, isso é, ângulo basal e ângulo do cordão, foram excluídas da descrição do material. Entretanto, a feição espaçamento entre os cordões foi utilizada, seguindo as recomendações e cuidados já mencionados. 


\subsection{ProcedênCIA das amostras}

O presente trabalho envolveu o exame de espécimes provenientes da Seqüência B (Bergamaschi, 1999; Bergamaschi \& Pereira, 2001), da Formação Ponta Grossa (?Lochkoviano-Frasniano), regiões de Ponta Grossa e Jaguariaíva (Fig.1 e Fig. 2), bem como outros que foram obtidos a partir do exame de Coleções Científicas da Universidade Estadual de Ponta Grossa (UEPG), da Universidade de Guarulhos (UNG) e da Universidade de São Paulo (USP) (vide anexo). Embora trabalhos de campo tenham sido também realizados na regiäo de Tibagi, seção da estrada de rodagem que liga esse município ao de Telêmaco-Borba, nenhum exemplar de conulário foi aí encontrado.

Em Jaguariaiva, o afloramento estudado localiza-se no corte da estrada de ferro Jaguariaíva - Arapoti (Fig. 3). O mesmo expõe os sedimentitos da seção-tipo do Membro Jaguariaiva, que ocorre ao longo da ferrovia Jaguariaiva-Arapoti, desde o $\mathrm{Km}$ 2,2 (altitude de $860 \mathrm{~m}$ ) até $\circ \mathrm{Km} \mathrm{6,6} \mathrm{(altitude} \mathrm{de} \mathrm{960m)} \mathrm{(Lange} \mathrm{\&} \mathrm{Petri,} \mathrm{1967).} \mathrm{Esses}$ foram atribuidos por Bergamaschi (1999) e Bergamaschi \& Pereira (2001) à Seqüência B, um Trato de Sistemas Transgressivo, na base da Formação Ponta Grossa (Fig. 2).

$\mathrm{Na}$ seção examinada, fósseis de conulários ocorrem nos intervalos situados a 29-32 metros, a 39 metros e a 44-48 metros do contato basal com a Formação Furnas (Fig. 3). As localidades estão, respectivamente, situadas segundo as coordenadas $24^{\circ} 14^{\prime} 05^{\prime \prime} \mathrm{S} / 49^{\circ} 42^{\prime} 54^{\prime \prime} \mathrm{W}$, aproximadamente no $\mathrm{Km} 3,8$ e $24^{\circ} 14^{\prime} 68^{\prime \prime} \mathrm{S} / 49^{\circ} 43^{\prime} 19^{\prime \prime} \mathrm{W}$, no $\mathrm{Km} 4,5$.

Nos intervalos acima, predominam os horizontes representados por depósitos de sufocamento, que correspondem a tempestitos distais (Simões et al., 2000a, c), que são progressivamente sucedidos por folhelho cinza escuro, laminado e siltitos e arenitos interlaminados, intensamente bioturbados (Bergamaschi \& Pereira, 2001) (Fig. 3). 


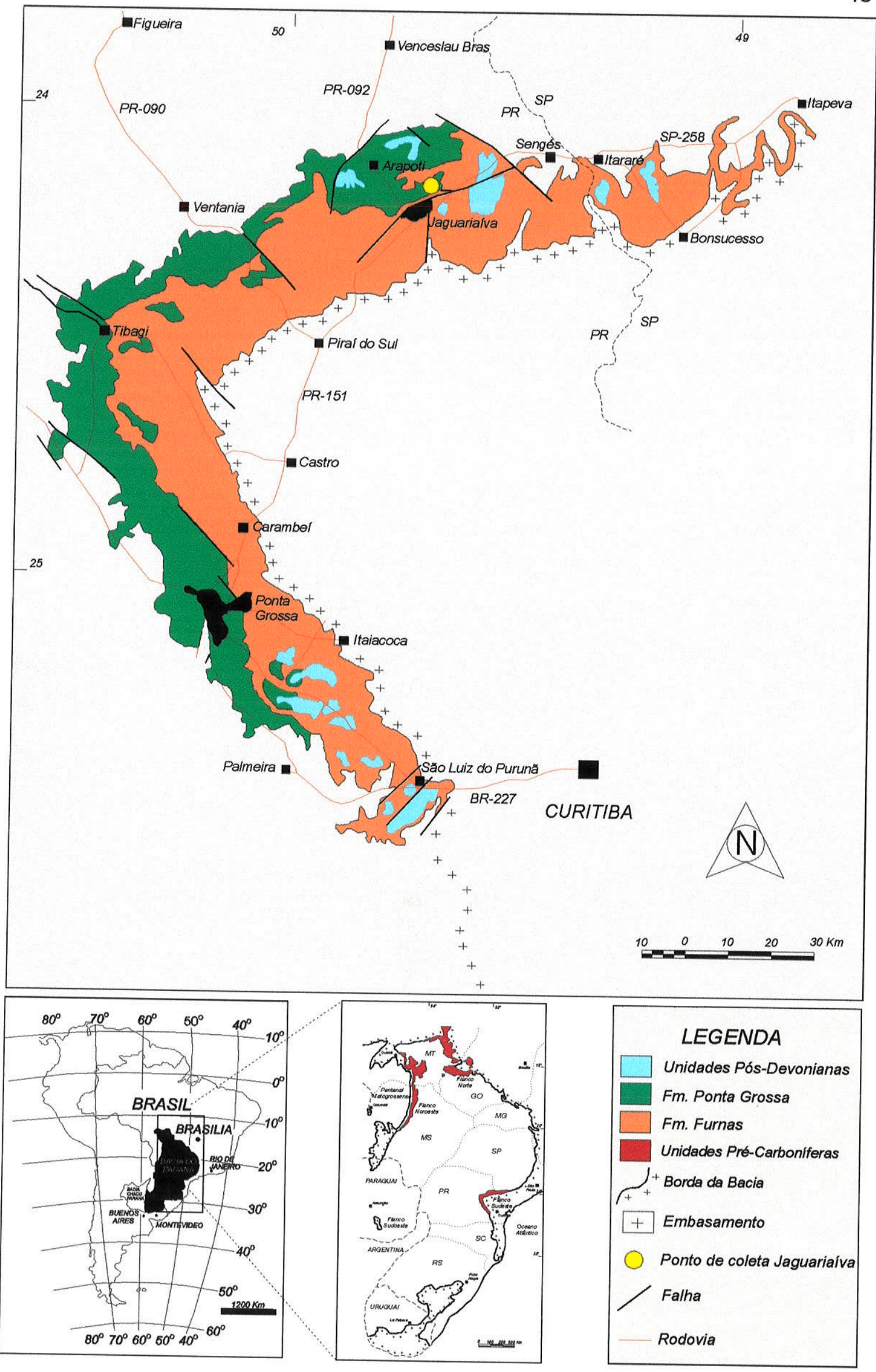

Figura 1- Mapa de localização dos afloramentos da Formação Ponta Grossa, mostrando a faixa de afloramentos devonianos, na bordaleste daBacia do Paraná. 


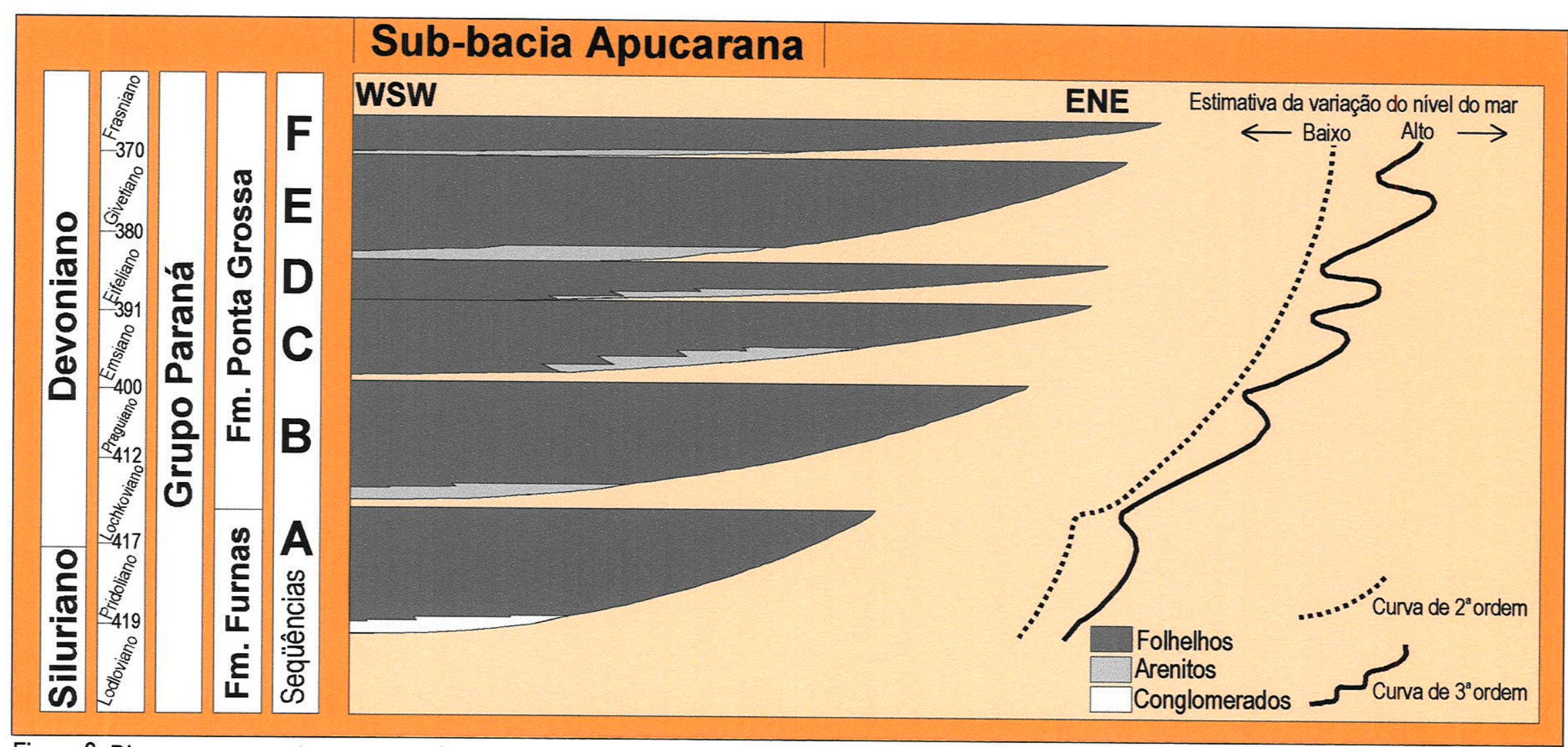

Figura 2- Diagrama espaço-tempo para o intervalo "Furnas-Ponta Grossa", na sub-bacia Apucarana, associada a uma estimativa de variação relativa do nivel do mar, segundo Bergamaschi (1999). 


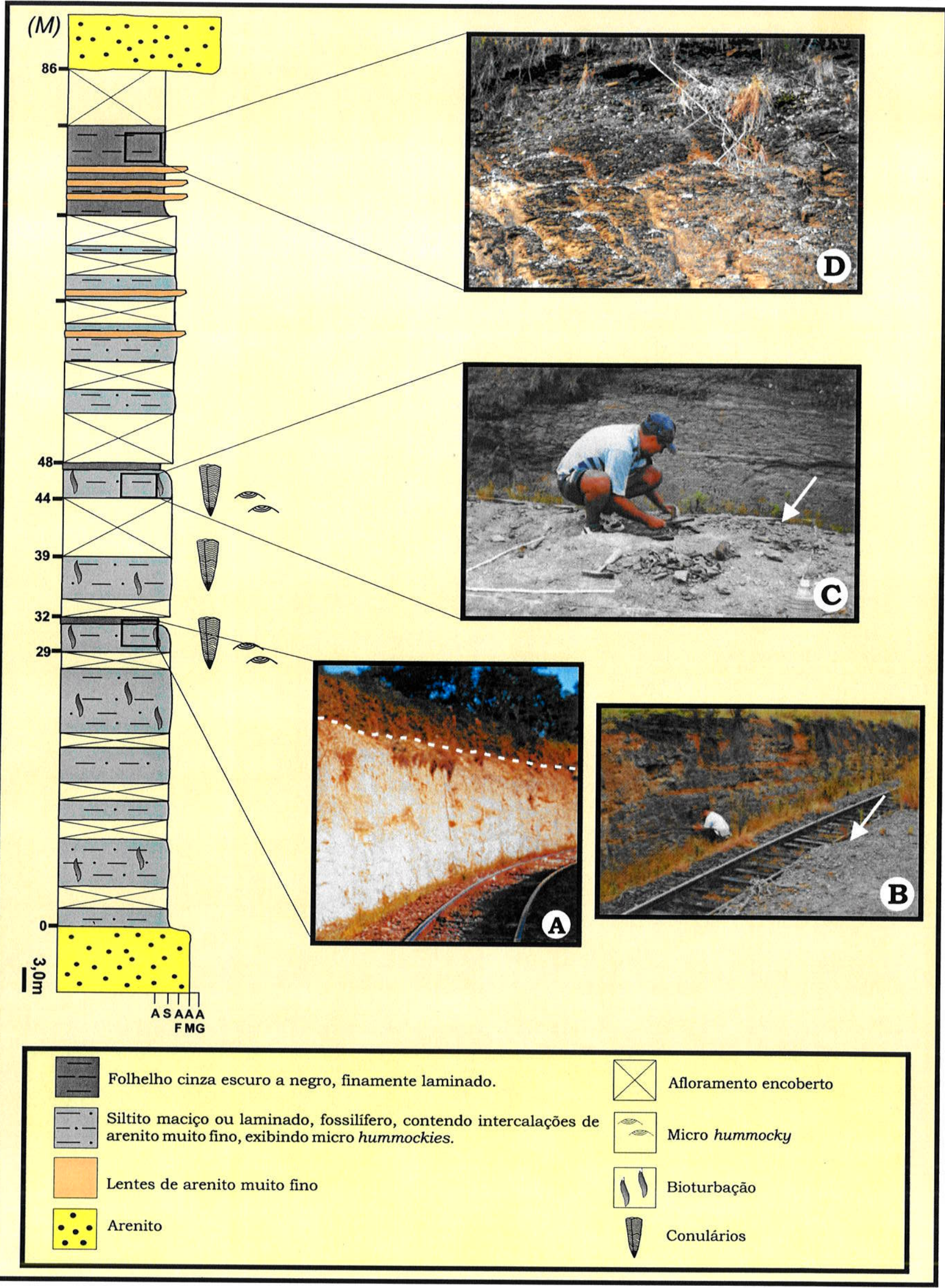

Figura 3- Seção colunar do afloramento situado na estrada de ferro Jaguariaíva-Arapoti, Jaguariaíva, PR, Formação Ponta Grossa, Seqüência B. Observe a distribuição vertical dos conulários. A, Intervalo de depósitos de sufocamento; B-C, Detalhe dos folhelhos da superfície de inundação marinha; D: Folhelhos da superfície de máxima inundação. Explicação: Setas em branco, superfície de inundação marinha; pontilhado em branco, limite entre os depósitos de sufocamento e a superfície de inundação marinha. 
Os folhelhos escuros correspondem a superficies de inundação marinha, enquanto os siltitos e arenitos apresentam evidências da ação de ondas. Os folhelhos e siltitos agrupam-se formando ciclos assimétricos maiores (parasseqüências), com até 20 metros de espessura (Bergamaschi, 1999; Bergamaschi \& Pereira, 2001).

A posição estratigráfica dos espécimes depositados na coleção da Universidade Estadual de Ponta Grossa, provenientes do município homônimo, é incerta. As poucas informações disponiveis, conforme referido anteriormente, indicam que esses provêm dos afloramentos informalmente designados de curva I e curva II (Kotzian, 1995). Os sedimentitos aflorantes nessa seção são, contudo, similares àqueles de Jaguariaiva, tanto em seu conteúdo fossilífero, como nas estruturas sedimentares.

\subsection{DESCRIÇÃo dO MATERIAL}

As feições morfológicas foram descritas, conforme já mencionado, com base em Sinclair (1940, 1942, 1948, 1952), Moore \& Harrington (1956a, b), Bischoff (1978), Van Iten (1991a, b), Van Iten et al. (1996), Babcock \& Feldmann (1986a, b, c), Feldmann \& Babcock (1986) e Babcock (1991a), levando em conta, na medida do possivel, as recomendações sugeridas por Leme et al. (2000b) e Rodrigues et al. (2000b):

\subsubsection{Preparação dos Fósseis}

Em decorrência do tipo de estudo aqui proposto, isso é, uma análise sistemática de detalhe e, tendo em vista que, a observação da maior parte das feições morfológicas (e.g., espaçamento relativo entre os cordões; proporção relativa de cordões alternados e opostos na linha mediana; presença ou ausência de nodos e cristas; morfologia de nodos e cristas padrões de articulações dos cordões; morfologia das carenas) (Figs. 4, 5 e 6) que são utilizadas na descrição e classificação dos conulários (sensu Babcock e Feldmann, 1986a) carece de auxílio de equipamentos 


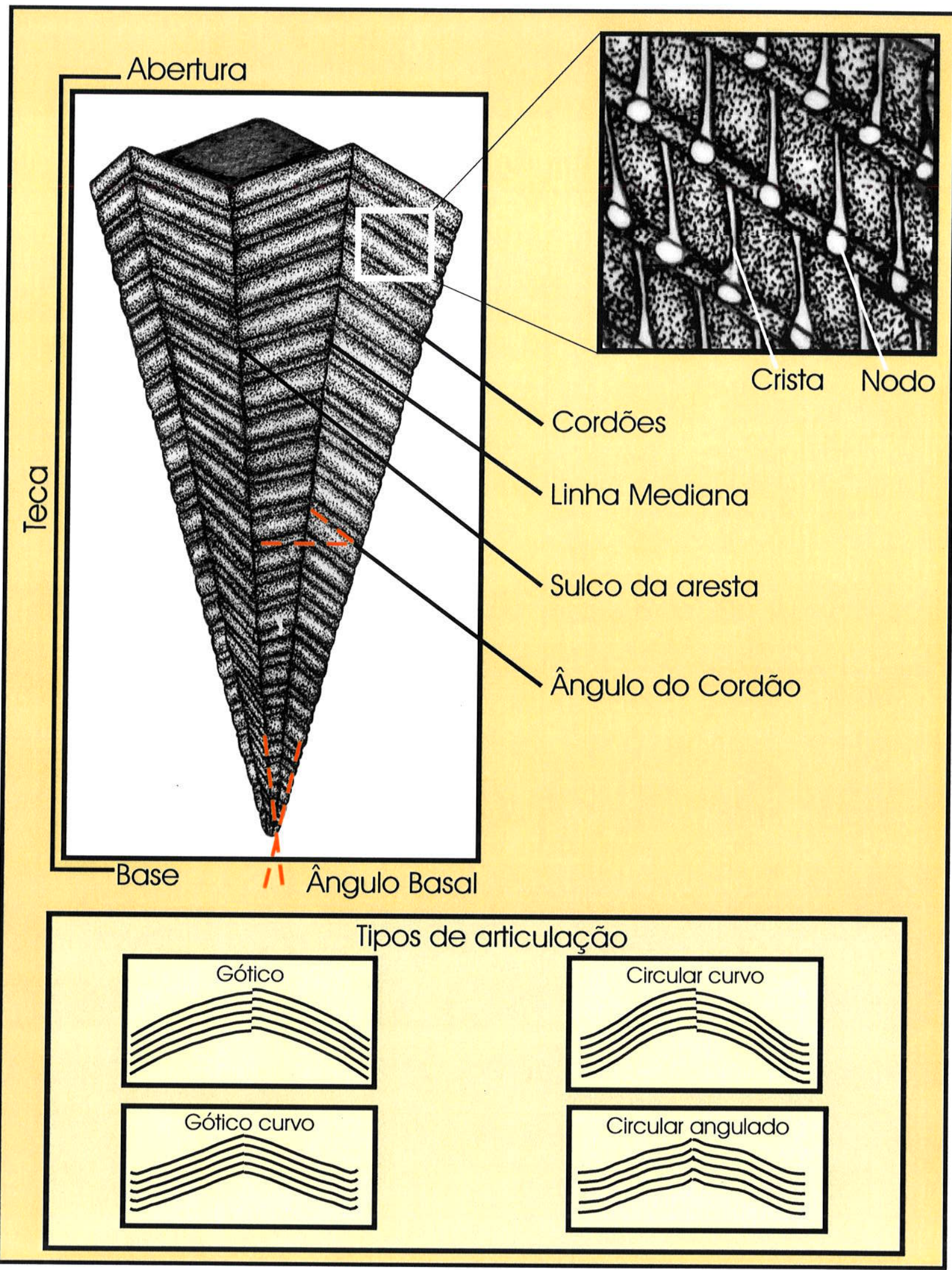

Figura 4- Morfologia geral dos conulários, com as principais feições e termos morfológicos utilizados nas descrições anatômicas. 


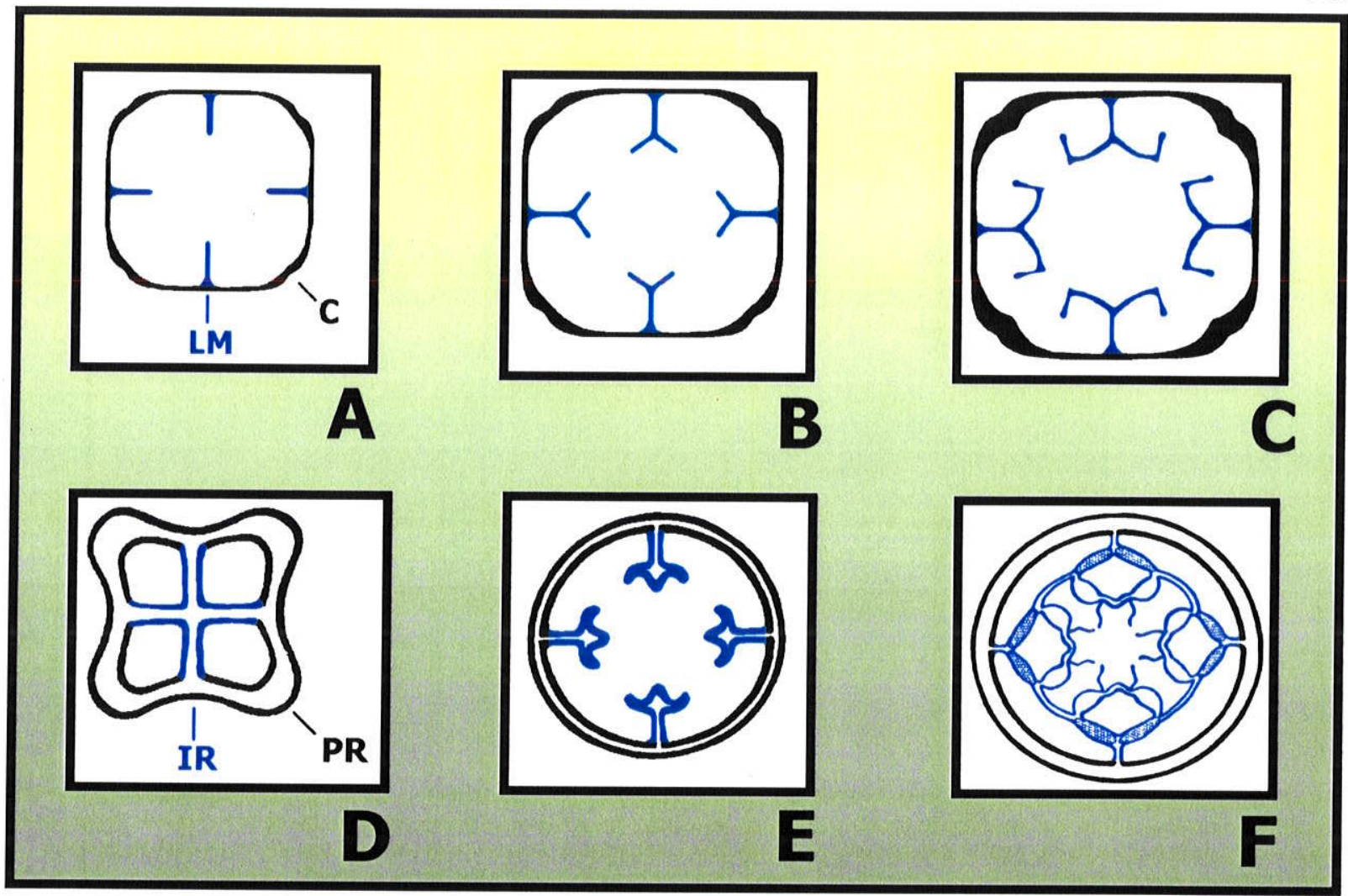

Figura 5- Comparação entre estruturas internas de Conulatae e Stauromedusae: A- C, Cortes transversais de Eoconularia loculata; D- F, Cortes transversais de Cratolorophus thetis, Stauromedusae, modificado de Jerre (1994).

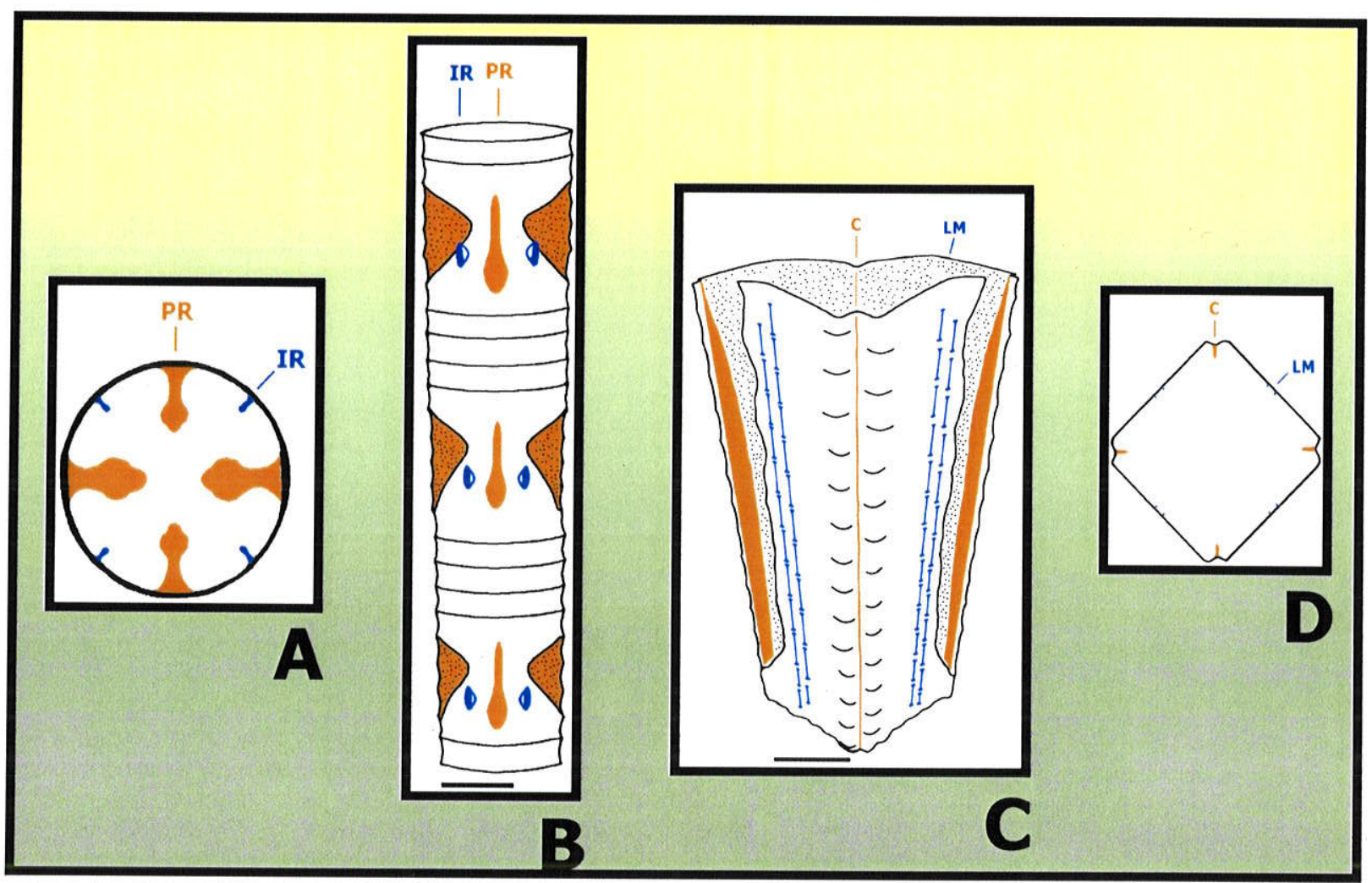

Figura 6- Comparação entre estruturas internas de Conulatae e Coronatae: A, Corte transversal de coronado; B, Coronado inteiro; C, Conulário inteiro; D, Corte transversal de conulário, modificado de Van Iten et al. (1996). 
ópticos (e.g., estereomicroscópio, microscópio eletrônico de varredura), grande atenção foi dispensada à preparação física das amostras.

Foram preparados 133 exemplares de conulários, provenientes dos afloramentos anteriormente mencionados (Fig. 3). Dentre eles, 116 espécimes pertencentes à Coleção Científica do Departamento de Zoologia do IBB/UNESP. Além desses, foram observados 06 espécimes provenientes da Coleção Cientifica do IGc/USP, 10 espécimes provenientes da Coleção Cientifica da UNG e 01 da Coleção Cientifica da UEPG (vide anexo).

Embora possa parecer pouco, deve ser lembrado aqui que conulários são elementos raros no registro geológico (Babcock et al., 1990) e que, em recente levantamento, Siviero \& Fernandes (2000) constataram que em todas as coleções paleontológicas oficiais do Rio de Janeiro, existem apenas 22 exemplares catalogados e disponiveis para estudo. Portanto, a coleçăo de conulários estudada é, possivelmente, a maior no Brasil.

No geral, os fósseis mantêm ainda uma fina película carbonosa recobrindo externamente a teca. Essa feição é importante, porque estão aí preservadas as principais características morfológicas empregadas na descrição e classificação dos conulários, sem levar em consideração, é claro, outras estruturas, tais como, os septos, as carenas e a microestrutura da teca, como descrito em Bischoff, (1978), Van Iten, (1991b), Van Iten, (1992a, b), Jerre, (1994) e Qian et al., (1997). Infelizmente, porém, em decorrência do intemperismo dos sedimentitos analisados, a película carbonosa não está, muitas vezes, preservada ao longo de todo o corpo do animal, dificultando ainda mais a sua preparação, dada à óbvia necessidade de observação dessa estrutura. Desse modo, a preparação do material estudado seguiu as etapas abaixo relacionadas: 
a- Preparacão física. Englobou a extração dos espécimes da matriz sedimentar, através da utilização de brocas de dentista (de vários tamanhos), além de estiletes, tendo início com a extração da matriz, até o limite com o fóssil. Em seguida, sob estereomicroscópio, os sedimentitos ainda restantes foram cuidadosamente retirados, liberando o fóssil da matriz. Normalmente, parte do fóssil, contendo também uma película escura, fica preservada na matriz. Na realidade, trata-se de um "negativo" da morfologia do animal, feição importante também, por conter estruturas (e.g., articulação dos cordões) que auxiliam na sua classificação.

Uma vez extraído da matriz, a superficie externa do fóssil foi atentamente examinada, sob estereomicroscópio, para retirada de grãos de sedimentos que podem estar presentes junto ao sulco da aresta e a área entre os cordōes do corpo do animal. Em adição, os grãos podem recobrir áreas importantes do esqueleto do animal, dificultando sua moldagem em látex, mencionada mais adiante.

b- Consolidacão dos espécimes. Dada à natureza friável dos sedimentitos da Formação Ponta Grossa que contêm os fósseis de conulários, à fragilidade intrínseca dos espécimes estudados e à necessidade de moldá-los em látex, os mesmos foram consolidados com verniz poliuretânico. Na literatura nacional, são raras as referências descrevendo as técnicas para consolidação artificial de fósseis ou de sua matriz (e.g., Rocha-Campos, 1969; Simões, inédito). Seguindo as orientações desses autores os exemplares foram consolidados, de acordo com o seguinte procedimento: a- as amostras foram submetidas à mistura de verniz poliuretânico e acetona na proporção de 2:1. Essa prática de preparação, utilizada anteriormente por Leme (2000) e Rodrigues (2000), mostrou que para esses sedimentitos, a concentração da solução utilizada mantém as feições morfológicas tênues presentes nos fósseis; $b$ - com um pincel macio, aplicou-se cuidadosamente a mistura sobre as amostras; c- esse 
procedimento foi repetido por volta de 2 vezes, dependendo do grau de decomposição da matriz e, d-após 24 horas, as amostras estavam prontas para serem manuseadas.

c- Moldagem em látex. Nesta fase, foram moldados os fósseis em melhor estado de conservação, isso é: aqueles cujos nodos, cristas, cordőes e linha mediana estão preservados. Os seguintes procedimentos foram seguidos: a- inicialmente, passou-se sobre o fóssil uma pequena quantidade de hidróxido de amônio a $35 \%$; bem seguida, com o auxílio de um pincel, aplicaram-se sobre os fósseis camadas finas de látex diluído em água e pigmentado com nanquim preto. Nessa etapa, é importante evitar a formação de bolhas; c- posteriormente, esse processo foi repetido por cerca de 5 vezes, aumentando a concentração do látex a cada nova aplicação; d-para se obter moldes mais resistentes, tiras de gaze foram intercaladas com as camadas de látex, e e- após a secagem completa, que levou aproximadamente 24 horas, o molde foi retirado do fóssil e suas bordas aparadas com tesoura.

d- Secão e polimento dos fósseis. Os cortes de espécimes que apresentavam estruturas internas foram realizados com o auxílio de pequenos discos de aço acoplados a caneta do motor de suspensão (aparelho odontológico). No corte, os espécimes foram fixados a uma morsa para cortar a região basal dos exemplares, onde tais estruturas encontravam-se preservadas. A partir daí, para facilitar a exposição das feições internas, as amostras foram desgastadas manualmente através de sucessivos polimentos, com carborundo.

e- Fotografia dos fósseis. Os fósseis foram fotografados com filme colorido, apenas para se obter um registro fotográfico geral de todo o material. 
f- Imagens digitais dos moldes de látex. Os espécimes estudados foram analisados e fotografados em estereomicroscópio Zeiss, modelo SV6, com câmera digital, JVC acoplada a um microcomputador PC e o software AxioVision. Esse método permitiu o alto poder de resolução e ampliação das imagens e possibilitou a obtenção das principais feições morfológicas dos conulários, diretamente na tela do computador, sendo o método mais adequado e eficiente para o material em estudo (veja Leme, 2000). 


\section{RESULTADOS}

\subsection{PALEONTOLOgia Sistemática}

A revisão sistemática aqui apresentada demonstrou que a fauna de conulários da Bacia do Paraná inclui, pelo menos, duas espécies pertencentes aos gêneros Conularia Sowerby 1820 e Paraconularia Sinclair 1940, abaixo descritas. Dentre os 133 exemplares examinados, 116 pertencem a Conularia quichua Ulrich 1890. Apenas dois exemplares (CuPg-1 e GP/1E4194c) foram atribuidos à Paraconularia africana (Sharpe 1856). O restante (15 espécimes) não pode ser atribuído a nenhum táxon, devido à qualidade de preservação. Invariavelmente, nesses casos, a ornamentação da teca não está preservada.

\section{PALEONTOLOGIA SISTEMÁTICA}

\section{SUBCLASSE CONULATAE, Collins et al. 2000 \\ FAMÍLIA Conulariidae, Walcott 1886 \\ GENERO Conularia Sowerby 1820}

Discussão. $O$ texto apresentado a seguir, referente ao gênero Conularia, está, em grande parte, fundamentado em Van Iten et al. (em preparação). Desde a proposição do gênero Conularia por Sowerby em 1820, tendo C. quadrisulcata Sowerby do Siluriano da Inglaterra (Sinclair, 1940) como a espécie tipo, esse gênero foi reinterpretado por diversos autores. Sinclair $(1940$, p. 73 ) diagnosticou-o da seguinte forma: "Conulários com cordões distintos, pouco espaçados, com nodos; cristas ou estrias atravessando todo o comprimento dos interespaços. Septos ao longo da teca ausentes". Sinclair (1940, p. 73 ) também designou C. niagarensis Hall (Siluriano) como uma espécie muito semelhante ao genótipo. Posteriormente, em seu trabalho sobre a 
classificação dos conulários, Sinclair (1952) atribuiu Conularia à subfamília Conulariinae subfam. nov., caracterizada (Sinclair, 1952, p. 137) por: "Conulários com o sulco da aresta raso que não interrompe a ornamentação, sem cordões marcados ou outras estruturas." Seguindo Sinclair (1940), Moore \& Harrington (1956b, p. F60) diagnosticaram o gênero Conularia como: "Conulários com cordões bem definidos, pouco espaçados, com nodos; cristas ou estrias atravessando todo o comprimento dos interespaços; linha mediana não marcada superficialmente por sulco ou elevação e sem septo interno." Esses mesmos autores (Moore \& Harrington, 1956b, p. F60) atribuíram Conularia à família Conularidae, caracterizada por incluir: "Conulários com arestas da teca marcadas por sulco longitudinal que não interrompe a ornamentação e não é acompanhado por um espessamento distinto."

Recentemente, Babcock \& Feldmann (1986a) reexaminaram espécies do gênero Conularia do Devoninano e Mississipiano da América Norte, as quais foram diagnosticadas como tendo "cordões, geralmente, pouco espaçados, $9-84 / \mathrm{cm}$. Aproximadamente $60 \%$ dos cordões são alternados na linha mediana; mais de $40 \%$ são opostos; dois cordões adjacentes na face formam um arco que atravessa a face. Ângulo basal pequeno, $9^{\circ}$ a $23^{\circ}$. Nodos, espinhos (cristas) adaperturais e espinhos (cristas) adapicais usualmente presentes e pouco espaçados, $1-7 / \mathrm{mm}^{\prime}$. Fundamentados nessa nova diagnose, Babcock \& Feldmann (1986a) atribuíram certas espécies a Conularia, sem, no entanto, revisarem as classificações prévias. Posteriormente, Babcock et al. (1990, p. 898) emendaram a diagnose de Babcock \& Feldmann (1986a) alterando apenas os valores de ângulo basal $\left(6^{\circ}\right.$ a $\left.23^{\circ}\right)$ e espaçamento de nodos e cristas adapicais $(1-10 / \mathrm{mm})$. Curiosamente, o conceito de Conularia de Babcock \& Feldmann (1986a) e Babcock et al. (1990) inclui espécies (e.g., C. subcarbonaria Meek \& Worthen) que não apresentam cristas no interespaço. Conforme indicado acima, Sinclair (1940) e Moore \& Harrington (1956b) atribuem a 
presença de cristas nos interespaços, como uma das características diagnósticas para esse gênero. Adicionalmente, a diagnose de Babcock \& Feldmann (1986a) e Babcock et al. (1990) não apresenta informações sobre a anatomia do sulco da aresta, outra característica importante nas diagnoses anteriores (Sinclair, 1940; Moore \& Harrington 1956b).

Conulários recentemente atribuidos ao gênero Conularia (Babcock \& Feldmann, 1986a; Jerre, 1993; Van Iten et al., 1996) consistem em organismos que, na maioria das vezes, apresentam quatro faces, cordões distintos, que arcam em direção a abertura através da face e apresentam numerosos nodos e cristas (Van Iten, et al., em preparação).

Os cordões são expressões de corrugações trocoidais e, em muitas espécies, mostram-se recurvados ou descontínuos na regiăo da linha mediana. Na maioria das espécies, os cordóes são sempre contínuos no sulco da aresta, onde geralmente são mais finos e curvam-se levemente em direção à abertura (e.g., Van Iten et al., 1996, Est. 3, fig. 2). Em apenas uma espécie, C. sarae Jerre (Siluriano, Suécia), os cordões não são contínuos no sulco da aresta e suas terminações alternam-se (veja Jerre, 1993, Est. 2, fig. 2).

O interespaço entre dois cordões adjacentes exibe numerosas cristas que podem ser levemente inclinadas em relação a linha mediana (Van Iten et al., 1996). Aparentemente, poucas são as espécies que não apresentam cristas no interespaço (e.g., C. subcarbonaria; Babcock \& Feldmann, 1986a, fig. 11.4). Na maioria delas, as cristas estendem-se por todo o comprimento do interespaço, conectando-se com o cordão adjacente (e.g., Reed, 1933, Est. 19, fig. 4a; Jerre, 1993, Est. 2., fig. 1; Van Iten et al., 1996, Est. 3, figs 1 e 4; Richardson \& Babcock, 2002, fig. 1.4, 5). Além disso, tanto os nodos quanto as cristas não se alinham longitudinalmente. No sulco da aresta, os nodos e as cristas são menos espaçados entre si ao longo do cordão, do 
que nas faces. As cristas, nessa região, são muito finas e são separadas por pequenas elevações chamadas de estrias (e.g., Jerre, 1993, Est. 2, fig. 1; Van Iten et al., 1996, Est. 3, fig. 2).

Recentemente, algumas espécies formalmente atribuidas a Conularia têm sido referidas a um novo gênero. Por exemplo, Hergarten (1985) estabeleceu o gênero Holoconularia, fundamentado em espécimes de conulários que apresentavam cordões descontínuos no sulco da aresta. Anteriormente, no entanto, Boucek (1939) propôs o gênero Mesoconularia, que incluiu espécies formalmente designadas como Conularia, porém essas não possuiam cristas. Em 1952, Sinclair erigiu o gênero Ctenoconularia, cujas características diagnósticas eram o ângulo basal pequeno (aproximadamente $10^{\circ}$ ), as cristas restritas à região basal, sendo que seu comprimento atingia apenas a metade do interespaço e os cordões que terminavam alternados na margem do sulco da aresta. Sinclair (1952) propôs também outros gêneros (e.g., Diconularia), incluindo espécies, tais como, Conularia micronema Meek que são similares a Conularia quadrisulcata, mas, com arestas possivelmente sem sulco e linha mediana associada a um pequeno septo (Moore \& Harrington, 1956b, p. F61). Babcock \& Feldmann (1986a), posteriormente, reinterpretaram Diconularia como um sinônimo júnior de Conularia.

As espécies do gênero Conularia, tradicionalmente, têm sido referidas como espécies com estruturas internas ausentes nas arestas (e.g., Sinclair, 1948, 1952; Moore \& Harrington, 1956b). Esse argumento, dentre outros, fundamentam as classificações taxonônicas, em termos de categorias supragenéticas. Entretanto, as ocorrências de C. quichua e C. milwaukeensis, além de outras espécies desse gênero internamente espessadas (C. albertensis Reed e C. splendida Billings) indicam que o conceito tradicional do gênero Conularia é muito restrito e deve ser questionado. Deve ser lembrado aqui que o caráter espessamento interno parece variar dentro das 
populações de Conularia, como indicado pelos dados dos espécimes da Bacia do Paraná, onde dentre 116 , apenas 3 possuem tal estrutura. Em adição, a visualização dos espessamentos internos exige espécimes em bom estado de conservação. Alternativamente, espessamentos internos, presentes nas arestas ou linhas medianas de no mínimo quatro espécies de Conularia, podem ter surgido independentemente nessas espécies. Similarmente, Conularia com cristas ausentes nos interespaços podem ter perdido essas estruturas secundariamente ou não ter preservado, devido ao grau de esfoliação da teca (Rodrigues, 2002; Simões et al. em preparação).

Desse modo, um conceito mais amplo do gênero Conularia poderia ser expresso da seguinte forma: conulários com cordões trocoidais, que se interrompem ou não na região da linha mediana, geralmente contínuos no sulco da aresta, onde curvam-se levemente em direção à abertura; articulação do tipo gótico ou circular angulado; interespaços geralmente atravessados por cristas que não se alinham longitudinalmente; nodos presentes; espessamentos internos na aresta e linha mediana podem estar presentes. Curiosamente, esse conceito é similar em muitos aspectos àquele apresentado por Sinclair (1940) e Moore \& Harrington (1956b), mas difere substancialmente do proposto por Babcock \& Feldmann (1986a) por excluir caracteres biométricos tais como, por exemplo, ângulo basal e espaçamento relativo dos cordões, dos nodos e das cristas, conforme já sugerido por Leme et al. (2000b), Rodrigues et al. (2000b) e Simões et al. (em preparação). 


\section{Conularia quichua Ulrich, 1890}

\section{Estampa 1 e 2}

Conularia quichua Ulrich. Kayser, 1897, p. 288, Est. 11, figs. 1-2; Thomas, 1905, p. 254-255, Est. 12, fig. 19.

Conularia cf. quichua Ulirich. Ahlfeld e Branisa, 1960, Est. 4, fig. 9; Lof, 1985.

Conularia (Mesoconularia) quichua Ulrich. Boucek, 1939, fig. 3e.

Mesoconularia quichua Ulrich. Sinclair, 1948, p. 119.

Conularia cf. undulata Conrad. Sensu Reed, 1904, p. 248-249, Est. 31, figs. 1-1a; Hansman et al., 1962, p. 21-22.

Conularia quichua var. nov. Branisa, 1965, Est. 43, fig. 2.

Conularia sp. Branisa, 1965, Est. 43, figs. 5-6.

Mesoconularia ulrichana Lima, 1989, p. 18.

Emenda à diagnose específica. Conularia com arestas e linhas medianas espessadas (Est. 1, figs. a, b, e, i). Carenas estendendo-se, na base, a uma estrutura à moda de "pilar central" (Est. 1, figs. a-d). Pontuações indeterminadas irregularmente distribuídas na região da abertura da teca (Est. 1, figs. e, $f, g, h$ ).

Descricão. Conulário completo, faltando a base em alguns exemplares $(n=47)$, apresentando quatro ou raramente cinco faces e comprimento variando de 5,94 a $9,55 \mathrm{~cm}$. Faces semelhantes na largura. Carenas presentes nas quatro arestas e restritas à região basal (Est. 1, figs. a, b). Estrutura à moda de um "pilar central" (Est. 1, figs. c, d), apresentando mesma constituição da teca, conectada às carenas. Espessamentos internos na região da linha mediana (Est. 1, fig. e, i). Pontuações de natureza não conhecida irregularmente distribuídas na região da abertura da teca (Est. 1 , figs. $e, f, g, h$ ). 


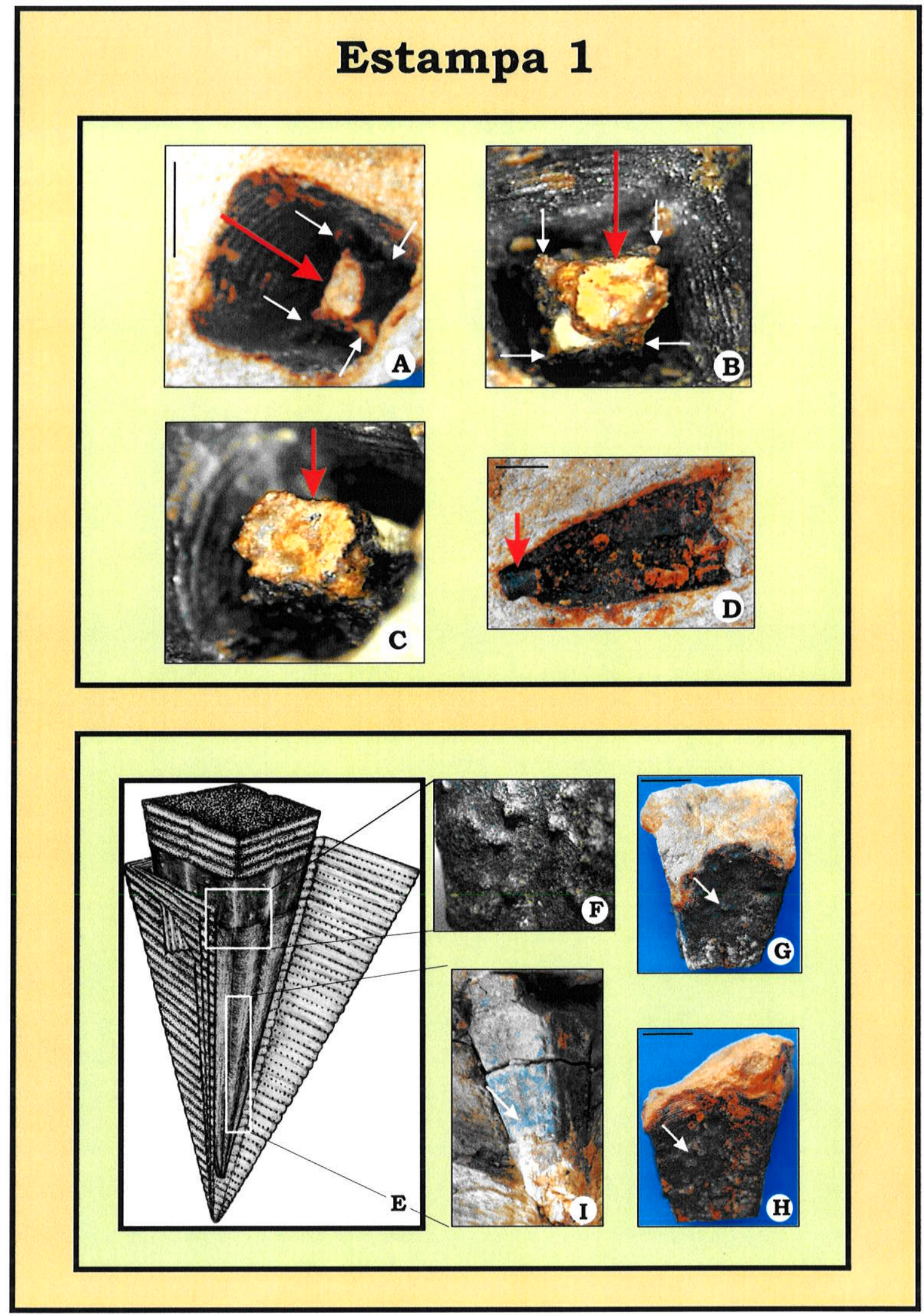

Estampa 1- Conularia quichua, estruturas internas: A-C, Detalhe das carenas na base, espécime DZP-3073a; B, x1,2; C-D, "Pilar central"; C, Espécime DZP-3073a x1,2; D, Espécime DZP-17057; E, Esquema do molde interno de conulário mostrando as camadas externas da teca e estruturas internas; $\mathrm{F}-\mathrm{H}$, Pontuações irregularmente distribuídas na região da abertura, espécime DZP-3082; F, x1,6; I, Septo na região da linha mediana, espécime DZP-3618. Explicação: Setas em branco, carenas, septo e pontuações; setas em vermelho, "pilar central"; escala gráfica $(0,5 \mathrm{~cm})$. 
Cordões sempre opostos na linha mediana, contínuos no sulco da aresta (Est. 2, figs. a, b , c, j, k), em número de 30 a 40, por centímetro, apresentando articulação do tipo circular angulado nas regiões da abertura e mediana e gótico a $10 \mathrm{~mm}$ da base (Est. 2, figs. $a, b, c)$. Nodos pequenos e hemisféricos (Est. 2, figs. $h$, i), em número de 4 a 5 , por milimetro, concentrados $(4$ a $7 / \mathrm{mm}$ ) nas proximidades das arestas e linhas medianas. Cristas longas e afiladas, atravessando todo o comprimento dos interespaços, predominantemente, intersectam os cordões no nodo e terminam entre dois nodos (Est. 2, figs. d-g). Crista adapical ausente. Parede basal presente no espécime DZP-3611a.

Ocorrências. Formação Ponta Grossa, Seqüência B (Membro Jaguariaíva), ?Neolochkoviano-Emsiano (Bergamaschi, 1999).

Localidades e horizontes fossiliferos. Afloramento situado nos quilômetros 3,8 e 4,5 da estrada de ferro (Ramal Jaguariaiva-Jacarezinho), Jaguariaíva, PR, nos intervalos de 29-32 m, a 39m, e de 44-48 m do contato basal com a Fm. Furnas. Afloramentos "curva l" e "curva II" em Ponta Grossa, PR.

Material examinado. Espécimes DZP-3073-3085, 3316-3318, 3321-3324, 3327, $3329-3331,3502-3505,3507-3517,3609-3621,3623-3624,3626-3634,3684,3686$, 16814-16815, 16818-16820, 17036-17053, 17057-17058 da Coleção Científica do Depto. de Zoologia, Laboratório de Paleontologia, IBB/UNESP; UEPG-D-058, da Coleção Cientifica do Depto. de Geociências da Universidade Federal de Ponta Grossa; GP/1E-2575, 3177- 3178, 3191, 4914, GP/3E-3569, da Coleção Científica do Depto. de Geologia Sedimentar e Ambiental do IG/USP; UnG- CuPg2, 4, 9, 10, 14, da Coleção Cinetífica do Laboratório de Geociências da Universidade de Guarulhos. 

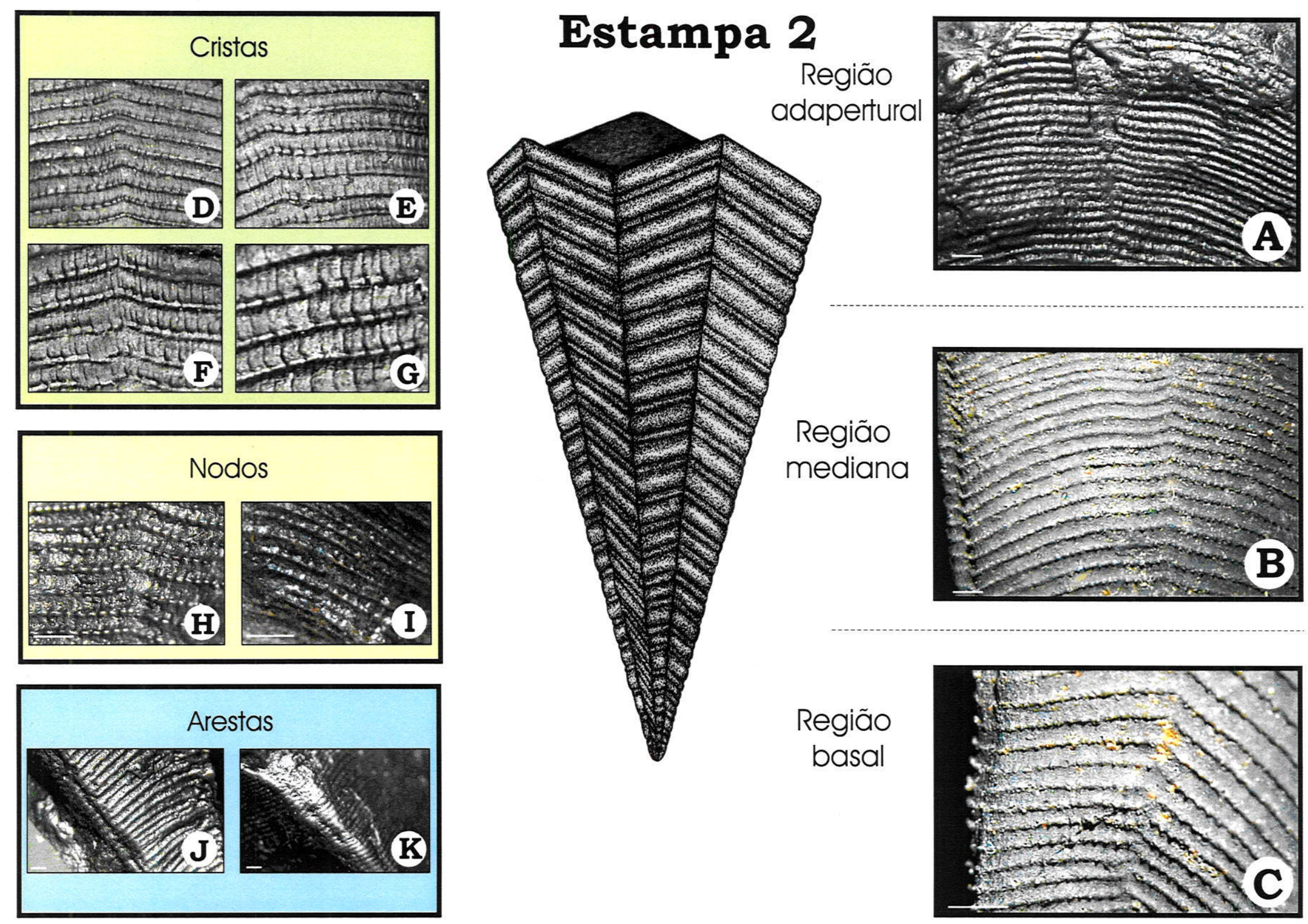

Estampa 2- Conularia quichua, morfologia geral: A-C, Articulação dos cordões ao longo da teca; A, Espécime DZP-3082; B-C, Espécime GP/1E-4914; DG; Cristas, espécime DZP-3509; D-E, X1,2; F-G, x1,6; H-I, Nodos; H, Espécime DZP-3082; I, Espécime DZP-3081b; J-K, Detalhe das arestas; J, Espécime DZP-3082; K, Espécime DZP-3331. Explicação: Escala gráfica (1mm). 
Discussão. Conularia quichua difere de todas as espécies descritas de Conularia por apresentar arestas espessadas na região basal, estendendo-se a um "pilar central" de mesma constituição da teca, portanto, mineralizado (Est. 1, figs. a-d). Tais estruturas podem estar relacionadas a septos longitudinais unidos na região basal, formando um "pilar central". Esse padrão ocorre em espécies de Stauromedusae (e.g., Craterolophus tethys). Os septos longitudinais de C. tethys são unidos a um centro comum na região basal $e$, na região do cálice, convergem para a cavidade gastrovascular (Jerre, 1994) (Fig. 5). Além disso, a linha mediana apresenta espessamentos pareados, como em Metaconularia Sinclair. Pontuações indeterminadas ocorrem irregularmente na região da abertura da teca.

Em sua grande maioria, os espécimes de C. quichua, aqui estudados, estão completos e inflados, permitindo a observação de certos caracteres (e.g., carenas, septos na linha mediana, pontuações musculares) não referidos para os espécimes do Devoniano da Bolivia, descritos por Babcock et al. (1987a), nem aqueles estudados por Clarke (1913), para a mesma unidade litoestratigráfica. Nesse sentido, a morfologia de $C$. quichua é mais complexa do que aquela originalmente descrita por Clarke (1913) e Babcock et al. (1987a).

Assim, como em outras espécies de Conularia, em C. quichua os cordões são sempre contínuos no sulco da aresta, onde se curvam adaperturalmente. Entretanto, nessa espécie as cristas são mais afiladas do que na maioria das outras espécies do gênero (e.g., C. milwaukeensis). O material da Bolivia está fortemente achatado e, portanto, os caracteres biométricos estão modificados. Segundo Babcock et al. (1987a), C. quichua é muito semelhante a C. niagarensis por possuir articulação dos cordões do tipo circular angulado, na maior parte da teca. Porém, C. quichua apresenta articulação dos cordões do tipo gótico na região basal. A única diferença entre C. quichua e C. niagarensis seria o ângulo basal. Contudo, diferenças na 
preservação entre espécimes inflados e fortemente achatados não permitem o uso dessa feição na diagnose dessa espécie (vide item 4.1). Dessa forma, o status de $C$. niagarensis como táxon válido deve ser avaliado no futuro.

Outra diferença marcante entre $C$. quichua e as demais espécies descritas de Conularia é a ocorrência de espécimes mostrando cinco faces verdadeiras (Fig. 7). A ocorrência de tecas não apresentando quatro faces tem sido observada em outros gêneros de conulários, incluindo Conularina triangulata (Raymond) (três faces) e Paraconularia missouriensis (Swallow) (seis faces) (Babcock et al., 1987b), mas não em Conularia. Portanto, o espécime de C. quichua (DZP-3081b, Fig. 7) com teca de cinco faces é o primeiro do gênero a ser documentado na literatura com tal caracteristica e também para os Conulatae, em geral.

Indivíduos da espécie Conularia quichua ocorrem isoladamente ou formando agrupamentos de dois ou três exemplares (Fig. 7). Anteriormente, agrupamentos de individuos do gênero Conularia estavam restritos às espécies $C$. splendida Billing, $C$. tenuicosta Ruedemann e C. congregata Hall (Van Iten \& Cox, 1992). Portanto, agrupamentos de Conularia quichua, são aqui reportados pela primeira vez (vide Rodrigues et al., 2001; Rodrigues, 2002).

A revisão efetuada indica que a fauna de conulários da Bacia do Paraná, Formação Ponta Grossa, é amplamente dominada por Conularia quichua (vide item 4.3). 


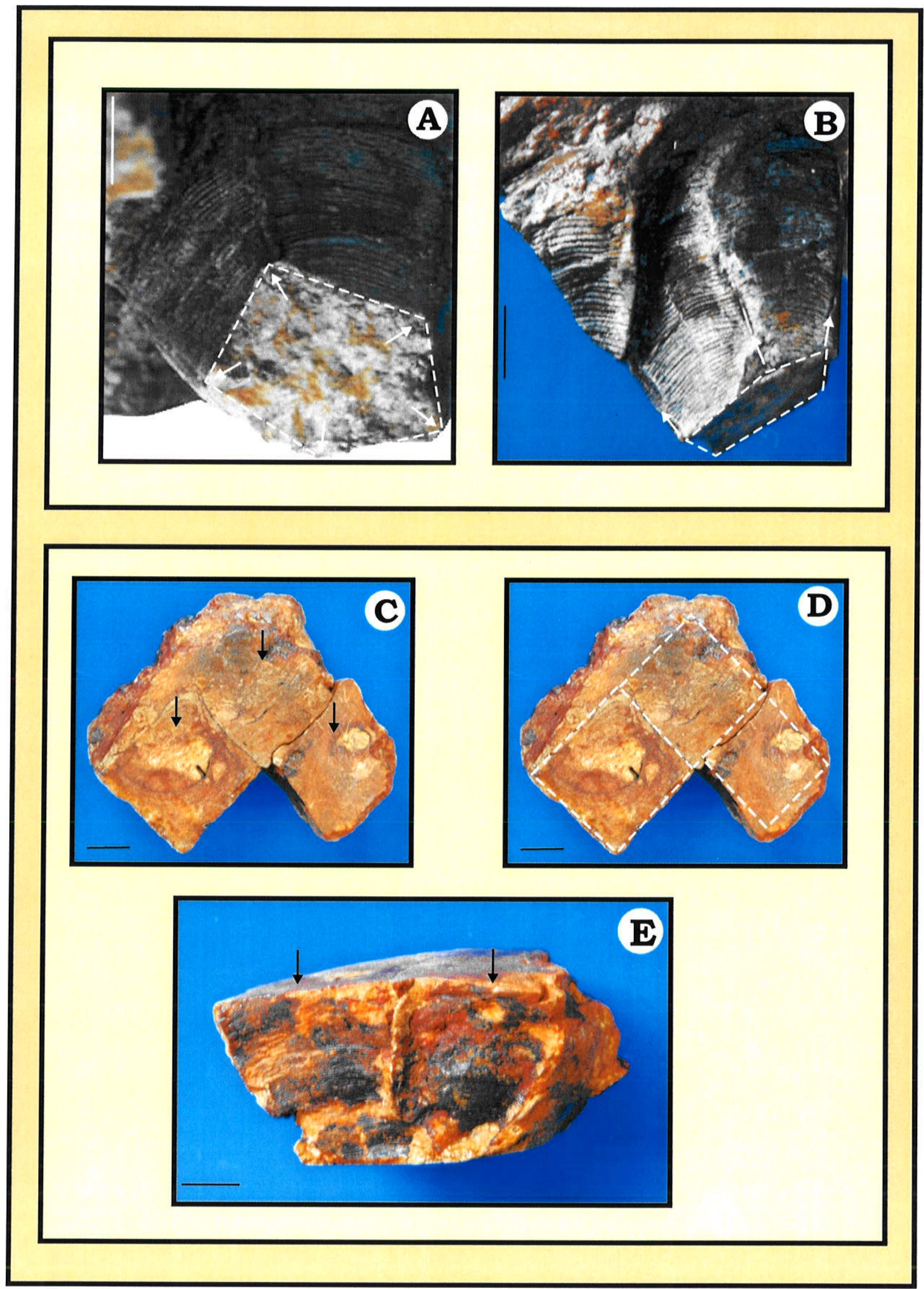

Figura 7- Conularia quichua: A-B, Espécime DZP-3081b com cinco faces verdadeiras; C-E, Agrupamento com três espécimes, exemplar DZP-3686a, b, c; C-D, Espécimes vistos em corte (vista superior); E, Mesmos espécimes, molde externo (vista lateral). Explicação: Setas em branco, arestas; setas em preto, espécimes agrupados; escala gráfica em A-B, $(0,5 \mathrm{~cm})$; em C-E, $(1 \mathrm{~cm})$. 


\section{GÊNERO Paraconularia Sinclair 1940}

Discussão. Alguns gêneros (e.g., Calloconularia Sinclair, Flectoconularia Waterhouse) são muito similares, em suas morfologias externas, a Paraconularia. Curiosamente, a partir de um exame cuidadoso das descrições apresentadas para esses gêneros, observa-se que os caracteres utilizados para diferenciá-los de Paraconularia necessitam ser revistos. Por exemplo, o gênero Calloconularia mostra caracteres muito similares a Paraconularia (e.g., cordões descontínuos no sulco da aresta, espaçamento dos cordões, linha mediana marcada apenas pela flexão dos cordões). Entretanto, Calloconularia é distinta de Paraconularia por apresentar cristas nos interespaços (Moore \& Harrington, 1956b, fig. 51.6; fig. 50, p. F63 e F64). Porém, a preservação dessa feição morfológica está estreitamente relacionada ao grau de esfoliação da teca, que varia de acordo com o grau de intemperismo (Fig. 7) (Rodrigues, 2002; Simões et al., em preparação).

Outro exemplo é identificado no artigo de Waterhouse (1979). Esse autor reconheceu três espécies de Paraconularia $[P$. derwentensis (Johnson), $P$. omata Waterhouse e P. matauraensis Waterhouse] para o Permiano e Triássico da Nova Zelândia. Além desse, o autor propôs o gênero Flectoconularia, a partir de tecas fragmentadas (Waterhouse, 1979, p. 484, fig. 4-7). O novo gênero foi diagnosticado por apresentar cordões que curvam-se para a base no sulco da aresta. Normalmente, em todos os conulários que apresentam essa feição (e.g., Paraconularia, Conularia, Metaconularia), os cordões no sulco da aresta curvam-se para a abertura. Notavelmente, porém, se os fragmentos da teca, utilizados por Waterhouse (1979) para eleger Flectoconularia, forem reorientados, ou seja, o que está representando a região basal, representar a região adapertural, os cordões do sulco da aresta curvase-ão em direção à abertura, como em todos os outros conulários conhecidos. 
Comparando esses fragmentos com os espécimes atribuídos a Paraconularia por Waterhouse, nota-se grande semelhança morfológica, não sendo possível diferenciálos desse por qualquer outro caráter. O material estudado por Waterhouse (1979) necessita, portanto de reexame urgente. 


\section{Paraconularia africana (Sharpe, 1856)}

\section{Estampa 3}

Conularia africana Sharpe, 1856 , p. 214, Est. 27, figs. 13a-b; Ulich, 1892, p. 29-31, Est. 3, fig. 4; Reed, 1904, p. 247-248; Shwarz, 1906, p. 362-363, Est. 7, figs. 13, 15; Reed, 1925, p. 103, Kiderlen, 1937, figs. 15, 26; 1-2; Moore e Harrington, 1956b, p. F60-F61, figs. 46, 11; Ahlfeld e Branisa, 1960, Est. 4, fig. 13; Hansman et al., 1962, p. 21; Branisa, 1965, Est. 44, figs. 1-3, 6, 12, 14-16; Babcock et al., 1987a, figs. 4AD, 8C, Tab. 1 .

Conularia africana var. striatula Kozlowski, 1923, p. 67-68, Est. 7, figs. 1-3.

Paraconularia africana (Sharpe). Sinclair, 1948, p. 187-188; Cecioni, 1982, Est. 1, figs. $A, B$.

Conularia s.l. striatula Kozlowski. Sinclair, 1948, p. 285.

Conularia africana striatula Kozlowki. Ahlfeld e Branisa, 1960, Est. 4, fig. 3; Branisa, 1965, Est. 44, figs. 5, 7, 10.

Conularia sp. Branisa, 1965, Est. 44, fig. 4, Est. 78, fig. 5.

Conularia baini Ulrich. Sensu Schwarz, 1906, p. 362, Est. 8 fig. 14; Branisa, 1965, Est. 44, figs. 14-16.

Emenda à diagnose específica. Paraconularia que apresenta arestas internamente espessadas (carenadas) (Est. 3, figs. $f-h$ ).

Descricão. Conulário completo, apresentando quatro faces e comprimento máximo de $12,2 \mathrm{~cm}$. Carenas presentes ao longo das arestas (Est. 3, figs. f-h). Espessamentos internos na região da linha mediana ausentes. Cordões alternados na linha mediana (Est. 3, fig. d), descontínuos no sulco da aresta (Est. 3, fig. e), em número de 10 a 30, por centímetro, apresentando articulação do tipo gótico, ao longo da teca (Est. 3, figs. a-c). Nodos, cristas e parede basal ausentes. 


\section{Estampa 3}
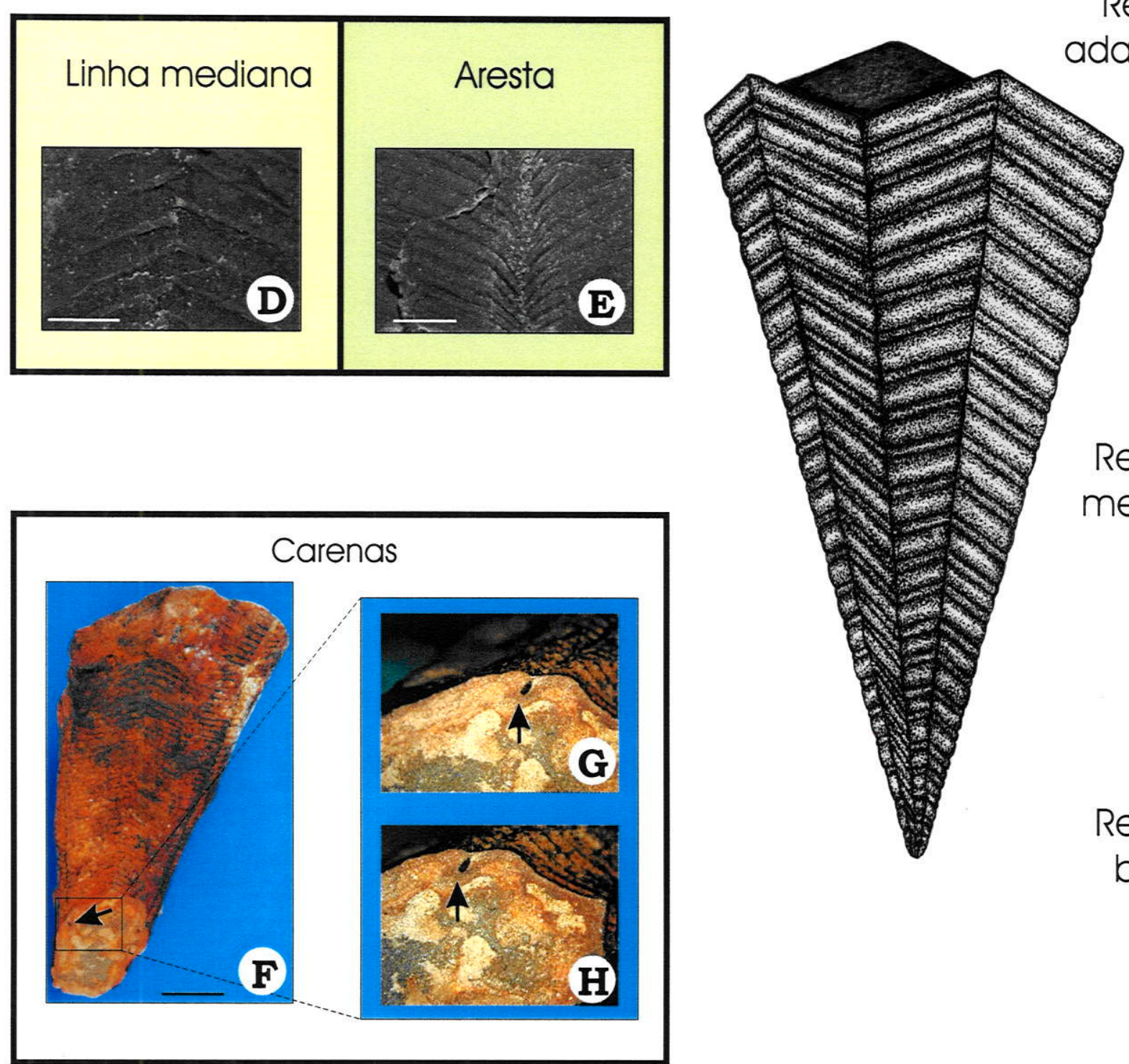

Região adapertural
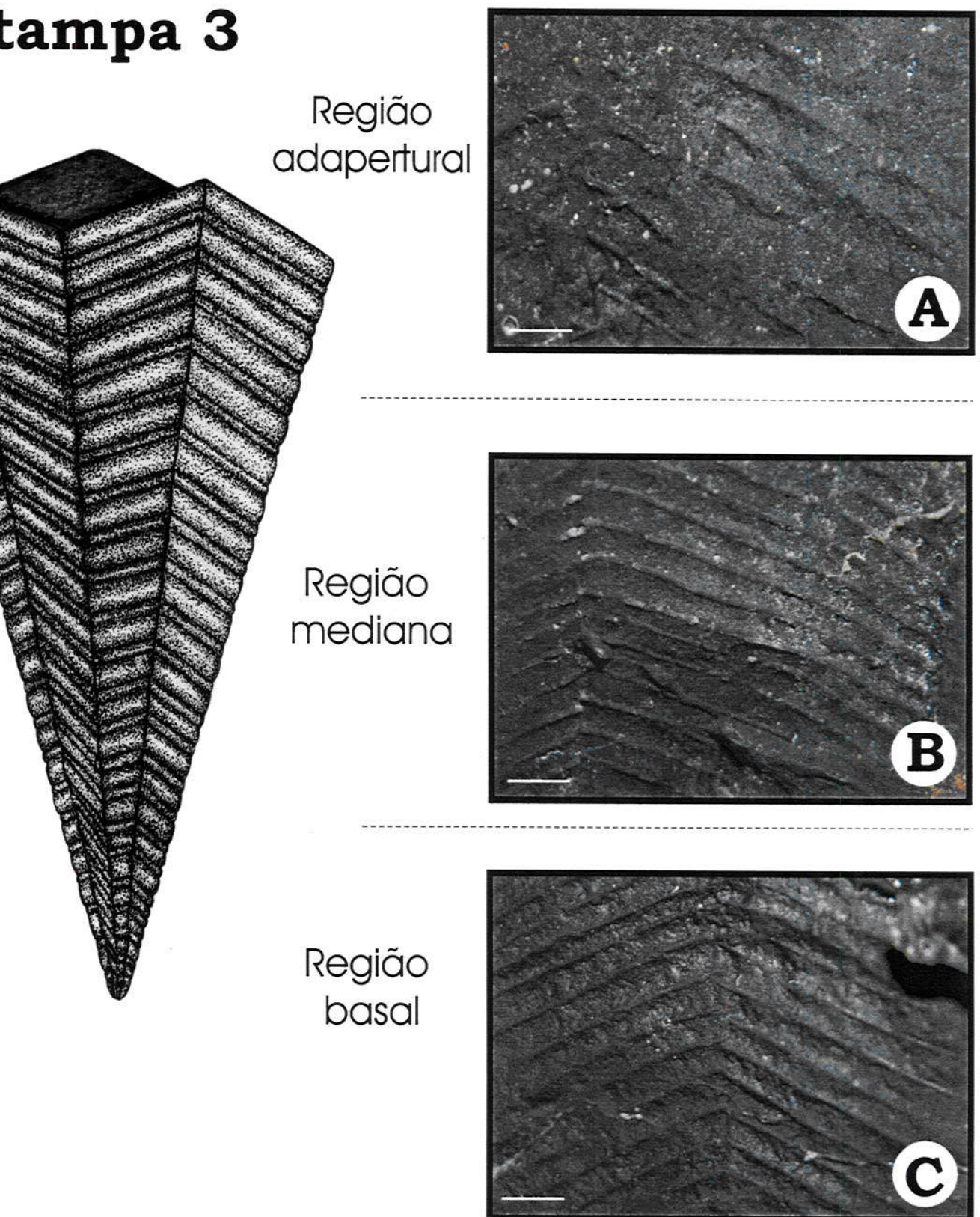

Estampa 3-Paraconularia africana, morfologia geral: A-E, Espécime CuPg-01; A-C, Articulação dos cordões ao longo da teca; D, Linha mediana; E, Aresta; FH, Carenas do espécime GP/3E-4194; G-H, x0,8, detalhe das carenas nas arestas. Explicação: Escala gráfica (2 mm). 
Ocorrências. Formação Ponta Grossa, Seqüência B (Membro Jaguariaíva), ?Neolochkoviano-Emsiano (Bergamaschi, 1999).

Localidades e horizonte fossilifero. Afloramento situado no $\mathrm{Km} \mathrm{4,5}$ da estrada de ferro (Ramal Jaguariaíva-Jacarezinho), Jaguariaíva, PR, no intervalo de 44-48m do contato basal com a Fm. Furnas. Nivel estratigráfico indeterminado.

Material examinado. Espécime CuPg-1 pertencente à Coleção Científica do Laboratório de Geociências da Universidade de Guarulhos (UNG); GP/3E-4194c, Coleção Científica do Depto. de Geologia Sedimentar e Ambiental do IG/USP.

Discussão. P. africana difere das espécies de Paraconularia por apresentar carenas ao longo das arestas, feição pela primeira vez descrita para essa espécie (Est. 3, figs. $f-h)$. Outras espécies do mesmo gênero exibem também espessamentos internos na teca. Por exemplo, Paraconularia ulrichana (Clarke), que ocorre na Formação Ponta Grossa (Clarke, 1913), apresenta carenas, mas somente nas linhas medianas. Outra espécie, Paraconularia crustula White, do Carbonífero da América do Norte é caracterizada por apresentar arestas carenadas, possuindo, no entanto, espessamentos internos nas linhas medianas (Van Iten, 1992a).

Outras feições morfológicas que caracterizam $P$. africana incluem o espaçamento entre os cordões, variando em número de 10 a 30 cordões, por centímetro e a articulação do tipo gótico ao longo da teca (Est. 3, figs. a-c). Embora os exemplares descritos por Babcock et al. (1987a) do Devoniano da Bolivia apresentem articulação do tipo gótico curvo, espécimes de $P$. africana da mesma localidade, referidos por Koslowski (1923) e exemplares do Devoniano do Uruguai (Mendéz-Alzola \& Sprechmann, 1973), também mostram articulação do tipo gótico. Outra feição 
morfológica descrita por Babcock et al. (1987a), que não foi observada no material examinado, é a presença de nodos e cristas adaperturais em número de 1 a 2 , por milímetro, ao longo do cordão. Curiosamente essas feições não foram encontradas também em exemplares de $P$. africana do Devoniano do Uruguai (Mendéz-Alzola \& Sprechmann, 1973) e da Bolivia (Conularia var. striatula Kozloswski, 1923). Entretanto, a preservação dessas feições está intimamente relacionada ao grau de esfoliação da teca (Fig. 8) (Rodrigues, 2002; Simões et al., em preparação).

Babcock et al. (1995) diferencia $P$. africana de $P$. sahara principalmente pela presença ou auséncia de cristas. Porém, a designação de $P$. sahara está fundamentada em um único exemplar (USNM 483893) incompleto e, segundo os autores, a ausência de nodos e cristas pode estar relacionada à quebra ou ao intemperismo (esfoliação da teca). Portanto, o status de $P$. sahara carece de revisão ulterior.

Clarke (1913) descreveu $P$. africana para a fauna devoniana da Bacia do Paraná, fundamentado em material proveniente da região de Ponta Grossa. Entretanto, os espécimes referidos por Clarke (1913, Estampa VIII, figs. 12-15) como pertencentes a $P$. africana, apresentam cordões finos e pouco espaçados. Essas não são feições comuns à $P$. africana. Desse modo, seria extremamente interessante revisar o material original de Clarke (1913). Uma vez que esse estudo está sendo conduzido pela aluna Fernanda Siviero (UFRJ), orientada do Prof. Dr. Antônio Carlos Sequeira Fernandes (Museu Nacional, RJ) e que o presente documento está sendo encerrado em setembro de 2002, prefere-se, de momento, aguardar os resultados para futuras comparações. De qualquer modo, contudo, a única ocorrência registrada de $P$. africana nos estratos da Formação Ponta Grossa é a do material aqui analisado, proveniente da região de Jaguariaiva, PR. Representa, desse modo, a primeira ocorrência dessa espécie na Bacia do Paraná (vide Leme et al., 2001). 


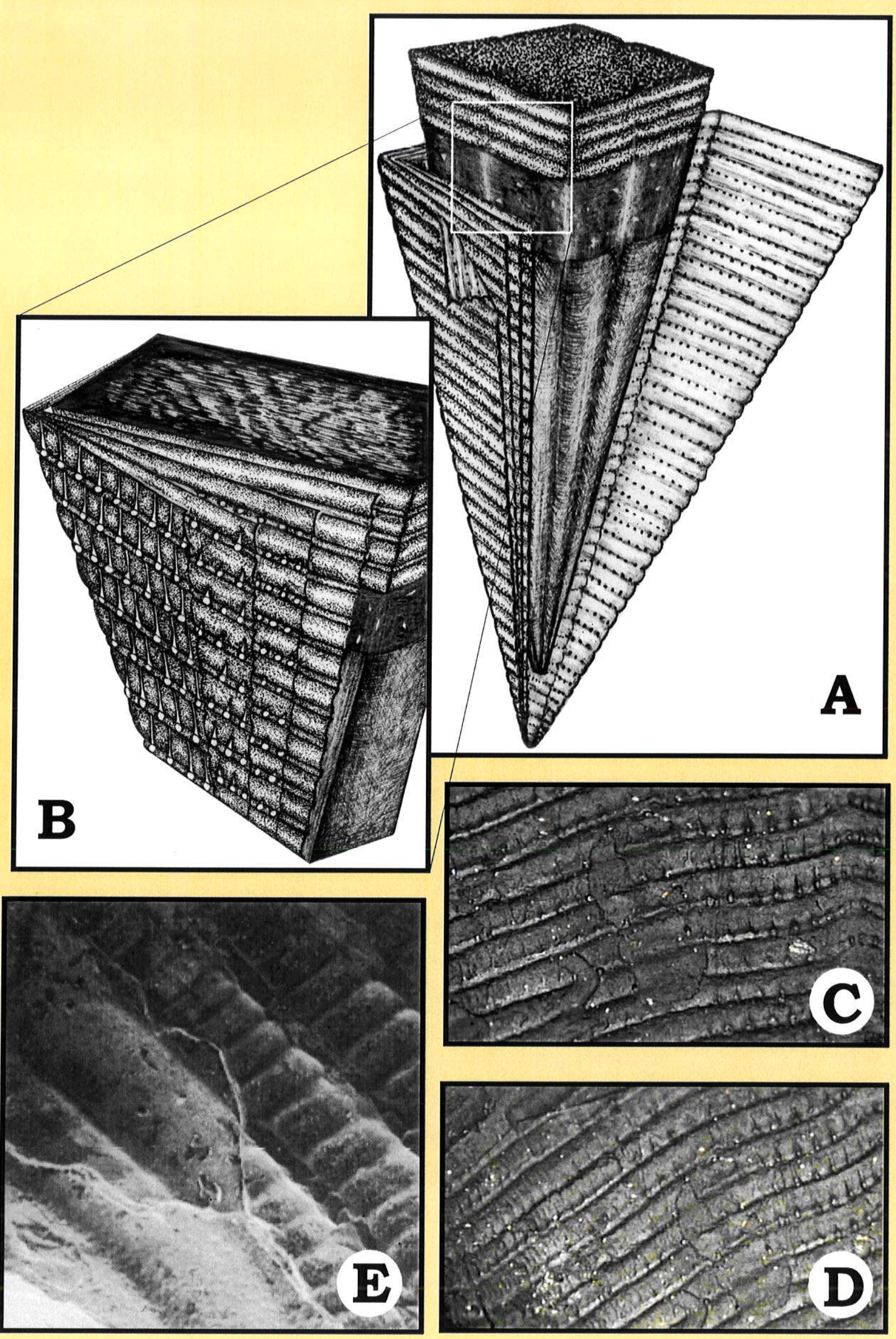

Figura 8- Esfoliação da teca de conulários: A-B, Esquema de esfoliação da teca de conulários; C-D, Conularia quichua, espécime DZP-3509, x1,6; C, Conularia trentonensis, x22. 


\section{DISCUSSÃO}

\subsection{ATRIBUTOS E TERMOS MORFOLOGICOS}

Não há consenso na literatura quanto à posição sistemática dos conulários, bem como o número de gêneros e espécies que compõem o escopo desse grupo (Moore \& Harrington 1956b; Babcock 1991; Babcock \& Feldmann 1986a, b, c; Babcock et al.1987a; Van Iten 1987; 1989; 1991a, b; 1992a, b; 1994; Van Iten et al. 1996; Qian et al. 1997; Collins et al., 2000 dentre outros). Isso decorre do pouco entendimento dos aspectos ontogenéticos, evolutivos e funcionais da morfologia da teca dos Conulatae (Bishoff, 1978).

A revisão da literatura mostra que autores distintos têm utilizado diferentes atributos e termos para a descrição da morfologia da teca dos conulários. Bischoff (1978), por exemplo, utilizou as características internas da teca para a descrição de conulários do Eosiluriano da Austrália. Sinclair (1940, 1942, 1948, 1952), Van Iten (1991a, b) e Van Iten et al. (1996), por outro lado, utilizaram uma combinação de feições, tanto externas como internas. Os termos empregados não são os mesmos de outros autores. Nesse sentido, uma tentativa de padronização da terminologia morfológica foi apresentada por Babcock \& Feldmann (1986a). Esses autores selecionaram e definiram, principalmente, feiçōes morfológicas externas, muitas passiveis de quantificação, tais como, espaçamento relativo dos cordões; ângulo basal; espaçamento entre nodos e cristas e ângulo dos cordões. Com exceção de apenas algumas feições morfológicas (e.g., padrão de articulação dos cordões, presença ou ausência de nodos e cristas), nenhum caráter qualitativo foi utilizado na diagnose de gêneros e espécies. De acordo com esses autores, as feições biométricas devem ser empregadas para definir gêneros (e.g., espaçamento relativo dos cordões) e espécies (e.g., ângulo do cordão). Embora na prática taxonômica essas feições tenham sido amplamente utilizadas, foi notado que muitos dos 
caracteres morfométricos (e.g., ângulo basal, ângulo do cordão, espaçamento entre cordões) variam, de acordo com o modo de preservação, o que coloca em cheque a validade dessas feições (Leme et al., 2000b; Rodrigues et al., 2000b; Rodrigues, 2002; Simões et al., em preparação). Em outras palavras, há a possibilidade de muitos táxons representarem espécies artificias (tafonômicas= "taphotaxa", sensu, Lucas, 2001) e não grupos biológicos naturais. Assim, a sistemática dos Conulatae não pode ser feita sem uma prévia e rigorosa análise tafonômica (Leme et al., 2000b; Rodrigues et al., 2000b; Rodrigues, 2002; Simões et al., em preparação). De fato, se tais caracteres refletissem relações de parentesco, úteis à identificação de grupos naturais dentre os conulários, a análise cladística resultante deveria mostrar árvores bem resolvidas e grupos monofiléticos, o que năo é verdadeiro (veja apêndice, mais adiante).

Dentre as feições que parecem variar, segundo o modo de preservação, destacam-se o ângulo basal e o espaçamento entre cordőes. $O$ ângulo basal é o ângulo medido a partir da interseção de duas linhas projetadas, tangentes às arestas adjacentes. Desse modo, essa feição é passivel de alteração dependendo do grau de achatamento e da direção dos esforços, se horizontais (=achatamento lateral) ou verticais (=achatamento ântero-posterior). Um mesmo táxon, preservado inflado, com achatamento lateral (DZP-3079), não mostrará os mesmos valores para os ângulos basais do que os preservados inflados, verticalmente, em relação ao plano de acamamento (DZP-3082) (vide Rodrigues, 2002; Simões et al., em preparação).

Em relação ao espaçamento entre cordões, nos exemplares preservados verticalmente, mesmo nos que apresentam pequeno achatamento ântero-posterior, o espaçamento entre cordões varia ao longo da teca (Fig. 9). 

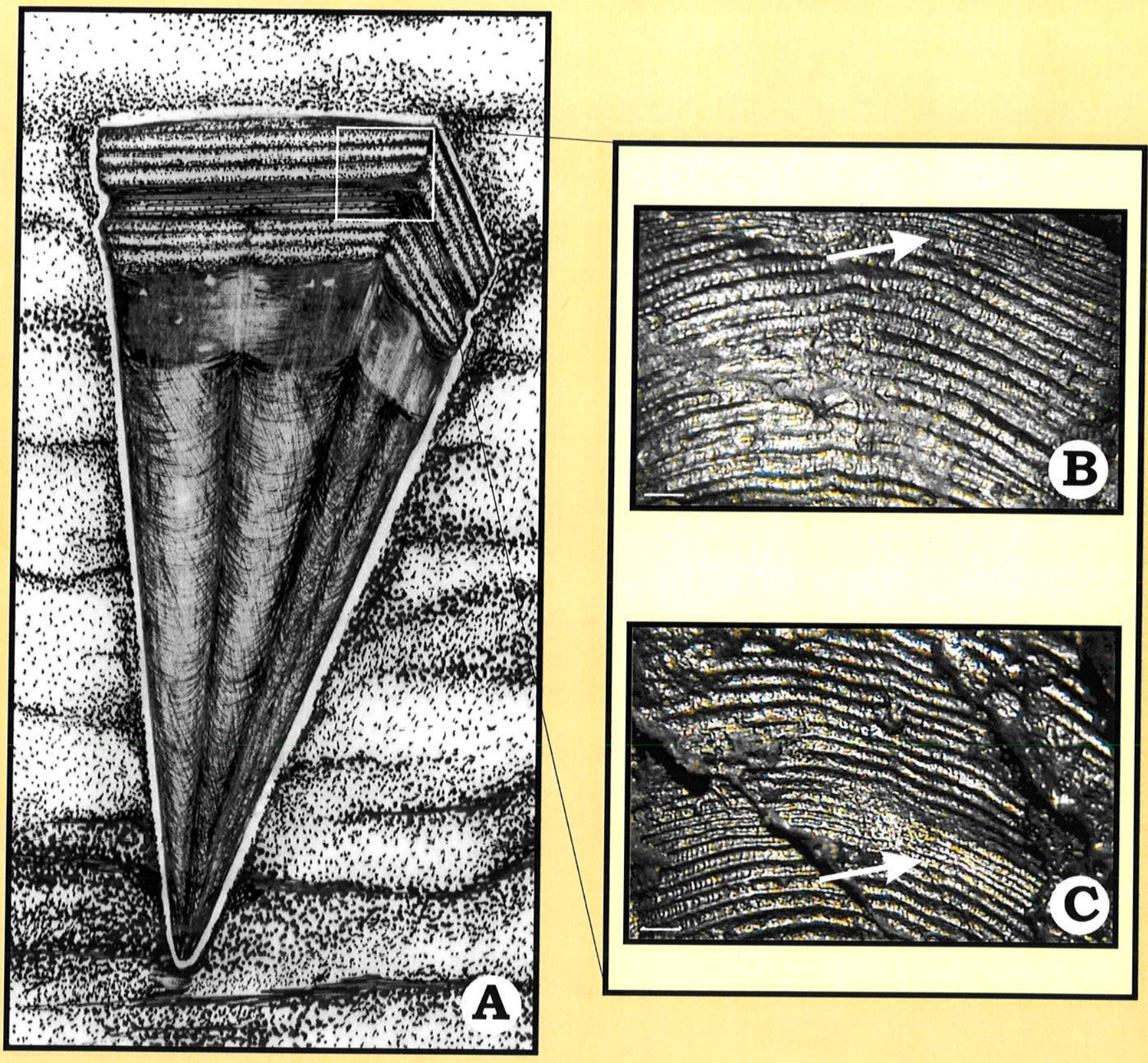

Figura 9- Conularia quichua, espécimes com leve achatamento ântero-posterior na abertura: A, Esquema de conulário apresenrando leve achatamento ântero-posterior, na abertura; B, Espécime DZP-3077; C, Espécime DZP3322. Explicação: Setas em branco, cordões com menor espaçamento entre si; escala gráfica (1 mm). 
Essa variação, assim como no caso discutido acima, pode ser natural ou decorrente do tipo de preservação. Nos exemplares achatados, há uma redução do espaçamento entre os cordões, que é mais acentuada, obviamente, na região onde a compressão foi maior. Normalmente, essa feição é notada junto à região da abertura da teca (Fig. 9).

Uma vez que Babcock \& Feldmann (1986a) sugerem que o espaçamento entre cordões seja utilizado na distinção genérica, qualquer variação nessa feição poderá conduzir a atribuições taxonômicas duvidosas. Também se o exemplar estudado for, por exemplo, representado apenas pela região deformada da abertura sua atribuição a um táxon já descrito poderá ser errônea (vide Rodrigues, 2002; Simões et al., em preparação).

A definição de conulários postulada por Feldmann \& Babcock (1986) e Babcock \& Feldmann (1986a, b, c) exclui algumas formas que eles consideraram morfologicamente distintas, como, por exemplo, a- conulários que possuem seções transversais elipticas ou circulares, b- com simetria radial, c- com estruturas internas mineralizadas (septos e carenas), e d- espécimes que não apresentam quatro faces [e.g., Conularina triangulata (Raymond), com três faces].

Adicionalmente, esses autores argumentaram que a teca dos conulários é constituída por dois componentes independentes, ou seja, cordões imersos no integumento. Os cordões são descritos como estruturas sólidas, estreitas, alongadas, subcirculares, em seção transversal, cobertas por um integumento fino, flexível, formado por várias camadas constituídas de fosfato de cálcio e proteina. Além disso, notaram que os nodos da teca dos conulários exibem pequenas projeções, nomeadas de espinhos (cristas) (Babcock \& Feldmann, 1986a).

No entanto, o exame de cortes da teca de conulários sob microscópio eletrônico de varredura mostra uma constituição contínua, com lamelas individuais de fosfato de 
cálcio (apatita), espessadas gradualmente em determinadas regiões, formando estruturas de sustentação, tais como, cordões, nodos, cristas, septos e carenas (Van Iten, 1992b). Tais estruturas constituem a ornamentação da teca. As lamelas individuais reúnem-se em duas camadas, uma interna lisa e outra externa ornamentada (Van Iten, 1991a, 1992b). Cumpre lembrar que Jerre (1993), fundamentado em argumentos de natureza anatômica, propôs a modificação de alguns dos termos introduzidos por Babcock \& Feldmann (1986a), como por exemplo, crista adapertural, ao invés de espinho adapertural. Nesse sentido, o estudo da morfologia dos conulários é ainda controverso, devido, em grande parte, ao emprego de termos morfológicos imprecisos, isso é, com múltiplos significados, dificultando, dentre outros, o estabelecimento de homologias entre os táxons.

\subsection{AFINIDAdes da FAuna de ConUláRIOS dA FormaÇÃo PONTA GROSSA}

O Devoniano é caracterizado por três domínios paleobiogeográficos, denominados Américas Orientais, Velho Mundo e Malvinocáfrico (Fig. 10a), os quais são bem definidos por suas faunas de braquiópodes (e.g., Spiriferida) e trilobitas (e.g., Calmoniidae) (Boucot, 1974, 1985). De especial interesse para o presente estudo é o Domínio Malvinocáfrico. Esse termo foi inicialmente proposto por Ritcher \& Richter (1942), para definir uma província englobando localidades austrais, caracterizada pelo alto grau de endemismo da fauna de trilobitas (Eldredge \& Ormiston, 1979). De fato, o Domínio Malvinocáfrico é bem definido na porção ocidental do Gondwana, havendo, ao norte do supercontinente, áreas transicionais entre os domínios.

O provincialismo exibido pelas faunas de trilobitas e braquiópodes que caracterizam o Domínio Malvinocáfrico é mais pronunciado durante o Emsiano e o Efeliano, englobando amplas áreas marinhas rasas, nas altas latitudes do Hemisfério Sul. 


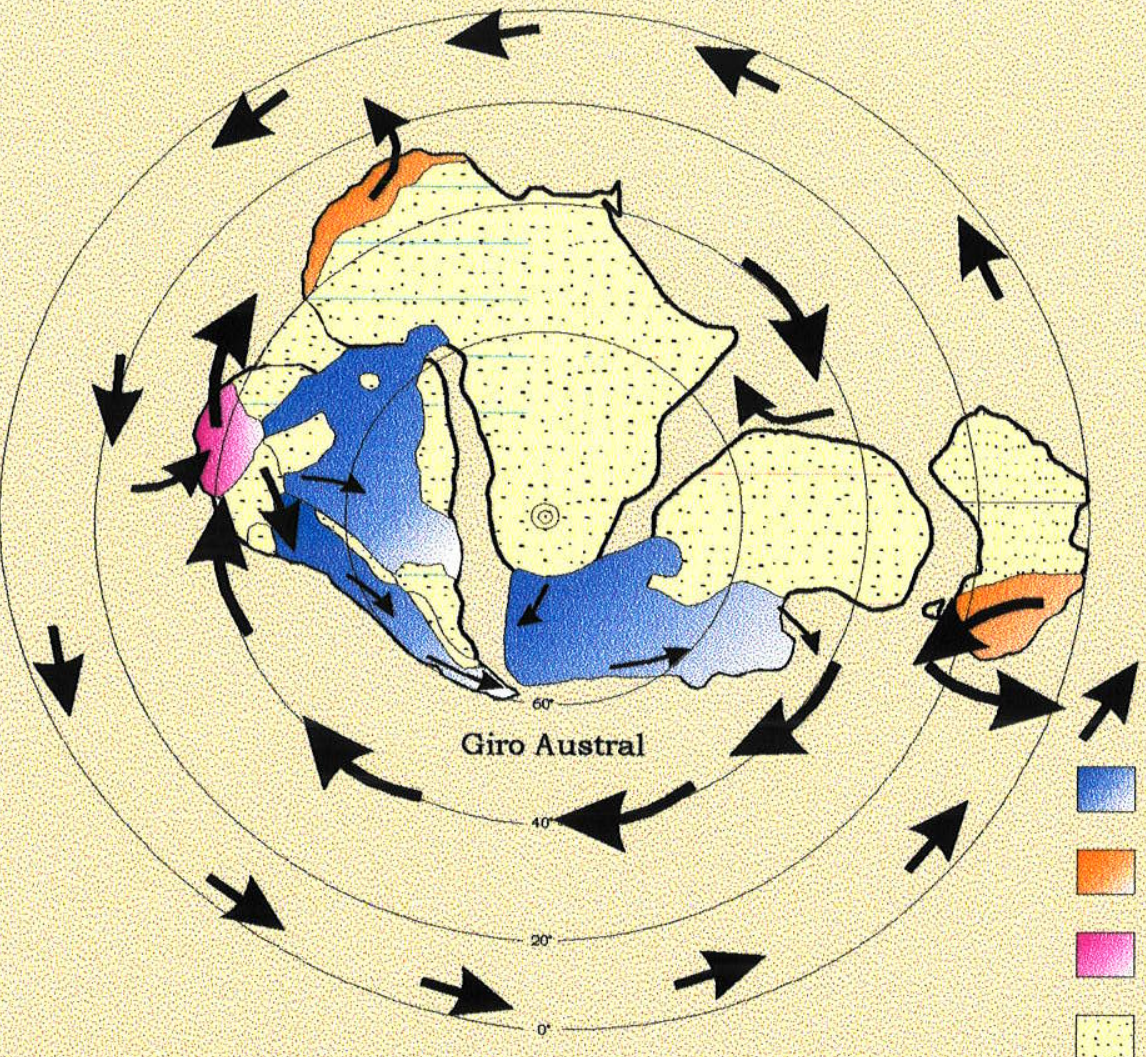

Sentido das paleocorrentes

Dominio Malvinocáfrico

Dominio Velho Mundo

Dominio Américas

Orientais

Áreas emersas

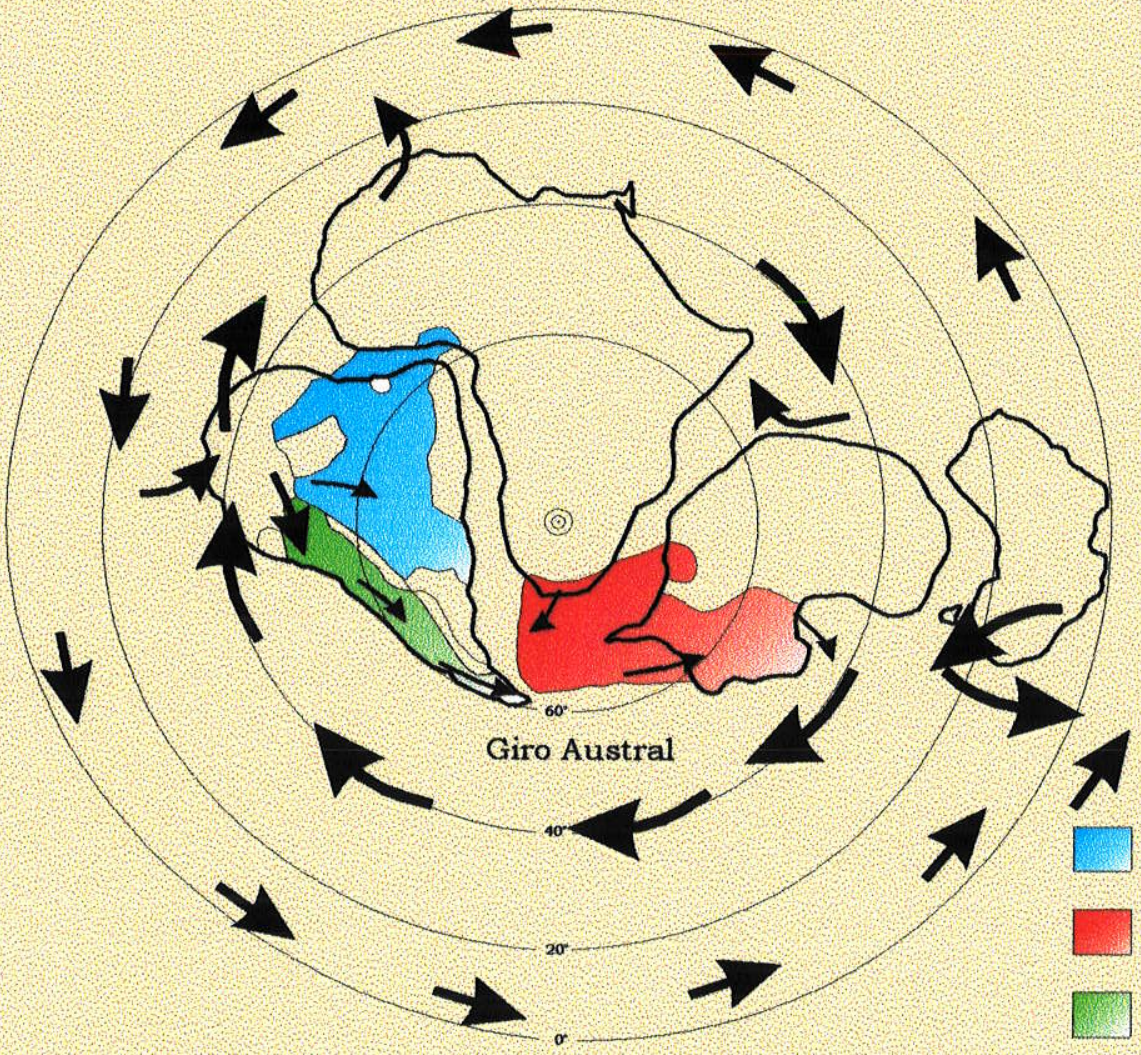

Sentido das paleocorrentes

Provincia Brasileira

Provincia Malvinocáfrica Sul-africana

Provincia Andina

Figura 10: Mapas paleogeográficos: A, Domínios paleobiogeográficos devonianos; B, Provincias do Domínio Malvinocáfrico, modificado de Eldredge \& Ormiston (1979). 
O domínio abrangeria, portanto, terrenos devonianos do Peru, da Bolívia, do Chile, do Paraguai, da Argentina, do Brasil, do Uruguai, da Antártica e da África do Sul (Boucot et al., 1969; Boucot, 1971; Eldredge \& Ormiston, 1979; Melo, 1985, 1986, 1988).

Fundamentados nas ocorrências de trilobitas da América do Sul, Eldredge \& Ormiston, (1979) propuseram subdividir o Domínio Malvinocáfrico em três províncias, isso é: a- Província Andina, Província Brasileira, Província Malvinocáfrica Sul-africana (Fig. 10b). No Brasil, a Bacia do Paraná constitui a principal área de abrangência da Província Brasileira, no âmbito do Domínio Malvinocáfrico, cujos táxons mais característicos, isso é, os braquiópodes (Australocoelia, Australospirifer) e os trilobitas (Calmonia), ocorrem na Formação Ponta Grossa. Diversos autores notaram (e.g. Cooper, 1977; Eldredge \& Ormiston, 1979), entretanto, que as faunas de braquiópodes e trilobitas da Formação Ponta Grossa são menos diversificadas do que as coevas encontradas em outras partes do Domínio Malvinocáfrico, como, por exemplo, na Bolívia e Argentina. O Quadro 1, sintetiza a composição taxonómica das faunas de conulários das principais áreas do Domínio Malvinocáfrico. Os dados indicam claramente que a fauna de conulários da Província Brasileira é uma "versão" menos diversificada daquela presente na Província Andina, especialmente da Bolívia. Enquanto a fauna boliviana é caracterizada por 6 espécies, sendo Conularia quichua Ulrich, Conularia albertensis Reed, Paraconularia africana (Sharpe), Paraconularia Ulrichana (Clarke) e Reticulaconularia baini (Ulirich) cosmopolitas e Malvinoconularia cahuanotensis (Branisa \& Vanek) endêmica, a da Bacia do Paraná é constituída por Conularia quichua, Paraconularia africana e Paraconularia ulrichana, todas pertencentes a gêneros e espécies cosmopolitas. Paraconularia africana, por exemplo, é encontrada em terrenos das províncias Andina, Brasileira e Sul-africana. 
Quadro 1: Composição taxonômica das faunas de conulários das principais áreas do Domínio Malvinocáfrico.

\begin{tabular}{|c|c|c|c|c|c|c|c|c|c|c|c|c|c|c|c|c|c|c|}
\hline \multirow[t]{4}{*}{ Localidades } & \multirow{4}{*}{ 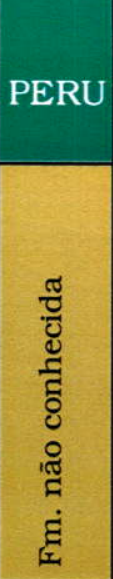 } & \multicolumn{5}{|c|}{ BOLÍVIA } & \multirow{2}{*}{\multicolumn{2}{|c|}{ CHILE }} & \multirow{2}{*}{\multicolumn{2}{|c|}{ ARGENTINA }} & \multirow{2}{*}{ PARAGUAI } & \multirow{2}{*}{\multicolumn{3}{|c|}{ URUGUAI }} & \multirow{2}{*}{\multicolumn{3}{|c|}{ BRASIL }} & \multirow{2}{*}{$\begin{array}{c}\text { ÁFR. DC } \\
\text { SUL }\end{array}$} \\
\hline & & Norte & \multicolumn{4}{|c|}{ Sul/Centro- Sul } & & & & & & & & & & & & \\
\hline & & \multirow[b]{2}{*}{ 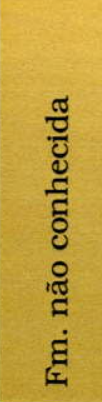 } & \multirow[b]{2}{*}{$\begin{array}{l}\frac{\pi}{0} \\
\text { 良 }\end{array}$} & \multirow[b]{2}{*}{ 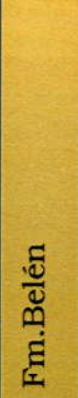 } & \multirow[b]{2}{*}{ 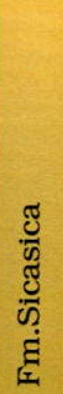 } & \multirow[b]{2}{*}{ 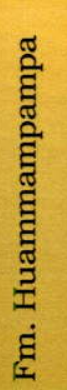 } & \multirow[b]{2}{*}{ 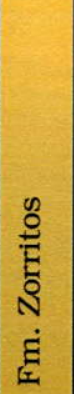 } & \multirow[b]{2}{*}{ 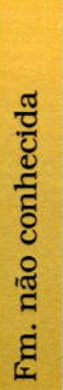 } & \multirow[b]{2}{*}{ 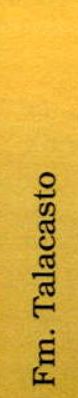 } & \multirow[b]{2}{*}{ 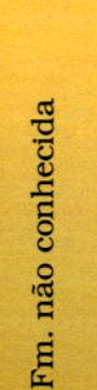 } & \multirow[b]{2}{*}{ 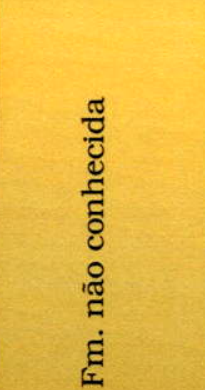 } & \multicolumn{3}{|c|}{ Fm. Cordobés } & \multicolumn{3}{|c|}{ Fm. Ponta Grossa } & \multirow[b]{2}{*}{ 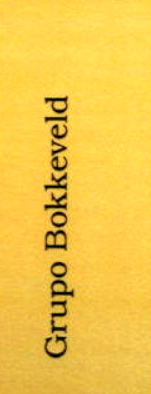 } \\
\hline & & & & & & & & & & & & 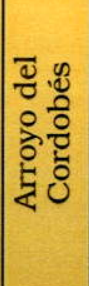 & 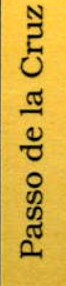 & 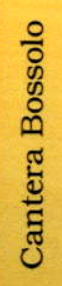 & 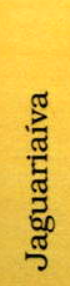 & $\begin{array}{l}\text { बूँ } \\
\text { है }\end{array}$ & 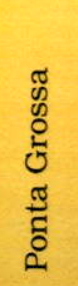 & \\
\hline Conularia quichua & $\mathrm{x}$ & & $\mathrm{x}$ & $\mathrm{X}$ & $\mathrm{x}$ & $\mathrm{x}$ & $\mathrm{X}$ & & $\mathrm{x}$ & & $\mathrm{x}$ & & & & $\mathrm{x}$ & & & ?X \\
\hline Conularia albertensis & & $\mathrm{X}$ & & $\mathrm{x}$ & $\mathrm{x}$ & & & & & & & & & & & & & $\mathrm{X}$ \\
\hline Paraconularia africana & $\mathrm{x}$ & & $\mathrm{x}$ & $\mathrm{x}$ & $\mathrm{x}$ & $\mathrm{x}$ & & & & $\mathrm{x}$ & & & $\mathrm{x}$ & & $\mathrm{X}$ & & $\mathrm{x}$ & $\mathrm{x}$ \\
\hline Paraconularia ulrichana & $\mathrm{x}$ & & & $\mathrm{x}$ & $\mathrm{x}$ & $\mathrm{x}$ & & $\mathrm{x}$ & & $\mathrm{x}$ & & $\mathrm{x}$ & & $\mathrm{X}$ & $\mathrm{X}$ & $\mathrm{X}$ & & $\mathrm{X}$ \\
\hline Reticulaconularia baini & & & & $\mathrm{x}$ & $\mathrm{x}$ & & & & & & & & & & & & & $\mathrm{x}$ \\
\hline $\begin{array}{l}\text { Malvinoconularia } \\
\text { cahuanotensis }\end{array}$ & & & & $\mathrm{x}$ & & & & & & & & & & & & & & \\
\hline
\end{tabular}

Fonte: Clarke (1913); Kozsloswisk (1923); Sinclair (1948); Mendéz-Alzola \& Sprechmann (1973); Babcock et al. (1987a). 
Além disso, os gêneros Conularia e Paraconularia são de ampla distribuição em áreas do Domínio das Américas Orientais e do Velho Mundo.

A ampla distribuição paleobiogeográfica apresentada por Conularia quichua, Paraconularia africana e Paraconularia ulrichana não é facilmente entendida à luz da paleobiologia dos conulários. Admitindo relação de parentesco entre os conulários e cifozoários é notável que a distribuição zoogeográfica desse grupo de cnidários, nos mares do Presente, é controlada pela temperatura (Arai, 1997, p. 201).

Notavelmente, vários autores (e.g., Boucot, 1974; Cooper, 1977; Eldredge \& Ormiston, 1979) postularam que a distribuição e a diversidade dos invertebrados marinhos no Domínio Malvinocáfrico está relacionada, em parte, a barreiras climáticas. De qualquer modo, considerando as paleolatitudes do intervalo de ocorrência dos conulários da Bolívia e da Bacia do Paraná a sua distribuiçăo latitudinal é apreciável. Durante o Devoniano, os conulários bolivianos viveram em águas entre $45^{\circ}$ e $50^{\circ}$ de latitude sul e as da Bacia do Paraná, próximas aos $70^{\circ}$ sul. Portanto, as espécies que colonizaram a Bacia do Paraná estavam submetidas a condições ambientais de águas muito frias, em decorrência da proximidade ao pólo da época. Não pode ser esquecido ainda que os gêneros Conularia e Paraconularia ocorrem, conforme já comentado, em terrenos do Domínio das Américas Orientais e do Velho Mundo e, portanto, em zonas tropicais do Devoniano. As espécies Conularia quichua, Paraconularia africana e Paraconularia ulrichana devem ter sido, portanto, euritérmicas. Curiosamente, espécies de cifozoários viventes que são cosmopolitas, são também euritérmicas, suportando, amplas variações de temperatura nas águas de mares subtropicais e tropicais, porém, não nas águas das regiōes polares (Arai, 1997).

Durante o Devoniano, a Bacia do Paraná não esteve apenas em posição latitudinal mais alta do que os mares da região andina, especialmente da Bolívia. Para alguns autores (Cooper, 1977; Eldredge \& Ormiston, 1979) o alto grau de endemismo 
da fauna de trilobitas da Província Brasileira, em comparação com a da Província Andina, sugere algum isolamento físico da Bacia do Paraná, durante o Devoniano. Autores como Eldredge \& Ormiston (1979), fundamentados nos padrões de correntes oceânicas do Devoniano, postularam migração das espécies andinas de trilobitas para a Bacia do Paraná (Fig. 10b). Curiosamente, as faunas de trilobitas da Província Brasileira apresentam maior grau de endemismo, do que a Andina, mesmo considerando tratar-se de um grupo com formas adultas com capacidade de locomoção (Cooper, 1977). Admitindo-se que o mesmo tenha ocorrido com as faunas de conulários, isso é, migração da área andina para a Bacia do Paraná, a comparação desse padrão, com os observados para os cifozoários viventes também não é fácil de ser compreendido. A ampla distribuição de algumas espécies de conulários no Dominio Malvinocáfrico sugere a presença de formas larvais planctônicas teleplânicas (sensu Scheltelma, 1989), isso é, com capacidade para sobreviver nas correntes oceânicas por prolongados períodos de tempo. A distribuição de larvas teleplânicas sugere que essas são capazes de uma dispersão transoceânica, pois são encontradas tanto no oceano Atlântico como no Pacífico (Ventura \& Pires, 2002). Nos cifozoários viventes, no entanto, as medusas são responsáveis pela maior dispersão das espécies, enquanto as plânulas, por apresentar um tempo de vida mais curto, são importantes na seleção de condições ambientais favoráveis para o assentamento e desenvolvimento da fase bentônica (Arai, 1997, pag. 139).

Em resumo, portanto, a fauna de conulários da Bacia do Paraná, à luz do conhecimento atual, é pouco diversificada, sendo constituida por espécies de ampla distribuição nos mares do Domínio Malvinocáfrico. Provavelmente, são espécies euritérmicas, não sendo, desse modo, úteis à caracterização das províncias paleobiogeográficas do Domínio Malvinocáfrico. 


\subsection{Distribuição ESTRATIGRÁficA dos CONULÁRIOS DA FORMAÇÃo PONTA GROSSA}

Conulários são macrofósseis comuns e conspícuos do registro fossilifero da Formação Ponta Grossa, do Estado do Paraná, municípios de Jaguariaiva e Ponta Grossa. Conforme já referido, ocorrem nos sedimentitos da seção-tipo do Membro Jaguariaíva ou Seqüência B (Fig. 3), um Trato de Sistemas Transgressivo, na base da Formação Ponta Grossa (Bergamaschi, 1999; Bergamaschi \& Pereira, 2001).

$\mathrm{Na}$ seção examinada em Jaguariaiva, os conulários ocorrem pontualmente na vertical. Em outras palavras, não ocorrem aleatoriamente na seção (vide Simões et al., 2000a; Rodrigues, 2002), sendo particularmente abundantes $(n=120)$ nos intervalos situados a 29-32 metros e a 44-48 metros do contato basal com a Formação Furnas (Fig. 3). Esses horizontes, denominados por Simões et al. (2000a) de "Conularia beds", representam horizontes de rápidos soterramentos, gerados por tempestades, correspondendo a intervalos cujas condiçőes batimétricas (transgressivas) estiveram mais propícias à formação dos depósitos de sufocamento ou à geração de tempestitos distais, preservando formas bentônicas da epifauna, in situ (Simões et al., 2000a; Simões et al., 2001b; Rodrigues, 2002).

O intervalo de 29-32m do contato basal com a Formação Furnas, (Fig. 3) representa o de maior abundância dos conulários ao longo da seção. Nesse intervalo de $3 \mathrm{~m}$, foram encontrados 67 espécimes de conulários, dentre os quais, 60 pertencentes a Conularia quichua e o restante, não identificados face às condições de preservação. Nenhum exemplar de Paraconularia africana foi encontrado nesse intervalo.

Apenas um exemplar de C. quichua (DZP-3634) foi encontrado à $39 \mathrm{~m}$ da base da Formação Furnas, acima, portanto, do intervalo referido anteriormente (Fig. 3). Esse nivel inclui sedimentitos depositados sob condições batimétricas mais rasas, 
altamente bioturbados, ou seja, possivelmente gerados acima do nivel de base de ondas de tempestades (Rodrigues, 2002).

Cerca de 52 espécimes foram coletados no intervalo de $44-48 \mathrm{~m}$, a partir do contato basal com a Formação Furnas. A maioria dos espécimes $(n=45)$ foi atribuído a Conularia quichua, 6 exemplares não foram identificados devido às condições de preservação e um exemplar (CuPg-01) foi atribuído à Paraconularia africana. Apesar do nível exato de ocorrência desse exemplar ser incerto, a partir das informaçóes de campo disponibilizadas pelo Laboratório de Geociências, UNG, foi possivel posicionálo dentro desse intervalo estratigráfico, não sendo possivel, entretanto, posicioná-lo com relação aos estratos que estão presentes no intervalo de 4 metros, isso é entre 44 e 48 metros da base com a Formação Furnas.

A posição estratigráfica do espécime depositado na coleção da Universidade Estadual de Ponta Grossa (D-058) e os provenientes do município homónimo é incerta. As poucas informações disponiveis, conforme referido anteriormente, indicam que esses provêm dos afloramentos informalmente designados de curva I e curva || (Kotzian, 1995).

Finalmente, os exemplares depositados na coleção científica da USP não apresentam informações à respeito do nível estratigráfico, não sendo possível determinar os horizontes de ocorrência.

Os dados acima mostram que, ao menos na seção de Jaguariaiva, Conularia quichua é a espécie com maior distribuição estratigráfica, sendo a ocorrência de Paraconularia africana, extremamente pontual. Até que trabalhos de detalhe sejam levados a cabo na região de Ponta Grossa, a correlação dos estratos da seção de Jaguariaíva com esses não é passivel de ser feita, com base na fauna de conulários. 


\section{CONSIDERAÇÕES FINAIS}

\subsection{CONClusónes}

a- Conulários são macrofósseis comuns e conspícuos do registro fossilífero da Formação Ponta Grossa, do Estado do Paraná, municípios de Jaguariaíva e Ponta Grossa. São, entretanto, particularmente abundantes nos sedimentitos que afloram na seção geológica do municipio de Jaguariaiva, equivalentes à Seqüência B (Membro Jaguariaíva), situados, respectivamente, nos intervalos situados a 29-32 metros e a 44-48 metros, a partir do contato basal com a Formação Furnas. Nesse intervalo, depósitos de sufocamento preservaram formas bentónicas da epifauna, in situ, como é o caso dos conulários estudados;

b- A despeito da natureza friável da matriz sedimentar e seu alto grau de intemperismo, afetando também a teca dos conulários estudados, causando esfoliação, os espécimes preservam, no geral, feições importantes para a sua descrição morfológica, isso é: a- espaçamento relativo entre os cordões; bproporção relativa de cordões alternados e opostos na linha mediana; c- presença ou ausência de nodos e cristas; d- morfologia de nodos/cristas e, e-padrões de articulações dos cordões;

c- A morfologia das espécies de conulários da Formação Ponta Grossa, Conularia quichua e Paraconularia africana mostra ser mais complexa do que aquela descrita por Clarke (1913) e Babcock et al. (1987a). De fato, uma das maiores contribuições do presente estudo é a descrição de feições morfológicas internas da teca, não conhecidas em C. quichua (carenas e septos), Paraconularia africana (carenas), bem como, para o grupo Conulatae (pilar central, pontuações de natureza desconhecida). Por essa razão, houve a necessidade de emendar a diagnose específica de Conularia quichua e Paraconularia africana; 
d- A revisão efetuada mostra que a fauna de conulários da Bacia do Paraná, Formação Ponta Grossa, é pouco diversificada, especialmente se comparada com a fauna Boliviana, sendo constituida por Conularia quichua Ulrich, 1890 e Paraconularia africana (Sharpe, 1856). Uma terceira espécie reconhecida por Clarke (1913), isso é, Paraconularia ulrichana (Clarke, 1913), não foi encontrada no material estudado, o que não significa, obrigatoriamente, que não esteja presente na Formação Ponta Grossa;

e- Dentre os 133 espécimes examinados, 116 foram atribuídos à Conularia quichua Ulrich, 1890, sendo apenas dois, os exemplares referidos à Paraconularia africana (Sharpe, 1856). Portanto, a revisão efetuada mostra que a fauna de conulários da Bacia do Paraná, Formação Ponta Grossa, é amplamente dominada por Conularia quichua;

f- Em Conularia quichua o número de faces é variável, com espécimes mostrando 4 ou 5 faces verdadeiras. Espécimes de Conularina triangulata e Paraconularia missouriensis, exibem, respectivamente, 3 e 6 faces verdadeiras. Essa é, portanto, a primeira ocorrência de espécimes com 5 faces verdadeiras, não apenas para o gênero Conularia, mas para os Conulatae, em geral;

g- Os espécimes referidos por Clarke (1913, Estampa VIII, figs. 12-15), como $P$. africana, não apresentam as feições morfológicas típicas dessa espécie e, portanto, não são aqui reconhecidas como pertencentes à essa espécie. Desse modo, a única ocorrência registrada de $P$. africana nos estratos da Formação Ponta Grossa é a do material aqui descrito, proveniente da região de Jaguariaiva, $\mathrm{PR}$, representando a primeira ocorrência dessa espécie na Bacia do Paraná;

h- Dados preliminares mostraram que do ponto de vista paleobiogeográfico há afinidades com as faunas de conulários do Domínio Malvinocáfrico, conforme 
indicado pela ocorrência comum de Conularia quichua e Paraconularia africana nos sedimentitos devonianos da Bolivia, Argentina, Peru e África do Sul;

i- A ampla distribuição paleobiogeográfica das espécies estudadas no âmbito do Dominio Malvinocáfrico sugere, fortemente, que essas foram euritérmicas, uma vez que ocorrem em terrenos das províncias Andina, Brasileira e Malvinocáfrica Sul-africana. Especialmente, essas duas últimas englobam áreas que estiveram situadas nas altas latitudes, próximas do pólo sul devoniano, enquanto a Andina esteve localizada em torno dos $40^{\circ}$ a $45^{\circ}$ de latitude sul;

j- Ao menos na seção de Jaguariaíva, Conularia quichua é a espécie com maior distribuição estratigráfica, sendo a ocorrência de Paraconularia africana extremamente pontual;

k- Finalmente, a partir de uma análise cladistica preliminar, nem todos agrupamentos taxonômicos (famílias e subfamílias) sugeridos por Moore \& Harrington (1956a, b) são consistentes (vide apêndice).

\subsection{RECOMENDAÇÕES E ESTRATÉGIAS PARA O FUTURO}

a- A utilização de caracteres biométricos (e.g., ângulo basal, ângulo do cordão, espaçamento entre cordões) deve ser evitada nas descrições morfológicas de Conulatae, dada a ampla variação desses em função do tipo de preservação (se com achatamento ântero-posterior ou lateral) apresentado;

b- Uma possivel alternativa para os problemas acima seria o emprego de técnicas de computação (e.g., software MATLAB versão 6.0, Release 12, The MathWorks Inc.) para reconstruções tridimensionais de corpos achatados, possibilitando resgatar a morfologia dos conulários e, a partir de então, recuperar valores biométricos para os caracteres como, ângulo basal, ângulo do cordão, espaçamento entre cordōes; 
c- $O$ estudo da sistemática dos Conulatae deve estar fundamentado na teoria cladística, procurando esclarecer as relações de parentesco dentro desse grupo e seu escopo, bem como a identificação das sinapomorfias de Conulatae e o reconhecimento de subgrupos monofiléticos. Para viabilizar essa análise, entretanto, estudos morfológicos minuciosos deverão ser realizados, incluindo não apenas a descrição de feições morfológicas externas, mas também internas da teca;

d- Revisões amplas deverão estar fundamentadas também no reexame dos espécimes de coleções já previamente estudadas. Isso porque muitos dados morfológicos não são passiveis de resgate apenas a partir dos dados de literatura. Como um exemplo, pode ser citado o caso dos espécimes estudados por L.E. Babcock e colaboradores, provenientes de amplas coleções, como a da Bolívia e da América do Norte. Esses autores não incluem nas descrições aspectos da morfologia interna (espessamentos internos) da teca dos conulários. Conforme discutido nesse documento, tais caracteres podem ser úteis no reconhecimento de gêneros e espécies e para traçar as afinidades dos conulários com outros grupos de cnidários (Scyphozoa);

e- Os dados aqui apresentados e discutidos, bem como os problemas levantados, mostram que é urgente uma revisão do clássico volume da série "Treatise on Invertebrate Paleontology", Part F, Coelenterata, Conulata (Moore \& Harrington, 1956a, b). 


\section{REFERÊNCIAS BIBLIOGRÁFICAS}

AHFELD, F. \& BRANISA, L. 1960. Geología de Bolívia. Instituto Boliviano del Petroleo, La Paz.

AMORIM, D.S. 1994. Elementos básicos de sistemática filogenética. Primeira edição. Sociedade Brasileira de Entomologia. Ribeirăo Preto, 314pp.

AMORIM, D.S. 1997. Elementos básicos de sistemática filogenética. Segunda edição. Editora Holos. Ribeirão Preto, 276pp.

ARAI, M.N. 1997. A Functional Biology of Scyphozoa. Primeira edição: Chapman \& Hall, Londres, 316pp.

ASSINE, M.L.; SOARES, P.C. \& MILANI, E.J. 1994. Sequências tectono-sedimentares mesopaleozóicas da Bacia do Paraná, Sul do Brasil. Revista Brasileira de Geociências, 24(2):77-89.

AZEVEDO-SOARES, H.L.C. 1999. Classe Tentaculita na Formação Ponta Grossa: uma proposta de sistematização. UERJ, Rio de Janeiro, RJ (Dissertação de Mestrado, Faculdade de Geologia). 132pp.

BABCOCK, L.E. 1990. Conulariid pearls. In: Evolutionary paleobiology of behavior and coevolution. A. J. Boucot (ed.). Elsevier Science Press, Amterdam, 68-71p.

BABCOCK, L.E. 1991. The enigma of conulariid affinities. In: The early evolution of Metazoa and the significance of problematic fossil taxa. A.M. Simonetta \& S.C. Morris (eds.). Cambridge University Press, 113-143p.

BABCOCK, L.E. \& FELDMANN, R.M. 1984. Mysterious fossils. Earth Science, $37(3): 16-17$

BABCOCK, L.E. \& FELDMANN, R.M. 1986a. Devonian and Mississipian conulariids of North America. Part A. General discription and Conularia. Annals of Carnegie Museum, 55:349-410. 
BABCOCK, L.E. \& FELDMANN, R.M. 1986b. Devonian and Mississipian conulariids of North America. Part B. Paraconularia, Reticulaconularia, new genus and organisms rejected from Conulariida. Annals of Carnegie Museum, 55:411-479.

BABCOCK, L.E. \& FELDMANN, R.M. 1986c. The phylum Conulariida. In:

Problematical Fossil Taxa. A. Hoffman \& M.H. Nitecki (eds.). Oxford University Press, 135-147p.

BABCOCK, L.E.; FELDMANN, R.M.; WILSON, M.T. \& SUÁREZ-RIGLOS, M. 1987a.

Devonian conulariids of Bolivia. National Geographic Research, 3:210-231.

BABCOCK, L.E.; FELDMANN, R.M. \& WILSON, M.T. 1987b. Teratology and pathology of some Paleozoic conulariids. Lethaia, 20:93-105.

BABCOCK, L.E.; GRAY, J.; BOUCOT, A.J.; HIMES, G.T. \& SIEGELE, P.K. 1990. First

Silurian conulariids from Paraguay. Journal of Paleontology, 64(6):897-902.

BABCOCK, L.E.; LANG, J. \& YAHAYA, M. 1995. First Carboniferous conulariids from Niger (west Africa). Journal of African Earth Sciences, 20(1):1-6.

BERGAMASCHI, S. 1999. Análise estratigráfica do Siluro-Devoniano (Formação Furnas e Ponta Grossa) da sub-bacia de Apucarana, Bacia do Paraná, Brasil. USP, São Paulo, SP (Tese de Doutoramento, Instituto de Geociências), 167pp. BERGAMASCHI, S. \& PEREIRA, E. 2001. Caracterização de Seqüências Deposicionais de $3^{\text {a }}$ ordem para o Siluro-Devoniano na Sub-Bacia de Apucarana, Bacia do Paraná, Brasil. In: Correlações de Seqüências Paleozóicas SulAmericanas. J.H.G. Melo \& G.J.S. Terra (eds.). Ciência Técnica Petróleo. Seção Exploração de Petróleo. 20:63.

BERGSTROMM, J. 1995. Conulariid affinities: a discution and reply. Geologiska Foreningens $i$ Stockholm Forhandlingar, 117:245-246.

BERNARD, F. 1895. Eléments de paléontologie. Libraire J. B. Bailliere \& Fils, Paris. 
BISCHOFF, G.C.O. 1978. Internal structures of conulariid tests and circonulariina $\mathrm{n}$. suborder (Cnidaria, Scyphozoa). Senckenbergiana Lethaea, 59:275-327.

BODENBERDEN, B.E.; WILSON, M.A. \& PALMER, T.J. 1989. Paleoecology of Sphenothallus on an Upper Ordovician hardground. Lethaia 22: 217-225.

BOSETTI, E.P. 1989a. Proposição de uma sistemática artificial para lingulídeos fósseis, baseada no estudo de lingulídeos da Formação Ponta Grossa (Devoniano), Bacia do Paraná, Brasil. In: XI CONGRESSO BRASILEIRO DE PALEONTOLOGIA, Curitiba, Anais ..., p.53.

BOSETTI, E.P. 1989b. Revisão sistemática dos Lingulida (Brachiopoda: Inarticulata) da Formação Ponta Grossa (Devoniano), Estado do Paraná, Brasil. In: XI CONGRESSO BRASILEIRO DE PALEONTOLOGIA, Curitiba, Anais ..., p.73.

BOSETTI, E.P. 1989c. Análise da estrutura e diversidade morfotípica de lingulídeos em algumas paleocomunidades fossilisadas in situ na Formação Ponta Grossa (Devoniano), Bacia do Paraná, Brasil. In: XI CONGRESSO BRASILEIRO DE PALEONTOLOGIA, Curitiba, Anais...,p.91.

BOUCEK, B. 1939. Conularida. In: Handbuch der Palaeozoologie. O. H. Schindewolf (ed.). Alemanha, 111-131p.

BOUCOT, A.J. 1971. Malvinokaffric Devonian marine community distribution and implications for Gondwana. Anais da Academia Brasileira de Ciência, Supl., 43:23-49.

BOUCOT, A.J. 1974. Silurian and Devonian biogeography. In: Paleogeography provinces and provinciality. C.A. Ross (ed.). Soc. Econ. Mineralogists and Paleontologists Spec. Pub. 21:165-176.

BOUCOT, A.J. 1985. Late Silurian-early Devonian biogeography, provincialism, evolution and extintion. Philosophical Transaction of the Royal Society of London, B, 309(1138):323-339. 
BOUCOT, A.J.; JOHNSON, J.G. \& TALENT, J.A. 1969. Early Devonian Brachiopod Zoogeography. Geological Society of America, Special Paper, 119:113.

BRANISA, L. 1965. Los fosiles guias de Bolivia. Servicio Geologico de Bolivia, Boletín, 6:282.

BRANISA, L. \& VANEK, J. 1973. Metaconularia cahuanotensis sp. n. from Bolivian Lower Devonian. Vestnik Ústrednihoústavu geologického, 48:95-96.

BROOD, K. 1995a. Morphology, structure and systematics of the conulariids. Geologiska Foreningens i Stockholm Forhandlingar, 117:121-137.

BROOD, K. 1995b. Conulariids affinities: a reply. Geologiska Foreningens i Stockholm Forhandlingar, 117:246.

CARVALHO, M. da G.P. \& QUADROS, L.P. 1987. Trilobitas devonianos do flanco noroeste da Bacia do Paraná. In: X CONGRESSO BRASILEIRO DE PALEONTOLOGIA, Rio de Janeiro, Anais..., 2:545-565.

CARVALHO, M. G.P. de \& EDGECOMBE, G.D. 1991. Lower- early middle Devonian calmoniid trilobites from Mato Grosso, Brazil, and related species from Paraná. American Museum Novitates, 3022:1-13.

CECIONI, R.R. 1982. El Devonico Inferior de la Formacion Lila, región de Antofagasta, Chile. III CONGRESSO CHILENO, vol. F.

CIGUEL, J.H.G. 1989. Bioestratigrafia dos Tentaculoidea no flanco oriental da Bacia do Paraná e sua ocorrência na América do Sul (Ordoviciano-Devoniano). USP, São Paulo, SP (Dissertação de Mestrado, Instituto de Geociências), 237pp.

CLARKE, J.M. 1913. Fósseis devonianos do Paraná. Monografias do Serviço Geológico e Mineralógico do Brasil, 1:1-353.

COLLINS, A.G.; MARQUES A.C. \& SIMŐES, M.G. 2000. The phylogenetic placement of Conulatae within Cnidaria. Geological Society of America, Abstracts with Programs 32(7): A-443. 
COLLINS, A.G. 1999.The early history of animals: a shotgun approach. Ph.D. thesis, University California at Berkeley, Departament of Integrative Biology, Berkeley, California.

COOPER, P. 1977. Paleolatitudes in the Devonian of Brazil and the FrasnianFamennian mass extinction. Palaeogeography, Palaeoclimatology, Palaeoecology, 21(3):165-207.

DOUGLAS, J.A. 1920. Geological sections through the Andes of Peru and Bolivia: II. From the port of Mollendo to the Inambari River. Quatemaly Journal of the Geological Society of London, 76(301):1-61.

EICHWALD, C.E. 1840. Lethaea Rossica, ou Paleontologie de la Russie. Tome 1, L'Ancienne Periode. Part 2, pp681-1657.

ELDREDGE, N. \& ORMISTON, L. 1979. Biogeography of Silurian and Devonian trilobites of the Malvinokaffric Realm. In: Historical Biogeography, plate tectonics and the changing enviroment. A.J. Boucot \& J. Gray (eds.) .Oregon State Univ. Press, Corvalis, $147-167 p$.

FELDMANN, R.M. \& BABCOCK, L.E. 1986. Exceptionally preserved conulariids from Ohio- reinterpretation of their anatomy. National Geographic Research, 2:464472.

FELDMANN, R.M.; HANNIBAL, J.T. \& BABCOCK, L.E. 1986. Fossil worms from the Devonian of North America (Sphenothalus) and Burma ("vermes") previously identified as phyllocarid arthropods. Joumal of Paleontology, 60(2):341-346.

FINKS, R.M. 1955. Conularia in a sponge from the west Texas Permian. Journal of Paleontology, 29(5):831-836.

HANSMAN, R.H.; SHAW, F.C. \& PETTYJOHN, W.A. 1962. Supplement to the catalog of the type specimens of fossils in the University of Cincinnati Museum. University of Cincinnati Press, Cincinnati. 
HARLAND, T.L. \& PICKERILL, R.K. 1987. Epizoic Schizocrania sp. from the Ordovician Trenton Group of Quebec, with comments on mode of life of conulariids. Journal of Paleontology, 61(4):844-849.

HERGARTEN, B. 1985. Die Conularien des Rheinischen Devons. Senckenbergiana Lethaea, 66:269-297.

HUGHES, N.C.; GUNDERSON, G.O \& WEEDON, M.J. 2000. Late Cambrian conulariids from Wisconsin and Minnesota. Joumal of Paleontology, 74(5):828838.

JERRE, F. 1993. Conulariid microfossils from the silurian Lower Visby Beds of Gotland, Sweden. Paleontology, 36:403-424.

JERRE, F. 1994. Anatomy and phylogenetic significance of Eoconularia loculata, a conulariid from the Silurian of Gotland. Lethaia, 27:97-109.

KAYSER, F.H.E. 1897. Beiträge zur Kenntniss einiger paläozischer Faunen SudAmerikas. Deutsche geologische Gesellschaft, Zeitschrift, 49(2):274-317.

KIDERLEN, H. 1937. Die Conularien. Über Bau and Leben der ersten Scyphozoa. Neues Jahrbuch für Mineralogie, Beilage- Band, 77:113-169.

KNIGHT, J.B. 1937. Conchopeltis Walcott, an Ordovician genus of the Conulariida. Journal of Paleontology, 11(3):186-188.

KNOD, R. 1908. Devonische Faunen Boliviens. In: XIV BEITRÄGE ZUR GEOLOGIE UND PALÄONTOLOGIE VON SUDAMERIKA. G. Steinmann (ed.). Neues Jahrbuch für Mineralogie, Geologie und Paläontologie, 25:493-600.

KOTZIAN, C.B. 1995. Estudo sistemático e morfo-funcional de bivalves (Mollusca) das Formações Vila Maria (Siluriano) e Ponta Grossa (Devoniano), Bacia do Paraná, Brasil: interpretação do regime hidrodinâmico-sedimentar. UFRGS, Porto Alegre, RS (Tese de Doutoramento, Instituto de Geociências), 378pp. 
KOZLOWSKI, R. 1913. Fossiles Devoniens de l'État de Paraná (Brésil). Annales de Paleontologie, 8:14-19.

KOZLOWSKI, R. 1923. Fauna Devonienne de Bolivie. Annales de Paleontologie, $12(1 / 2): 1-112$.

KOZLOWSKI, R. 1968. Nouvelles observations sur les conulaires. Acta Palaeontologica Polonica, 13:497-535.

LAMMERS, G.E. \& YOUNG, H.R. 1984. A conulariid from the Mississipian of Manitoba. Canadian Journal of Earth Science, 21:609-611.

LANGE, F.W. \& PETRI, S. 1967. The Devonian of the Paraná Basin. In: Problems in Brazilian Devonian Geology. J. J. Bigarella (ed.). Boletim Paranaense de Geociências, 21-22:5-55.

LEME, J.M. 2000. Sistemática dos Conulariida Babcock \&Feldmann, 1986, da Formação Ponta Grossa, Devoniano (?Lochkoviano-Frasniano), da Bacia do Paraná e suas implicações paleobiogeográficas e filogenéticas. UNESP, Botucatu, SP, (Monografia apresentada ao Departamento de Zoologia, IB), 51p.

LEME, J.M.; RODRIGUES, S.C. \& SIMǑES, M.G. 2000a. Systematic revison of the conulariids (Cnidaria) of the Ponta Grossa Formation (Lochkovian-Frasnian), from Paraná Basin, Brazil: a preliminary report. In: VIII Simpósio Internacional de Iniciação Científica da Universidade de São Paulo, Boletim de Resumos, sem paginação, versão em $C D$.

LEME, J.M.; RODRIGUES, S.C. \& SIMŐES, M.G. 2000b. Systematic of the Conulatae (Cnidaria) of the Ponta Grossa Formation (?Lochkoviano-Frasniano), from Paraná Basin, Brazil. In: Reunião Anual da Sociedade Brasileira de Paelontologia, Paleo-2000/SP, Boletim de Resumos, p. 9.

LEME, J.M.; RODRIGUES, S.C. \& SIMÕES, M.G. 2001. First occurrence of Paraconularia africana (Sharpe) 1856 in sediments of the Ponta Grossa 
Formation (?Lochkovia-Frasnian), Jaguariaíva region, Paraná Basin, Brazil. In: Reunião Anual da Sociedade Brasileira de PaLEontologia, Paleo- 2001/SP, Boletim de Resumos, p. 13.

LIMA, M.R. 1989. Fósseis do Brasil. T. A. Queiroz (ed.). EDUSP, São Paulo, 118p.

LINDSTROM, G. 1884. On the Silurian Gastropoda and Pteropoda of Gtland. Kongligla Svenska Vetenskaps-Akademiens, Handlingar 19(6):1-250.

LOF, P. 1985. Elsevier's Invertebrate Fossils Chart. Elsevier, Amsterdam.

LUCAS, S. 2001. Taphotaxon. Lethaia 34:30.

MACHADO, D.M.C. 1999. Nuculites Conrad, 1841 (Mollusca, Bivalvia): sistemática e implicações paleobiogeográfica. UFRGS, Porto Alegre, RS (Tese de Doutoramento, Instituto Geociéncias), 298pp.

MARIÑELARENA, M.P. 1970. Algunas especies de Paraconularia Sinclair del "Sistema de Tépuel"(Chubut) y sus relaciónes com faunas del hemisferio austral. Ameghiniana, 7:139-150.

MARQUES, A.C. 1997. Evolução basal nos Metazoa, com ênfase nas relações entre os Cnidaria. USP, São Paulo, SP (Tese de Doutorado, Instituto de Biociências), 415pp.

MARQUES, A.C. \& COLLINS, A. G. 2000. The enigma of Conulatae and their phylogenetic placement within Cnidaria. In: REUNIÃO ANUAL DA SOCIEDADE BRASILEIRA DE PALEONTOLOGIA, PALEO- 2000/SP, Boletim de Resumos, p.11.

MCKINNEY, F.K.; DEVOLVE, J.J. \& SOBIERAJ, J. 1995. Conularia sp. from the Pyrénées: further support for scyphozoan affinities of the Conularida. Lethaia, 28:229-236. 
MELO, J.H.G. 1985. A Província Malvinocáfrica no Devoniano do Brasil: estado atual dos conhecimentos. UFRJ, Rio de Janeiro, RJ (Dissertação de Mestrado, Instituto de Geociências), 180pp.

MELO, J.H.G. 1986. The Mailvinokaffric reaim in the Devonian of Brazil: present state of Knowledge. Anais da Academia Brasileira de Ciências, 58(1):170.

MELO, J.H.G. 1988. The Malvinokaffric realm in the Devonian of Brazil. In: Devonian of the world: proceedings of the second intemational symposium on the Devonian system, proceedings... Calgary, Alberta: Canadian Society of Geologists, 669$673 p$.

MENDÉZ-ALZOLA, R. \& SPRECHMANN, P.G. 1973. Fauna del Devonico Temprano del Uruguay, II. Sobre representantes de Conularia y Mesoconularia (Conulariidae, Conulariinae). Revista de Biologia del Uruguay, 1(2):129-138.

MOORE, R.C. \& HARRINGTON, H.J. 1956a. Scyphozoa. In: Treatise on Invertebrate Paleontology, Part F, Coelenterata. R.C. Moore (ed.). Geological Society of America and University of Kansas Press, F27-F38.

MOORE, R.C. \& HARRINGTON, H.J. 1956b. Conulata. In: Treatise on Invertebrate Paleontology, Part F, Coelenterata. R.C. Moore (ed.). Geological Society of America and University of Kansas Press, F54-F66.

MORSCH, S.M. 1984a. Nova ocorrência de moluscos (Bivalvia) no Devoniano da Bacia do Paraná, Brasil. In: III CONGRESSO LATINO-AMERICANO DE PALEONTOLOGIA, México, Mem..., 96-102p.

MORSCH, S.M. 1984b. Revisão sistemática de bivalves (Mollusca) provenientes de estratos da Formação Ponta Grossa - Devoniano no estado do Paraná. UFRGS, Porto Alegre, RS (Dissertação de Mestrado, Instituto de Geociências), 106pp. 
MORSCH, S.M. 1986. Bivalves (Mollusca) na Formação Ponta Grossa (Bacia do Paraná-Devoniano). Revisão Sistemática. Anais da Academia Brasileira de Ciência, 58(3):403-431.

MORSCH, S.M. 1987. Pholadella (?) jaguariaivensis sp. n. e Pholadella (?) epops (Clark). n. com. (Mollusca-Bivalvia) na Formação Ponta Grossa, Bacia do Paraná, Devoniano (Brasil). In: IV CONGRESSO LATINOAMERICANO DE PALEONTOLOGIA, Santa Cruz de la Sierra, 1987. Anales..., 1:193-199.

MORTIN, J. 1985. The shell structure and zoological affinities of conulariids. Palaeontological Association Annual Conference Abstracts, Wales, 12-13.

OLIVER, W.A.Jr 1984. Conchopeltis: its affinities and significance. Paleontographica Americana, 54:141-147.

OLIVEIRA, A. I. \& LEONARDOS, O.H. 1943. Geologia do Brasil. Segunda edição, Série Didática: Serviço de Informação Agrícola, Brasil.

PARFREY, S.M. 1982. Paleozoic conulariids from Tasmania. Alcheringa, 6:69-75.

PETRI, S. \& FÚLFARO, V.J. 1983. Geologia do Brasil: Fanerozóico. EDUSP, São Paulo, SP, 631pp.

POPP, M.T.B. 1985. Revisão dos trilobitas calmoniideos e comunidades faunisticas da Formação Ponta Grossa, Devoniano do Estado do Paraná. UFRGS, Porto Alegre, RS (Tese de Doutoramento, Instituto Geociências), 112pp.

QIAN,Y.; VAN ITEN, H.; COX, R.S.; MAO-YAN, Z. \& ER-JUN, Z. 1997. A brief account of Emeiconularia trigemme, a new genus and species of protoconulariid. Acta Micropalaeontologica Sinica, 14(4):475-488.

QUADROS, R. 1987. Paleontologia dos brachiopoda - Lingulida, Strophomenida, Spiriferina, Terebratulida - devonianos, da Serra de Atimã e arredores, Mato Grosso, Brasil. UFRGS, Porto Alegre, RS (Tese de Doutoramento, Instituto de Geociências), 87pp. 
REED, F.R.C. 1904. Mollusca from the Bokkeveld Beds. South African Museum Annals, 4:239-274.

REED, F.R.C. 1925. Revision of the fauna of the Bokkeveld Beds. South African Museum Anna/s, 22:27-225.

REED, F.R.C. 1933. Some new species of Conularia from Girvan. Geological Magazine, 70:354-358.

RICHARDSON, J.G. \& BABCOCK, L.E. 2002. Weird things from the Middle Ordovician of North America interpreted as conulariid fragments. Journal of Paleontology, 76(2):391-393.

RICHTER, R. \& RICHTER, E. 1942. Die Trilobiten der Weismer-Schichten am Hohen Venn, mit Bemerkunger über die Malvinocaffrisch Provinz. Senckenbergische Naturforscher, Gesellschafte, Ablandlungen 25:156-179.

ROCHA-CAMPOS, A.C. 1969. Moluscos e braquiópodes eogondvânicos do Brasil e Argentina. USP, São Paulo, SP. (Tese de Livre-Docência, Faculdade de Filosofia, Ciências e Letras), 158pp.

RODRIGUES, S.C. 2000. Tafonomia Comparada dos Conulariida Babcock \&Feldmann, 1986, da Formação Ponta Grossa, Devoniano (?LochkovianoFrasniano), da Bacia do Paraná: implicaçóes paleoecológicas e paleoambientais. UNESP, Botucatu, SP, (Monografia apresentada ao Departamento de Zoologia, IB), 36p.

RODRIGUES, S.C. 2002. Tafonomia comparada dos Conulatae Collins, et al. 2000, Formação Ponta Grossa, Devoniano (?Lochkoviano-Frasniano), Bacia do Paraná: implicações paleoeautocológicas e paleoambientais. USP, São Paulo, SP (Dissertação de Mestrado, Instituto de Geociências).

RODRIGUES, S.C.; LEME, J.M. \& SIMÔES, M.G. 2000a. Paleoecology of the conulariids (Cnidaria) of the Ponta Grossa Formation (Lochkovian-Frasnian), 
from Paraná Basin, Brazil. In: VIII Simpósio Internacional de Iniciação Cientifica da Universidade de São Paulo, Boletim de Resumos, sem paginação, versão em CD.

RODRIGUES,S.C.; LEME, J.M. \& SIMŐES, M.G. 2000b. The role of taphonomy in the taxonomic study of the Devonian Conulatae: some examples from Ponta Grossa Formation (?Lochloviano-Frasniano), Paraná Basin, Brasil. In: Reunião Anual da Sociedade Brasileira de Paelontologia, Paleo- 2000/SP, Boletim de Resumos, p. 15.

RODRIGUES, S.C.; LEME, J.M. \& SIMŐES, M.G. 2001. Conularia cf. quichua Ulrich: a solitary or clustered marine invertebrate? In: Reunião Anual da Sociedade Brasileira de Paleontologia, Paleo- 2001/SP, Boletim de Resumos, p. 12.

SCHELTEMA, R.S. 1989. Planktonic and non-planktonic development among prosobranch gastropods and its relationship to the geographic range of species. In: Reproduction, genetics and distributions of marine organisms. J.S. Ryland \& P.A. Tyler (eds.). Olsen \& Olsen, Fredensborg, Dinamarca.

SCHWARZ, E.H.L. 1906. South African Palaeozoic fossils. Albany Museum, Records, $1: 347-404$

SHARPE, D. 1856. Descriptions of Palaeozoic Mollusca from South Africa. Transactions of the Geological Society of London, ser. 2(7):206-215.

SIMŐES, M.G. (inédito). Relatório FAPESP, 93/2747-0, 1994. 72pp.

SIMŐES, M.G.; MELLO, L.H.C.; LEME, J.M.; RODRIGUES, S.C. \& MARQUES, A.C. 1999. Devonian conulariid taphonomy and their paleoecological implications. In: Geological Society of America, Abstracts with Programs: A-468.

SIMÕES, M.G., MELLO, L.H.C., RODRIGUES, S.C, LEME, J.M. \& MARQUES, A.C. 2000a. Conulariid taphonomy as a tool in paleoenvironmental analysis. Revista Brasileira de Geociências, 30(4): 757-762. 
SIMÓES, M.G.; MARQUES, A.C. \& COLLINS, A.G. 2000b. In situ preservation of conulariids from the Ponta Grossa Formation (Devonian of Brazil), with comments on the phylogenetic placement of Conulatae within Cnidaria. Paleobios, 20(1):9.

SIMŐES, M.G.; GHILARDI, R.P.; SALES, A.M.F.; RODRIGUES,S.C. \& ; LEME, J.M. 2000c. Taphonomy and genesis of the "Conularia Beds" from Ponta Grossa Formation (Devonian) within a Sequence Stratigraphy framework. In: Reunião Anual da Sociedade Brasileira de Paelontologia, Paleo- 2000/SP, Boletim de Resumos, p. 20.

SIMŐES, M.G.; VAN ITEN, H.; LEME, J.M. \& RODRIGUES, S.C. 2001a. Conulatae, na extinct group of marine cnidarians: major problems of interpretation and strategies for future research. In: XVIICONGRESSO BRASILEIRO DE PALEONTOLOGIA, Boletim de resumos, p. 99.

SIMŐES, M.G.; GHILARDI, R.P.; SALES, A.M.F.; RODRIGUES, S.C. \& LEME, J.M. 2001b. Taphonomy and seguency stratigraphic as integrated tools in paleoenvironmental analysis: some examples from the Paraná (Devonian) and Araripe (Cretaceous) Basins, Brazil. In: XVIICONGRESSO BRASILEIRO DE PALEONTOLOGIA, Boletim de resumos, p. 31.

SIMÖES, M.G.; RODRIGUES, S.C.; LEME, J.M. \& VAN ITEN, H. (em preparação). Body fossils as Taphotaxa: some Middle Paleozoic conulariids (Cnidaria) as possible exemples. Lethaia.

SINCLAIR, G.W. 1940. A discussion of the genus Metaconularia with descriptions of new species. Transactions of the Royal Society of Canada, 34:101-121.

SINCLAIR, G.W. 1942. The Chazy Conularida and their congeners. Annals of the Carnegie Museum, 29:219-240. 
SINCLAIR, G.W. 1948. The biology of the Conularia. Ph.D. thesis, McGill University, Montreal, Quebec.

SINCLAIR, G.W. 1952. A classification of the Conularida. Fieldiana Geology, 10(13):135-145.

SIVIERO, F. \& FERNANDES, A.C.S. 2000. Conularildeos brasileiros: problemas taxonômicos e registros. In: REUNIÃO ANUAL DA SOCIEDADE BRASILEIRA DE PALEONTOLOGIA, PALEO-2000/SP, Boletim de Resumos, p.21.

SOWERBY, J. 1820 (datado 1821). The mineral conchology of Great Britain; or coloured figures and descriptions of those remains of testaceous animals or shells, which have been preserved at variouus times and depths in the Earth, vol. 3, Parte 46. London, 1-194p.

STEUL, H. 1984. Die systematische Stellung der Conularien. Giessener Geologische Schriften, 37:117pp.

SUGIYAMA, T. 1942. Studies on the japanese Conularida. Geological Society of Japan, 49:390-399.

TERMIER, H. \& TERMIER, G. 1949. Position systématique et biologie des conulaires. Revue Scientifique, 86:711-722.

TERMIER, H. \& TERMIER, G. 1953. Les Conularides. In: Traité de Paléontologie, Onychophores, Arthropodes, Echinodermes, Stomocordes. J., Piveteau (ed.). Masson \& Cie., Paris. 3:1006-1013p.

THOMAS, I. 1905. Neue Beiträge zur Kenntnis der devonischen Fauna Argentiniens. Deutsche Geologische Gesellschft, Zeitschrift, 57:233-290.

ULRICH, A. 1892. Palaeozoische Versteinerungen aus Bolivien. Neues Jahrbuch für Mineralogie, Geologie und Paläontologie, 8:5-116. 
VAN ITEN, H. 1987. The mode of life of the Conulariida and its implications for conulariids affinities. Geological Society of America, Abstracts with Programs, 19:876.

VAN ITEN, H. 1989. Relic conulariid soft parts and their bearing on conulariid affinities. Geological Society of America, Abstracts with Programs, 21:256.

VAN ITEN, H. 1991a. Evolutionary affinities of conulariids. In: The early evolution of Metazoa and the significance of problematic fossil taxa. A.M. Simonetta \& S.C. Morris (eds.). Cambridge University Press, 145-155.

VAN ITEN, H. 1991b. Anatomy, patterns of occurrence, and nature of the conulariid schott. Palaeontology, 34:939-954.

VAN ITEN, H. 1992a. Morphology and phylogenetic significance of the corners and midlines of the conulariid test. Paleontology, 35:335-358.

VAN ITEN, H. 1992b. Microstructure and growth of the conulariid test: implications for conulariid affinities. Paleontology, 35:359-372.

VAN ITEN, H. 1994. Redescription of Glyptoconularia gracilis (Hall), an Ordovician conulariid from North America. New York State Museum Bulletin, 481:363-366.

VAN ITEN, H. \& COX, R.S. 1992. Evidence of clonal budding in a radial cluster of Paraconularia crustula (White) (Pennsylvanian: ?Cnidaria). Lethaia, 25:421-426.

VAN ITEN, H.; COX, R.S. \& MAPES, R.H. 1992. New data on the morphology of Sphenothallus Hall: implications for its affinities. Lethaia, 25:135-144.

VAN ITEN, H.; FITZKE, J.A. \& COX, R.S. 1996. Problematical fossil cnidarians from the Upper Ordovician of the North-Central USA. Palaeontology, 39:1037-1064.

VAN ITEN, H., ZHU, Z.K \& ZHU, M.Y. 2000. Anatomy and systematic of the Devonian conulariids Changshaconus Zhu, 1985 and Reticulaconularia Babcock et Feldmann, 1986. Acta Palaeontologica Sinica, 39(4):466-475. 
VAN ITEN, H.; LEME, J.M.; RODRIGUES, S.C. \& SIMÓES, M.G. (em preparação). New data on the thecal anatomy and biostratinimy of Conularia milwaukeensis Cleland, 1911 and C. quichua Uirich, 1890 (Devonian, North-Central United States and South-America). Journal of Paleontology.

VANUXEM, L. 1842. Geology of New York. Part 3. Survey of Third Geological District. Albany: C. Van Benthuysen.

VENTURA, C.R.R. \& PIRES, D.O. 2002. Ciclo de vida de invertebrados marinhos. In: Biologia Marinha. Interciência, 50-67p.

WALCOTT, C.D. 1886. Second contribution to the studies on the Cambrian faunas of North America. Bulletin of the United States Geological Survey, 30:1-369.

WATERHOUSE, J.B. 1979. Permian and Triassic conulariid species from New Zealand. Journal of the Royal Society of New Zealand, 9(4):475-489.

WATERHOUSE, J.B. 1986. Late palaeozoic Scyphozoa and Brachiopoda (Inarticulata, Strophominida, Pruductida and Rhynchonellida) from the Southeast Bower Basin, Australia. Palaeontographica, 193:1-77.

WERNER, B. 1966. Stephanoscyphus (Scyphozoa Coronatae) und siene direkte Abstammung von den fossilen Conulata. Helgoländer Wissenschaftliche Meeresuntersuchungen, 13:17-21.

WERNER, B. 1967. Stephanoscyphus Allman (Scyphozoa Coronatae), ein rezenterVertreter der Conulata? Paläontologische Zeitschrift, 41:137-153.

WERNER, B. 1969. Neue Beitraege zur Evolution der Scyphozoa und Cnidaria. In: I Simpósio Intemacional de Zoofilogenia. University of Salamanca, Salamanca, 223-244p.

WERNER, B. 1973. New investigations on systematics and evolution of the class Scyphozoa and the phylum Cnidaria. Seto Marine Biology Labaratory Publicattions, 20:35-61. 
WIMAN, C. 1895. Palaeontologische Notizen. 1 und 2. University of Upsala, Geological Institution, Bulletin, 2:109-117. 


\section{APÊNDICE}

\section{ANÁLISE CLADÍSTICA PRELIMINAR DOS CONULATAE}

... $E$ possivel e recomendável treinar sistematas. Os jovens năo precisam aprender por imitaçăo ou condicionamento, como chimpanzés amestrados. Eles ainda precisam do conhecimento neural dos especimes, como todos os taxonomistas, mas podem $\theta$ devem aprender a teoria $\theta$ o método. Uma consequéncia notável dessa circunstancia relativamente nova $\theta$ demoliçăa a que a última geraçăo de filogeneticistas está submetendo o odifício taxonómico tradicional." (N. Bernardi, 1997). 
Introducão. A aplicação da metodologia cladística no estudo desse grupo de invertebrados marinhos, extintos não é fácil, em parte, dada à dificuldade de obtenção de caracteres individualizados e da descrição precisa das condições dos caracteres para todos os táxons terminais. A despeito dessas dificuldades, apoiada na ampla revisão crítica da literatura internacional, apresentada no item 1.4, na experiência acumulada com o material do Devoniano da Bacia do Paraná e nas longas discussóes com o Dr. Heyo Van Iten (Hanover College, Indiana) é nítida a urgência de aplicação do método cladístico na sistemática dos Conulatae. Essa análise deve procurar esclarecer as relações entre as espécies que compõem o grupo interno $e$ a determinação de seu escopo, na tentativa de resolução de questões importantes, tais como: a- quais são as sinapomorfias do grupo (Conulatae) ou, em outras palavras, que caracteres definem esse grupo? b- são monofiléticas as famílias e subfamílias de conulários identificados na literatura, os quais foram reconhecidos através de análises fenéticas (Moore \& Harrington, 1956a, b)?

Enfocando o problema. Com o intuito de verificar esses problemas e reconhecer grupos naturais dentro dos Conulatae, os dados descritivos disponiveis na literatura foram compilados, resultando na elaboração de uma matriz de caracteres prévia. Em outras palavras, se tais caracteres refletissem relações de parentesco, úteis à identificação de grupos naturais dentre os conulários, a análise cladística resultante deveria mostrar árvores bem resolvidas, com índices (índices de retenção e de consistência) aceitáveis, além de grupos monofiléticos, dentre os táxons escolhidos para compor o grupo interno.

Em uma primeira tentativa, uma matriz contendo 17 caracteres, dos quais, 3 englobando feições internas da teca (e.g., presença de carenas, presença de septos e tipo de septos) e 14 correspondendo a feições externas (e.g. sulco das arestas, 
articulação dos cordões, etc), incluiu 41 táxons (todos os gêneros descritos), dos quais 4 constituiram o grupo externo. Conforme discussões com o filogeneticista Prof. Dr. Antônio Carlos Marques (especialista em Scyphozoa), do Departamento de Zoologia da USP, os resultados preliminares indicaram não haver consistência dos agrupamentos sugeridos pelas propostas de classificação, demonstrando que os caracteres fenéticos utilizados para distinção dos grupos de conulários necessitam, conforme indicado nesse documento, de urgente revisão.

Outra tentativa foi à elaboração de uma matriz de caracteres morfológicos incluindo somente os caracteres e táxons sugeridos por Moore \& Harrington (1956b), no clássico "Treatise on Invertebrate Paleontology", Part F, Coelenterata, Conulata (discussão abaixo).

Definindo os táxons terminais. Moore e Harrington (1956b) reconhecem duas familias de conulários (Conulariellidae Kiderlen e Conulariidae Walcott) dentro da subordem Conulariina Miller \& Gurley. A Família Conulariellidae Kiderlen inclui apenas um gênero, Conulariella Boucek. Já, a Familia Conulariidae, é constituída por três subfamílias (Conulariinae Walcott, Paraconularinae Sinclair e Ctenoconulariinae Sinclair) abrangendo um total de 15 gêneros. Portanto, os táxons terminais que compõe o estudo aqui realizado estão representados, no Quadro 1, a seguir: 
Quadro 1. Subfamílias e gêneros da familia Conulariidae Walcott e Conulariellidae Kiderlen (Moore \& Harrington, 1956b).

\begin{tabular}{|c|c|}
\hline \multicolumn{2}{|c|}{ FAMILIA CONULARIELLIDAE Kiderlen (Moore 8 Harrington, 1956b) } \\
\hline \multicolumn{2}{|r|}{ Conulariella } \\
\hline \multicolumn{2}{|c|}{ FAMfLIA CONULARIIDAE Walcott (Moore \& Harrington, 1956b) } \\
\hline \multirow{8}{*}{ Conulariinae } & Conularia \\
\hline & Arcaheoconularia \\
\hline & Anaconularia \\
\hline & Metaconularia \\
\hline & Mesoconularia \\
\hline & Diconularia \\
\hline & Exoconularia \\
\hline & Pseudoconularia \\
\hline \multirow{4}{*}{ Paraconulariinae } & Paraconularia \\
\hline & Eoconularia \\
\hline & Neoconularia \\
\hline & Calloconularia \\
\hline \multirow{3}{*}{ Ctenoconulariinae } & Ctenoconularia \\
\hline & Climacoconus \\
\hline & Conularina \\
\hline
\end{tabular}

Método filogenético. A distribuição dos estados dos caracteres para cada táxon terminal está listada na matriz de caracteres (Quadro 2). As informações contidas na matriz de caracteres foram transformadas em arquivo através do programa MacClade 4 (Maddison \& Maddison, 1998), para que pudessem ser analisadas. Em seguida, foi realizada a análise cladística empregando o programa PAUP* 4.0 v.8 (Swofford, 1998), de 16 táxons (Conulariella o grupo externo), com 7 caracteres, todos não ordenados. Dados ausentes foram representados por pontos de interrogação ("?") e caracteres não aplicáveis por traços ("-"). Para este estudo preliminar, que incluiu somente os caracteres e táxons sugeridos por Moore \& Harrington (1956b), foi empregado o algoritmo exato Branch and Bound, pois poucos caracteres estavam disponiveis em relação ao número de táxons utilizados. Dessa maneira, a utilização 
desse algorítimo permitiu a obtenção dos resultados utilizando um menor tempo de cálculo (Marques, 1997). Posteriormente, foi aplicado o comando de consenso estrito para as árvores encontradas.

\section{Lista de Caracteres.}

Caráter 1: Ornamentacão no sulco da aresta.

0 : ausente

1: descontínuo

2: contínuo

Os sulcos, presentes em cada uma das arestas, formadas entre duas faces adjacentes, podem apresentar ornamentação, tanto por cordőes como por tubérculos. Tal ornamentação arranja-se por todo o sulco, de maneira continua ou descontínua. Também, pode chegar apenas até as margens do sulco, sendo essa categoria interpretada como ornamentação ausente no sulco da aresta (Fig. 1).

\section{Caráter 2: Ornamentação da teca.}

0 : com cordões

1: ausente

2: com tubérculos

Ornamentação da teca é dada através de espessamentos transversais da parede, ao longo de toda a teca. Esses espessamentos podem formar cordóes ou tubérculos (Fig. 2). 


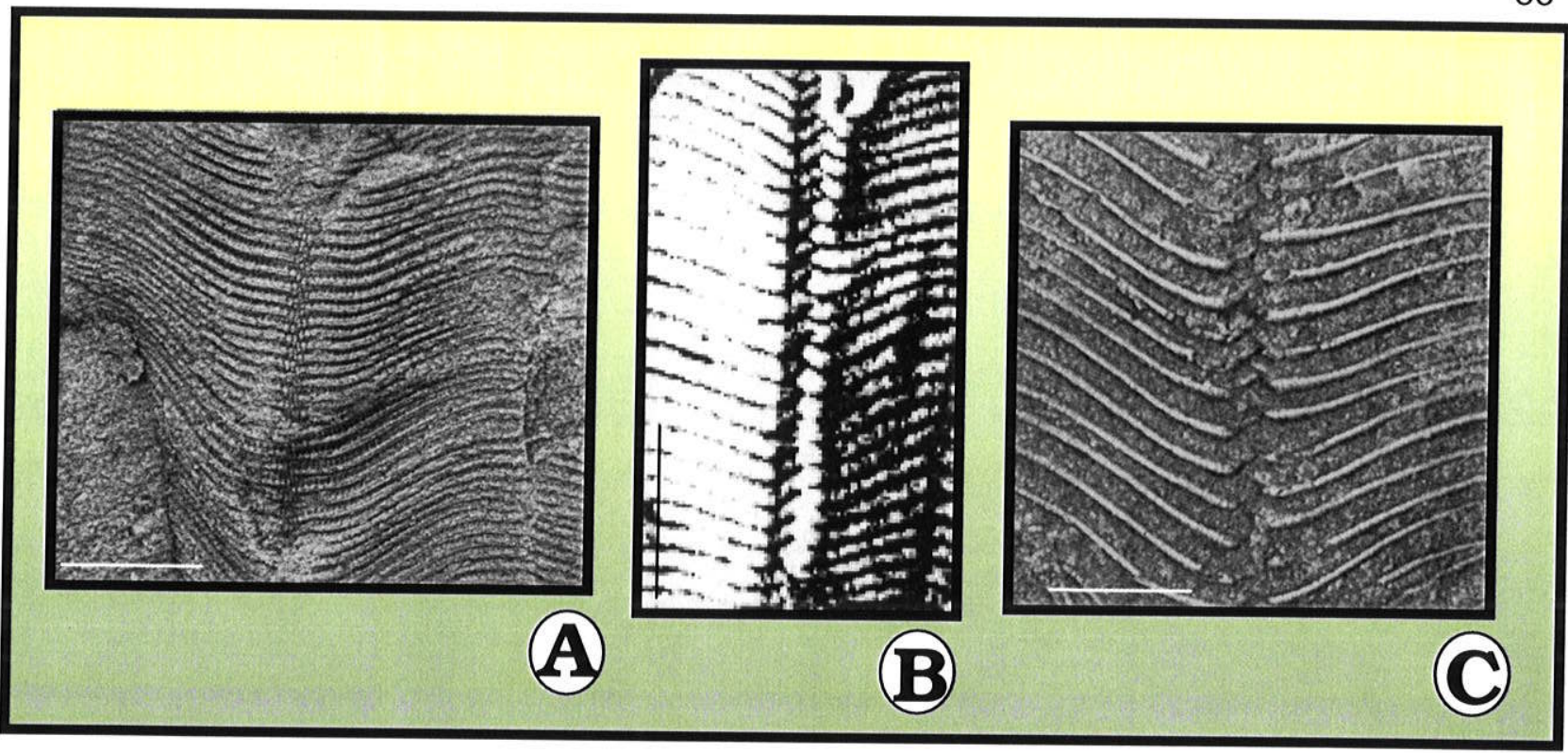

Figura 1- Ornamentação no sulco da aresta: A, Detalhe da aresta de Conularia desiderata, com os cordões contínuos no sulco da aresta; B, Detalhe da aresta de Paraconularia inaequicostata, com cordões descontínuos no sulco da aresta e C, Detalhe da aresta de Paraconularia subulata, com cordões chegando somente até as margens do sulco da aresta. Explicação: Escala gráfica: A e C, (1 mm); B, (1 cm).

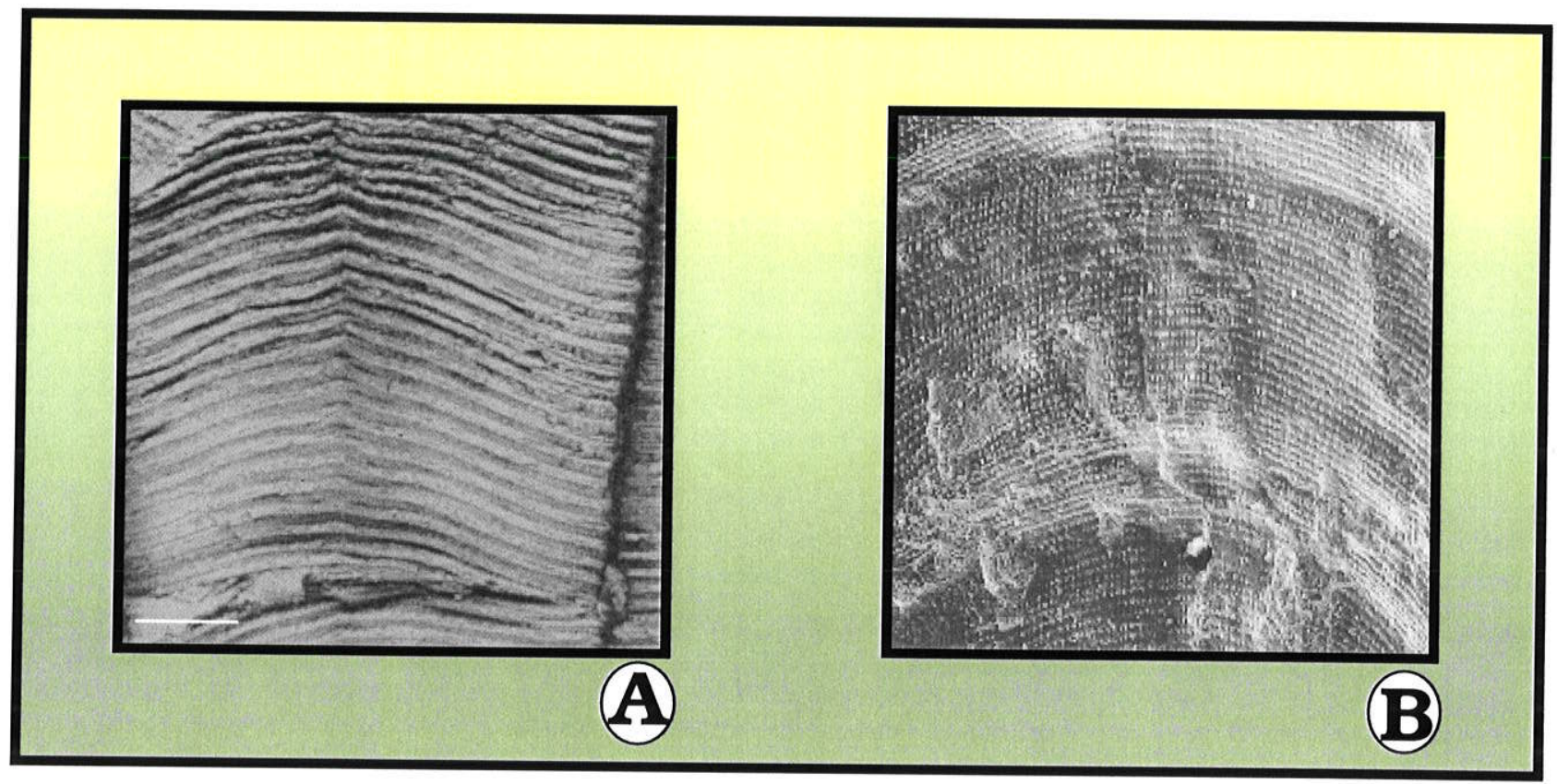

Figura 2- Ornamentação da teca: A, Vista lateral de Conularia elegantula mostrando teca ornamentada por cordões; B, Vista lateral de Metaconularia heymani, mostrando teca ornamentada por tubérculos, x30. Explicação: Escala gráfica $(1 \mathrm{~mm})$. 
Caráter 3: Ornamentação no cordão.

0 : liso

1: com nodos

2: com cristas

Os cordões, que ornamentam a teca, podem ser lisos ou apresentarem estruturas hemisféricas, chamadas nodos, ou projeções adaperturais da teca, ao longo do interespaço, chamadas cristas (Fig. 3).

Caráter 4: Dobra externa na linha mediana.

0 : ausente

1: presente

A linha mediana pode ser marcada por uma elevação ou espessamento externo, longitudinal, da teca (Fig. 4).

Caráter 5: Espessamento interno da teca.

0 : ausente

1: presente

Estrutura morfológica interna que consiste no espessamento centrípeto da teca nas regiões das arestas ou linhas medianas (Fig. 5).

Caráter 6: Espaçamento da ornamentação da teca.

$0:$ pouco espaçada

1: muito espaçada

Espaçamento entre cordões ou tubérculos que ornamentam a teca. Podem ser próximos ou distantes entre si (Fig. 6). 


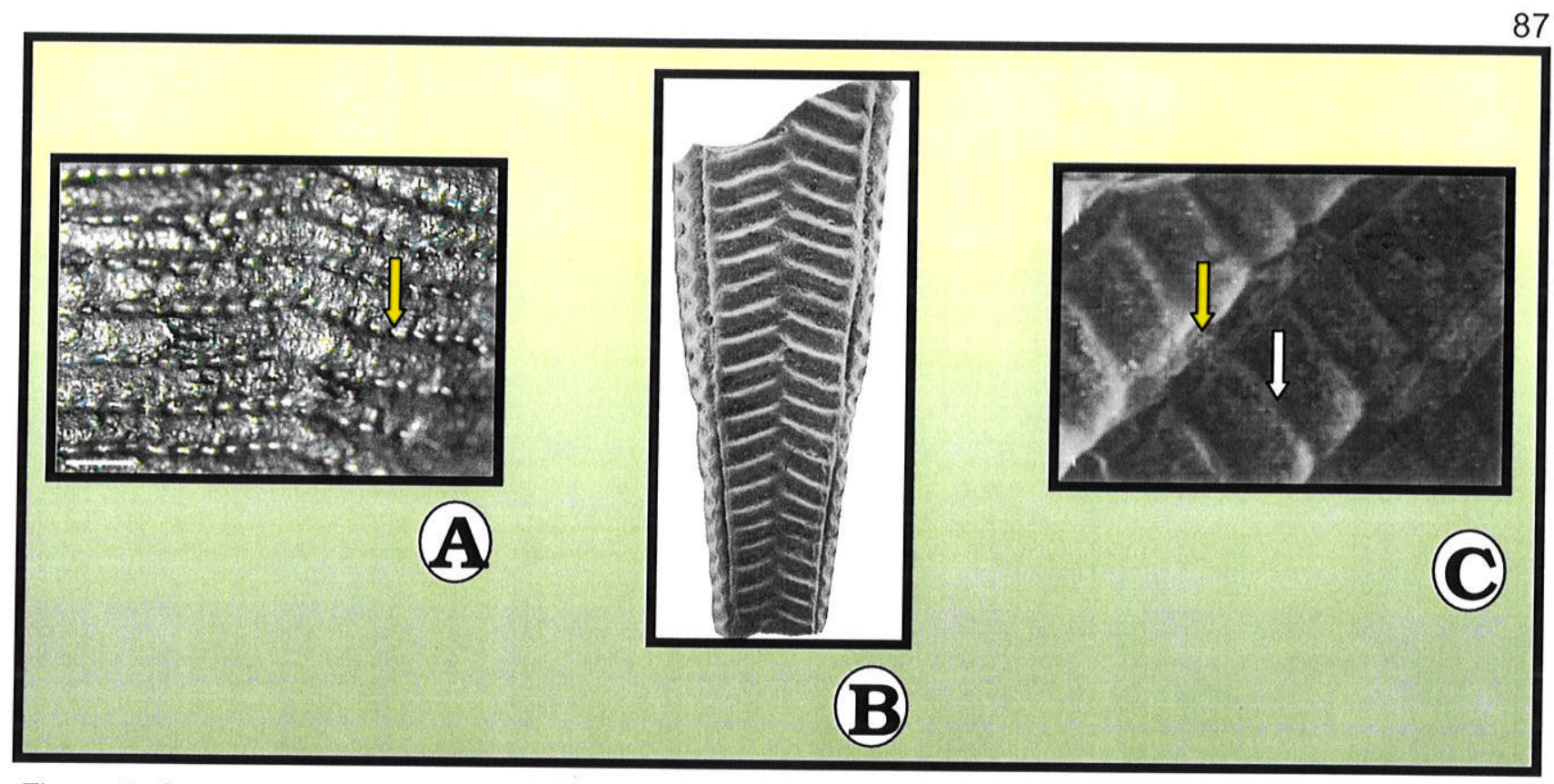

Figura 3- Ornamentação no cordão: A, Detalhe da face de Conularia quichua mostrando cordões com nodos; B, Vista lateral de Climacoconus pumilis com cordões lisos, x30,6; C, Detalhe da face de Conularia trentonensis mostrando cordões com cristas e nodos, x22. Explicação: Setas em amarelo, nodos; Seta em branco, crista; escala gráfica (1 mm).

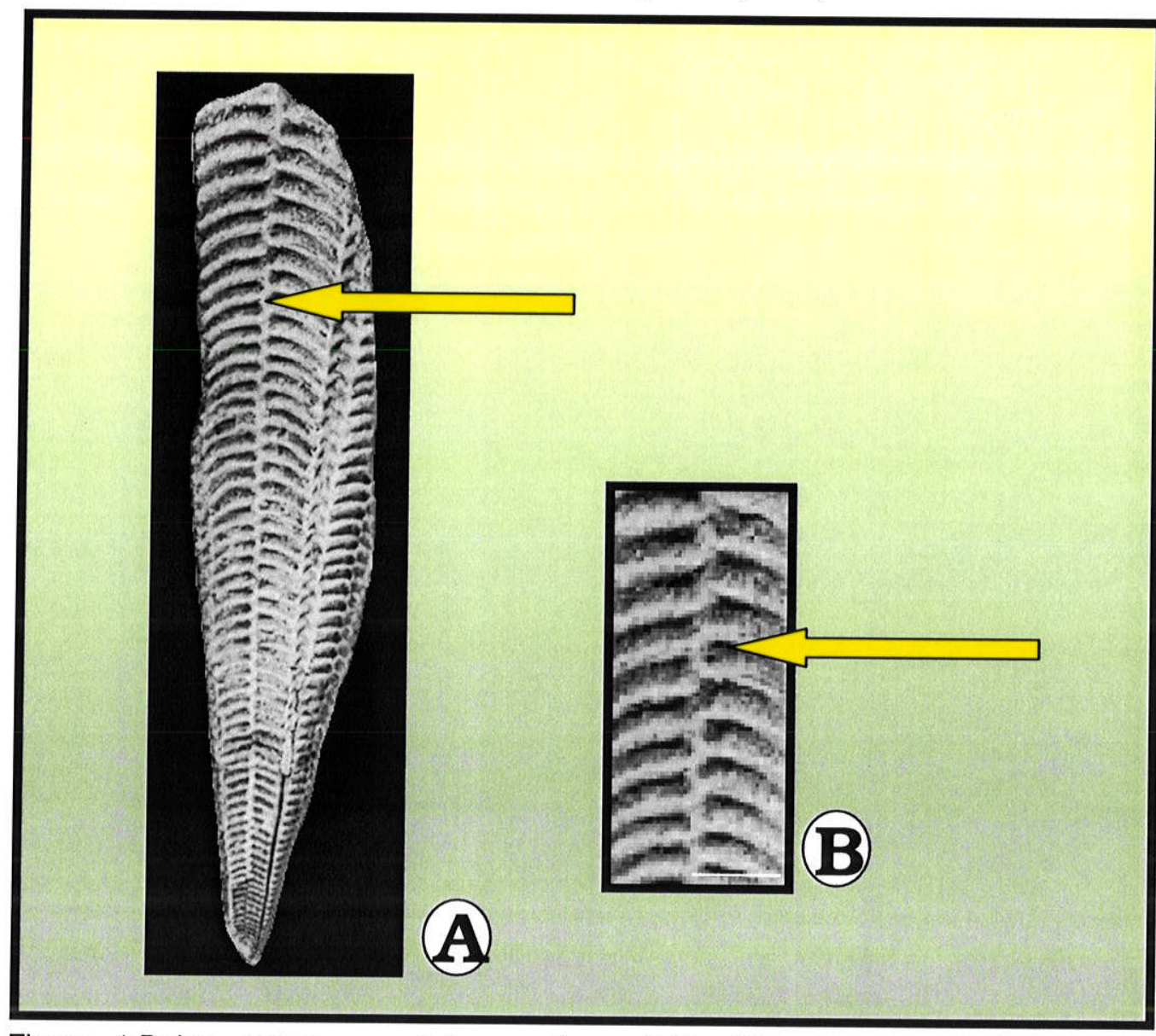

Figura 4-Dobra externa na linha mediana: A-B, Climacoconus quadratus x2,6. Explicação: Setas em amarelo, dobra externa na linha mediana; escala gráfica $(0,5 \mathrm{~cm})$. 

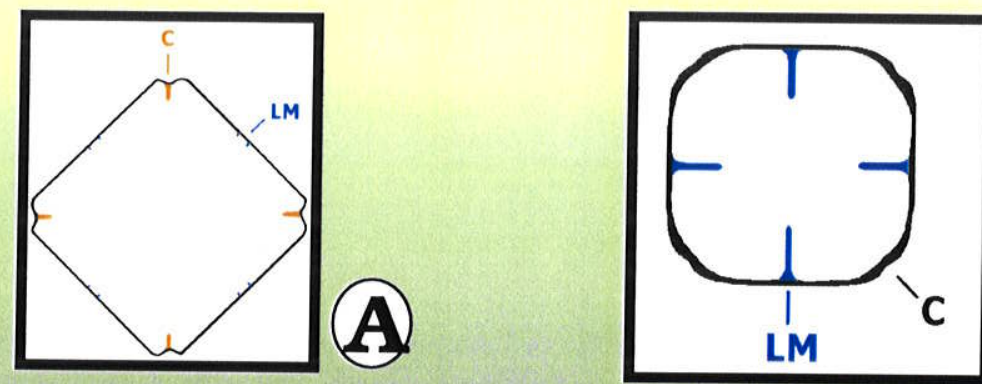

Figura 5- Espessamentos internos da teca: A, Vista do corte transversal Climacoconus sinclairi; B, Vista do corte transversal de Eoconularia loculata. Explicação: C- Carena; LM- Linha mediana com septos.

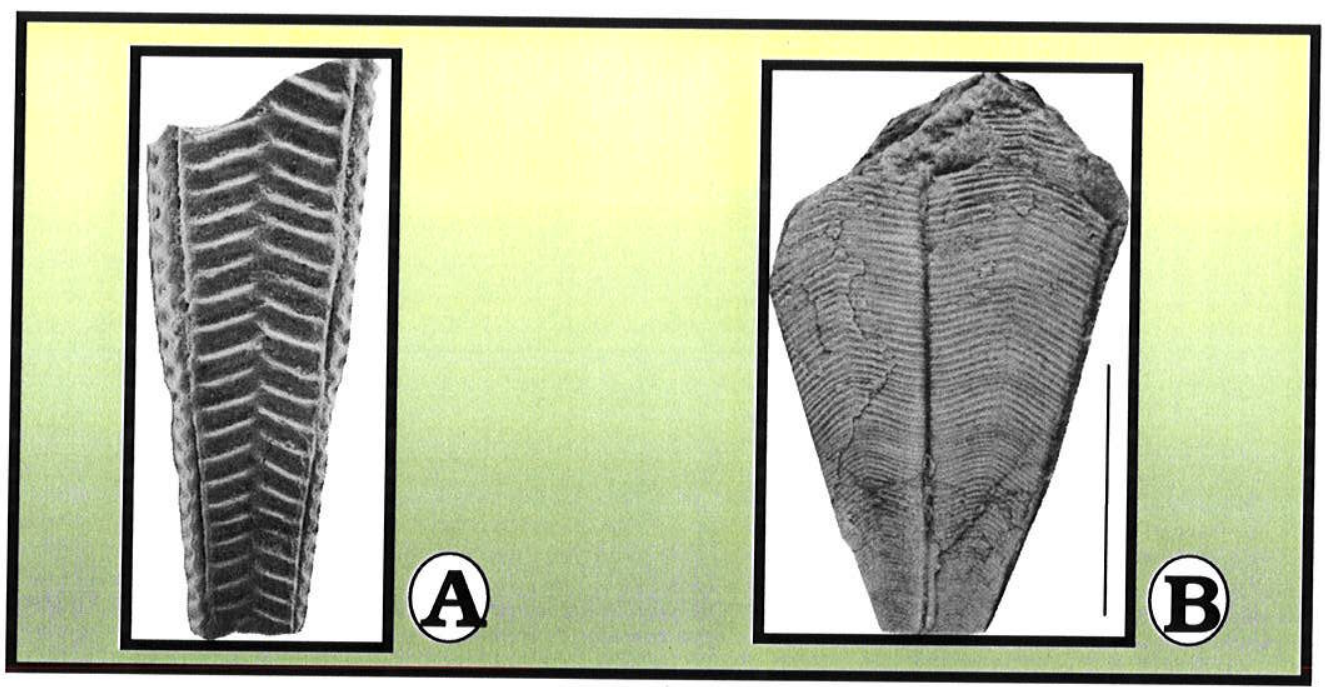

Figura 6- Espaçamento da ornamentação da teca: A, Detalhe da face de Climacoconus pumilis, com os cordões distantes entre si, x30,6; B, Detalhe da face de Conularia pyramidales, com cordões próximos entre si. Explicação: Escala gráfica $(1 \mathrm{~cm})$.

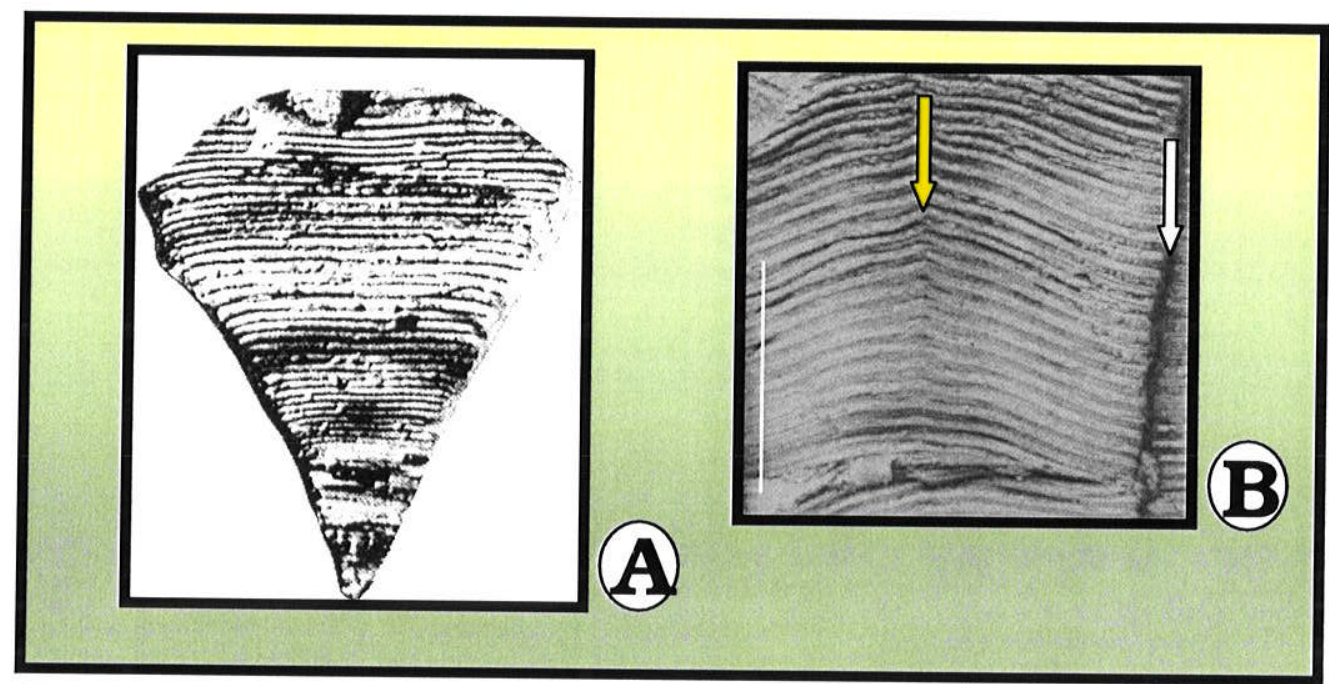

Figura 7- Flexão adapertural dos cordões na região da linha mediana: A, Detalhe da face de Conulariella robusta, com cordões sem flexão na região da linha mediana, x1,0; B, Detalhe da face de Conularia elegantula, com cordões flexionados na linha mediana. Explicação: Setas em amarelo, linha mediana; setas em branco, aresta; escala gráfica $(0,5 \mathrm{~cm})$. 
Caráter 7: Flexão adapertural dos cordöes na região da linha mediana.

$0:$ ausente

1: presente

Os cordőes que omamentam a teca podem flexionar-se adaperturalmente na região da linha mediana, marcando essa região, ou manter-se retos (Fig. 7).

\section{Matriz de Caracteres.}

A matriz de caracteres obtida está representada no Quadro 2, abaixo:

Quadro 2: Matriz de caracteres morfológicos. "?" significa dados ausentes; "-" caracteres não aplicáveis.

\begin{tabular}{l|c|c|c|c|c|c|c} 
& $\mathbf{1}$ & $\mathbf{2}$ & $\mathbf{3}$ & $\mathbf{4}$ & $\mathbf{5}$ & $\mathbf{6}$ & $\mathbf{7}$ \\
\hline CONULARIELLA & 0 & 0 & 0 & 0 & 0 & 0 & 0 \\
\hline Anaconularia & - & 1 & - & 0 & 0 & - & - \\
\hline Archaeoconularia & 2 & 0 & $?$ & 0 & 0 & 0 & 1 \\
\hline Calloconularia & 1 & 0 & 2 & 0 & 0 & 1 & 1 \\
\hline Climacoconus & 1 & 0 & 0 & 1 & 1 & 1 & 1 \\
\hline Conularia & 2 & 0 & 2 & 0 & 0 & 0 & 1 \\
\hline Conularina & 1 & 0 & 0 & 1 & 1 & 0 & 1 \\
\hline Ctenoconularia & 0 & 0 & 2 & 0 & 1 & 1 & 1 \\
\hline Diconularia & 2 & 0 & 1 & 0 & 0 & 0 & 1 \\
\hline Eoconularia & 1 & 0 & 0 & 0 & 1 & 1 & 1 \\
\hline Exoconularia & 2 & 0 & 1 & 0 & 0 & 0 & 1 \\
\hline Mesoconularia & 2 & 0 & 1 & 0 & 0 & 0 & 1 \\
\hline Metaconularia & 2 & 2 & 0 & 0 & 0 & 0 & 1 \\
\hline Neoconularia & 1 & 0 & $?$ & 0 & 0 & $?$ & 1 \\
\hline Paraconularia & 1 & 0 & 2 & 0 & 0 & 1 & 1 \\
\hline Pseudoconularia & 2 & 2 & 0 & 1 & 0 & 0 & 1
\end{tabular}


Discussão. A análise realizada resultou em 89 cladogramas $(L=14 ; C l=0,71$; $\mathrm{Rl}=0,80$ ) e sua árvore de consenso estrito (Fig. 8) não é totalmente resolvida. Uma análise crítica dos dados da matriz (Quadro 2) mostra também que os táxons Diconularia, Exoconularia e Mesoconularia são essencialmente similares. Portanto, extraindo da análise os táxons Diconularia e Exoconularia, mantendo Mesoconularia, por ser o mais antigo na literatura, foram obtidas 29 árvores $(L=14 ; C l=0,71 ; R I=0,77)$. Tendo o grupo externo como ponto de enraizamento, a árvore de consenso estrito resultante mostra o grupo Conulariidae (Moore \& Harrington, 1956b) como monofilético, sustentado pela presença de flexão adapertural dos cordões na região da linha mediana. Nesse contexto, há uma politomia basal e apenas um clado definido. $O$ clado Climacoconus + Conularina + Eoconularia + Ctenoconularia, tem como sinapomorfia a presença de espessamentos internos, tais como, carenas e septos. Adicionalmente, o clado formado pelos gêneros Climacoconus, Conularina e Eoconularia (Fig. 8) é caracterizado pela presença de cordões descontínuos no sulco da aresta.

Esse caráter aparece também em Calloconularia, Neoconularia e Paraconularia, representando, portanto, um caráter homoplástico. O mesmo ocorre para o caráter dobra externa na linha mediana, identificado em Climacoconus e Conularina. Esse caráter também está presente em Pseudoconularia. Uma vez que não é possível reconhecer autapomorfias para os gêneros Climacoconus e Conularina o status desses carece de comprovação.

Do ponto de vista taxonômico, embora a análise tenha sido realizada somente com base nos caracteres definidos por Moore \& Harrington (1956b), não há possibilidade de identificação dos grupos que poderiam representar as subfamílias ou qualquer outra categoria supragenérica reconhecida pelos autores. 


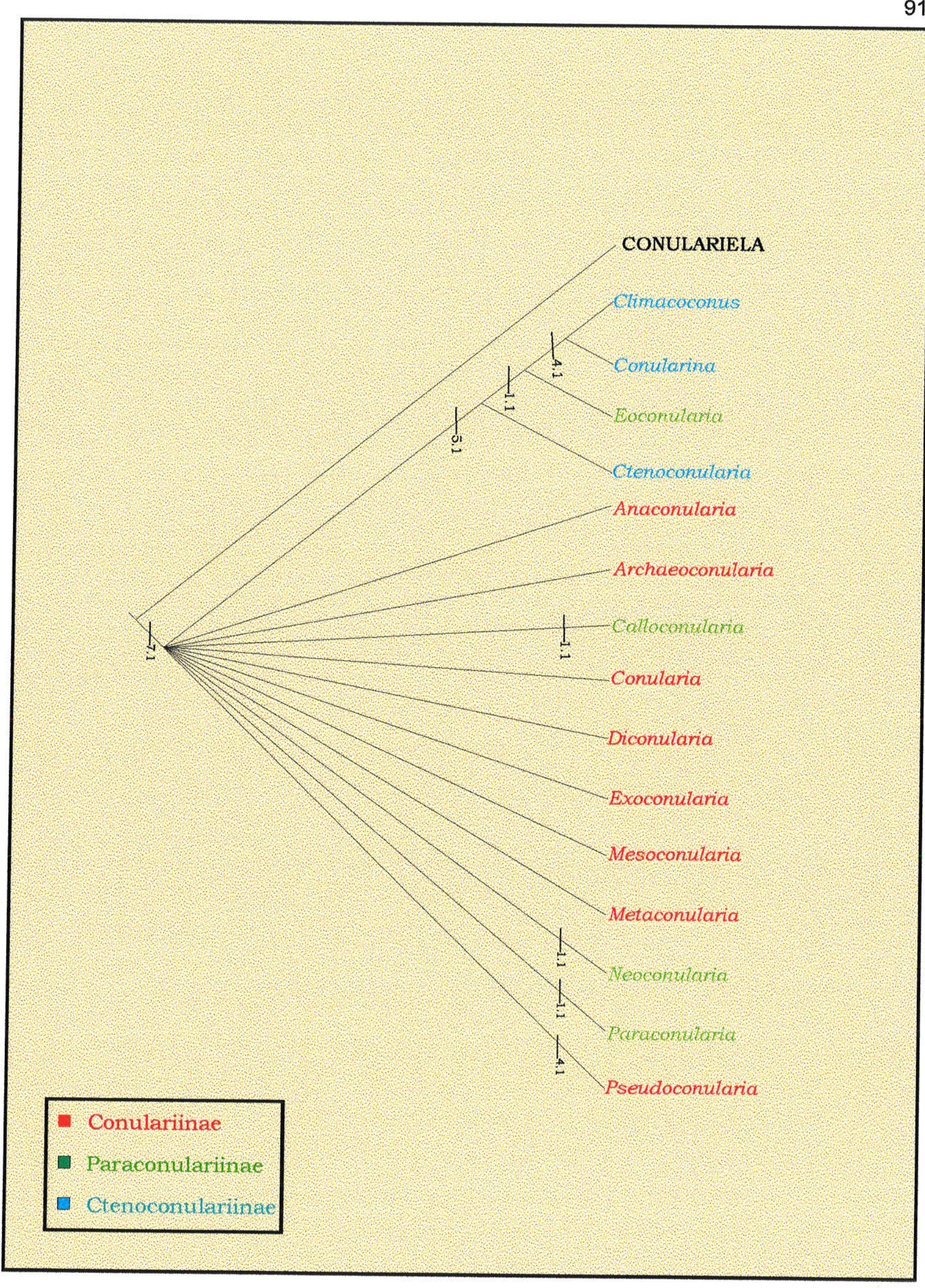

Figura 8- Cladograma resultante de análise de consenso estrito de 89 cladogramas derivados da matriz do quadro 2, Subfamílias (Moore \& Harrington, 1956b). 
A única exceção é o clado Climacoconus + Conularina + Eoconularia + Ctenoconularia, acrescido de Eoconularia. Os gêneros Climacoconus, Conularina e Ctenoconularia foram agrupados por Moore \& Harrington (1956b) na Subfamília Ctenoconulariinae. Dessa forma, os outros agrupamentos propostos por Moore \& Harrington (1956b), subfamilias Conulariinae e Paraconulariinae não são consistentes (Fig. 8). A partir dos dados derivados de uma análise ainda muito preliminar, é notável a urgência do emprego da metodologia cladística como base para a revisão sistemática do grupo.

\section{Referências Bibliográficas do Apêndice.}

MADDISON D.R. \& MADDISON W.P., 1998. MacClade 4.01. Analysis of Philogeny and Character Evolution.

MARQUES, A.C. 1997. Evolução basal nos Metazoa, com ênfase nas relações entre os Cnidaria. USP, São Paulo, SP (Tese de Doutorado, Instituto de Biociências), 415pp.

MOORE, R.C. \& HARRINGTON, H.J. 1956a. Scyphozoa. In: Treatise on Invertebrate Paleontology, Part F, Coelenterata. R.C. Moore (ed.). Geological Society of America and University of Kansas Press, F27-F38.

MOORE, R.C. \& HARRINGTON, H.J. 1956b. Conulata. In: Treatise on Invertebrate Paleontology, Part F, Coelenterata. R.C. Moore (ed.). Geological Society of America and University of Kansas Press, F54-F66.

SWOFFORD, D.L. 1998. PAUP: Phylogenetics Analysis Using Parsimony (and other methods), 4.0 . 


\section{ANEXO}

Quadro da relacão de espécimes de conulários examinados, depositados nas colecões científicas da UNESP; USP; UNG e UEPG. 


\section{ANEXO}

\section{Quadro da relacão de espécimes de conulários examinados, depositados nas colecões cientificas da UNESP; USP; UNG e UEPG.}

\begin{tabular}{|c|c|c|c|c|c|}
\hline Exemplar & $\begin{array}{c}\text { Unid. } \\
\text { Litoestrat. }\end{array}$ & Procedência & Espécie & $\mathbf{n}$ & Col. Científica \\
\hline $\begin{array}{c}\text { DZP-3073 } \\
a, b \\
\end{array}$ & $\begin{array}{c}\text { Fm. Ponta } \\
\text { Grossa, } \\
\text { Seqüência B } \\
\end{array}$ & $\begin{array}{l}\text { Afl. corte estrada } \\
\text { ferro/Jaguariaiva } \\
\text {-Arapoti. } \\
\end{array}$ & Conularia quichua & 2 & UNESP \\
\hline DZP-3074 & $\begin{array}{c}\text { Fm. Ponta } \\
\text { Grossa, } \\
\text { Seqüência B }\end{array}$ & $\begin{array}{l}\text { Afl. corte estrada } \\
\text { ferro/Jaguariaiva } \\
\text {-Arapoti. } \\
\end{array}$ & Conularia quichua & 1 & UNESP \\
\hline DZP-3075 & $\begin{array}{c}\text { Fm. Ponta } \\
\text { Grossa, } \\
\text { Seqüência B }\end{array}$ & $\begin{array}{l}\text { Afl. corte estrada } \\
\text { ferro/Jaguariaiva } \\
\text {-Arapoti. } \\
\end{array}$ & Conularia quichua & 1 & UNESP \\
\hline DZP-3076 & $\begin{array}{c}\text { Fm. Ponta } \\
\text { Grossa, } \\
\text { Seqüência B }\end{array}$ & $\begin{array}{l}\text { Afl. corte estrada } \\
\text { ferro/Jaguariaiva } \\
\text {-Arapoti. } \\
\end{array}$ & Conularia quichua & 1 & UNESP \\
\hline DZP-3077 & $\begin{array}{c}\text { Fm. Ponta } \\
\text { Grossa, } \\
\text { Seqüência B } \\
\end{array}$ & $\begin{array}{l}\text { Afl. corte estrada } \\
\text { ferro/Jaguariaiva } \\
\text {-Arapoti. } \\
\end{array}$ & Conularia quichua & 1 & UNESP \\
\hline DZP-3078 & $\begin{array}{c}\text { Fm, Ponta } \\
\text { Grossa, } \\
\text { Seqüência B }\end{array}$ & $\begin{array}{l}\text { Afl. corte estrada } \\
\text { ferro/Jaguariaiva } \\
\text {-Arapoti. } \\
\end{array}$ & Conularia quichua & 1 & UNESP \\
\hline DZP-3079 & $\begin{array}{c}\text { Fm. Ponta } \\
\text { Grossa, } \\
\text { Seqüência B }\end{array}$ & \begin{tabular}{l|} 
Afl. corte estrada \\
ferro/Jaguariaiva \\
-Arapoti. \\
\end{tabular} & Conularia quichua & 1 & UNESP \\
\hline DZP-3080 & $\begin{array}{c}\text { Fm. Ponta } \\
\text { Grossa, } \\
\text { Seqüência B } \\
\end{array}$ & $\begin{array}{l}\text { Afl. corte estrada } \\
\text { ferro/Jaguariaiva } \\
\text {-Arapoti. } \\
\end{array}$ & Conularia quichua & 1 & UNESP \\
\hline $\begin{array}{c}\text { DZP-3081 } \\
\mathrm{a}, \mathrm{b}\end{array}$ & $\begin{array}{c}\text { Fm. Ponta } \\
\text { Grossa, } \\
\text { Seqüência B }\end{array}$ & \begin{tabular}{l|} 
Afl. corte estrada \\
ferro/Jaguariaiva \\
-Arapoti. \\
\end{tabular} & $\begin{array}{c}\text { Conularia quichua } \\
\text { Agrupamento }\end{array}$ & 2 & UNESP \\
\hline DZP-3082 & $\begin{array}{c}\text { Fm. Ponta } \\
\text { Grossa, } \\
\text { Seqüềncia B }\end{array}$ & \begin{tabular}{|l|} 
Afl. corte estrada \\
ferro/Jaguariaiva \\
-Arapoti. \\
\end{tabular} & Conularia quichua & 1 & UNESP \\
\hline DZP-3083 & $\begin{array}{c}\text { Fm. Ponta } \\
\text { Grossa, } \\
\text { Seqüência B }\end{array}$ & $\begin{array}{l}\text { Afl. corte estrada } \\
\text { ferro/Jaguariaíva } \\
\text {-Arapoti. } \\
\end{array}$ & Conularia quichua & 1 & UNESP \\
\hline $\begin{array}{c}\text { DZP-3084 } \\
\mathrm{a}, \mathrm{b}\end{array}$ & $\begin{array}{c}\text { Fm. Ponta } \\
\text { Grossa, } \\
\text { Seqüência B }\end{array}$ & $\begin{array}{l}\text { Afl. corte estrada } \\
\text { ferro/Jaguariaíva } \\
\text {-Arapoti. } \\
\end{array}$ & Conularia quichua & 2 & UNESP \\
\hline DZP-3085 & $\begin{array}{c}\text { Fm. Ponta } \\
\text { Grossa, } \\
\text { Seqüência B } \\
\end{array}$ & $\begin{array}{l}\text { Afl. corte estrada } \\
\text { ferro/Jaguariaiva } \\
\text {-Arapoti. } \\
\end{array}$ & Conularia quichua & 1 & UNESP \\
\hline DZP-3314 & $\begin{array}{c}\text { Fm. Ponta } \\
\text { Grossa, } \\
\text { Seqüência B } \\
\end{array}$ & $\begin{array}{l}\text { Afl. corte estrada } \\
\text { ferro/Jaguariaiva } \\
\text {-Arapoti. }\end{array}$ & Indeterminada & 1 & UNESP \\
\hline DZP-3315 & $\begin{array}{c}\text { Fm. Ponta } \\
\text { Grossa, } \\
\text { Seqüēncia B } \\
\end{array}$ & $\begin{array}{l}\text { Afl. corte estrada } \\
\text { ferro/Jaguariaiva } \\
\text {-Arapoti. }\end{array}$ & Indeterminada & 1 & UNESP \\
\hline
\end{tabular}




\begin{tabular}{|c|c|c|c|c|c|}
\hline $\begin{array}{c}D Z P-3316 \\
a, b\end{array}$ & $\begin{array}{c}\text { Fm. Ponta } \\
\text { Grossa, } \\
\text { Seqüência B }\end{array}$ & \begin{tabular}{|l|} 
Afl. corte estrada \\
ferro/Jaguariaiva \\
-Arapoti.
\end{tabular} & Conularia quichua & 2 & UNESP \\
\hline DZP-3317 & $\begin{array}{c}\text { Fm. Ponta } \\
\text { Grossa, } \\
\text { Seqüência B }\end{array}$ & \begin{tabular}{l|} 
Afl. corte estrada \\
ferro/Jaguariaiva \\
-Arapoti.
\end{tabular} & Conularia quichua & 1 & UNESP \\
\hline DZP-3318 & $\begin{array}{c}\text { Fm. Ponta } \\
\text { Grossa, } \\
\text { Seqüência B }\end{array}$ & \begin{tabular}{|l|} 
Afl. corte estrada \\
ferro/Jaguariaiva \\
-Arapoti.
\end{tabular} & Conularia quichua & 1 & UNESP \\
\hline DZP-3319 & $\begin{array}{c}\text { Fm. Ponta } \\
\text { Grossa, } \\
\text { Seqüência B }\end{array}$ & $\begin{array}{l}\text { Afl. corte estrada } \\
\text { ferro/Jaguariaiva } \\
\text {-Arapoti. } \\
\end{array}$ & Indeterminada & 1 & UNESP \\
\hline DZP-3320 & $\begin{array}{c}\text { Fm. Ponta } \\
\text { Grossa, } \\
\text { Seqüência B }\end{array}$ & \begin{tabular}{l|} 
Afl. corte estrada \\
ferro/Jaguariaiva \\
-Arapoti. \\
\end{tabular} & Indeterminada & 1 & UNESP \\
\hline DZP-3321 & $\begin{array}{c}\text { Fm. Ponta } \\
\text { Grossa, } \\
\text { Seqüência B } \\
\end{array}$ & $\begin{array}{l}\text { Afl. corte estrada } \\
\text { ferro/Jaguariaiva } \\
\text {-Arapoti. } \\
\end{array}$ & Conularia quichua & 1 & UNESP \\
\hline DZP-3322 & $\begin{array}{c}\text { Fm. Ponta } \\
\text { Grossa, } \\
\text { Seqüência B }\end{array}$ & $\begin{array}{l}\text { Afl. corte estrada } \\
\text { ferro/Jaguariaiva } \\
\text {-Arapoti. }\end{array}$ & Conularia quichua & 1 & UNESP \\
\hline DZP-3323 & $\begin{array}{c}\text { Fm. Ponta } \\
\text { Grossa, } \\
\text { Seqüência B } \\
\end{array}$ & $\begin{array}{l}\text { Afl. corte estrada } \\
\text { ferro/Jaguariaiva } \\
\text {-Arapoti. } \\
\end{array}$ & Conularia quichua & 1 & UNESP \\
\hline DZP-3324 & $\begin{array}{c}\text { Fm. Ponta } \\
\text { Grossa, } \\
\text { Seqüência B }\end{array}$ & $\begin{array}{l}\text { Afl. corte estrada } \\
\text { ferro/Jaguariaiva } \\
\text {-Arapoti. } \\
\end{array}$ & Conularia quichua & 1 & UNESP \\
\hline DZP-3325 & $\begin{array}{c}\text { Fm. Ponta } \\
\text { Grossa, } \\
\text { Seqüência B } \\
\end{array}$ & $\begin{array}{l}\text { Afl. corte estrada } \\
\text { ferro/Jaguariaiva } \\
\text {-Arapoti. } \\
\end{array}$ & Indeterminada & 1 & UNESP \\
\hline DZP-3327 & $\begin{array}{c}\text { Fm. Ponta } \\
\text { Grossa, } \\
\text { Seqüência B }\end{array}$ & \begin{tabular}{l|} 
Afl. corte estrada \\
ferro/Jaguariaiva \\
-Arapoti. \\
\end{tabular} & Conularia quichua & 1 & UNESP \\
\hline DZP-3328 & $\begin{array}{c}\text { Fm. Ponta } \\
\text { Grossa, } \\
\text { Seqüência B }\end{array}$ & $\begin{array}{l}\text { Afl. corte estrada } \\
\text { ferro/Jaguariaiva } \\
\text {-Arapoti. } \\
\end{array}$ & Indeterminada & 1 & UNESP \\
\hline DZP-3329 & $\begin{array}{c}\text { Fm. Ponta } \\
\text { Grossa, } \\
\text { Seqüência B }\end{array}$ & \begin{tabular}{|l|} 
Afl. corte estrada \\
ferro/Jaguariaiva \\
-Arapoti.
\end{tabular} & Conularia quichua & 1 & UNESP \\
\hline DZP-3330 & $\begin{array}{c}\text { Fm. Ponta } \\
\text { Grossa, } \\
\text { Seqüência B }\end{array}$ & \begin{tabular}{l|} 
Afl. corte estrada \\
ferro/Jaguariaiva \\
-Arapoti. \\
\end{tabular} & Conularia quichua & 1 & UNESP \\
\hline DZP-3331 & $\begin{array}{c}\text { Fm. Ponta } \\
\text { Grossa, } \\
\text { Seqüência B } \\
\end{array}$ & $\begin{array}{l}\text { Afl. corte estrada } \\
\text { ferro/Jaguariaiva } \\
\text {-Arapoti. }\end{array}$ & Conularia quichua & 1 & UNESP \\
\hline DZP-3502 & $\begin{array}{c}\text { Fm. Ponta } \\
\text { Grossa, } \\
\text { Seqüência B }\end{array}$ & $\begin{array}{l}\text { Afl. corte estrada } \\
\text { ferro/Jaguariaiva } \\
\text {-Arapoti. } \\
\end{array}$ & Conularia quichua & 1 & UNESP \\
\hline DZP-3503 & $\begin{array}{c}\text { Fm. Ponta } \\
\text { Grossa, } \\
\text { Seqüência B } \\
\end{array}$ & $\begin{array}{l}\text { Afl. corte estrada } \\
\text { ferro/Jaguariaiva } \\
\text {-Arapoti. } \\
\end{array}$ & Conularia quichua & 1 & UNESP \\
\hline \multirow[t]{2}{*}{ DZP-3504 } & $\begin{array}{c}\text { Fm. Ponta } \\
\text { Grossa, } \\
\text { Seqüência B }\end{array}$ & $\begin{array}{l}\text { Afl. corte estrada } \\
\text { ferro/Jaguariaiva } \\
\text {-Arapoti. }\end{array}$ & Conularia quichua & 1 & UNESP \\
\hline & Fm. Ponta & Afl. corte estrada & & & \\
\hline
\end{tabular}




\begin{tabular}{|c|c|c|c|c|c|}
\hline $\begin{array}{c}\text { DZP-3505 } \\
a, b\end{array}$ & $\begin{array}{c}\text { Grossa, } \\
\text { Seqüência B }\end{array}$ & $\begin{array}{l}\text { ferro/Jaguariaíva } \\
\text {-Arapoti. }\end{array}$ & $\begin{array}{l}\text { Conularia quichua } \\
\text { Agrupamento }\end{array}$ & 2 & UNESP \\
\hline $\begin{array}{c}\text { DZP-3506 } \\
\text { a, b } \\
\end{array}$ & $\begin{array}{c}\text { Fm. Ponta } \\
\text { Grossa, } \\
\text { Seqüência B }\end{array}$ & $\begin{array}{l}\text { Afl. corte estrada } \\
\text { ferro/Jaguariaiva } \\
\text {-Arapoti. }\end{array}$ & Indeterminada & 2 & UNESP \\
\hline DZP-3507 & $\begin{array}{c}\text { Fm. Ponta } \\
\text { Grossa, } \\
\text { Seqüência B } \\
\end{array}$ & \begin{tabular}{|l|} 
Afl. corte estrada \\
ferro/Jaguariaiva \\
-Arapoti. \\
\end{tabular} & Conularia quichua & 1 & UNESP \\
\hline DZP-3508 & $\begin{array}{c}\text { Fm. Ponta } \\
\text { Grossa, } \\
\text { Seqüência B } \\
\end{array}$ & \begin{tabular}{l|} 
Afl. corte estrada \\
ferro/Jaguariaíva \\
-Arapoti. \\
\end{tabular} & Conularia quichua & 1 & UNESP \\
\hline DZP-3509 & $\begin{array}{c}\text { Fm. Ponta } \\
\text { Grossa, } \\
\text { Seqüência B } \\
\end{array}$ & $\begin{array}{l}\text { Afl. corte estrada } \\
\text { ferro/Jaguariaiva } \\
\text {-Arapoti. } \\
\end{array}$ & Conularia quichua & 1 & UNESP \\
\hline DZP-3510 & $\begin{array}{c}\text { Fm. Ponta } \\
\text { Grossa, } \\
\text { Seqüência B }\end{array}$ & 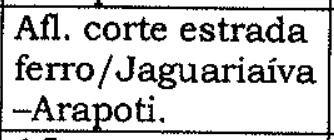 & Conularia quichua & 1 & UNESP \\
\hline DZP-3511 & $\begin{array}{c}\text { Fm. Ponta } \\
\text { Grossa, } \\
\text { Seqüencia B }\end{array}$ & $\begin{array}{l}\text { Afl. corte estrada } \\
\text { ferro/Jaguariaíva } \\
\text {-Arapoti. }\end{array}$ & Conularia quichua & 1 & UNESP \\
\hline DZP-3512 & $\begin{array}{c}\text { Fm. Ponta } \\
\text { Grossa, } \\
\text { Seqüência B } \\
\end{array}$ & $\begin{array}{l}\text { Afl. corte estrada } \\
\text { ferro/Jaguariaiva } \\
\text {-Arapoti. } \\
\end{array}$ & Conularia quichua & 1 & UNESP \\
\hline DZP-3513 & $\begin{array}{c}\text { Fm. Ponta } \\
\text { Grossa, } \\
\text { Seqüência B }\end{array}$ & $\begin{array}{l}\text { Afl. corte estrada } \\
\text { ferro/Jaguariaiva } \\
\text {-Arapoti. } \\
\end{array}$ & Conularia quichua & 1 & UNESP \\
\hline DZP-3514 & $\begin{array}{c}\text { Fm. Ponta } \\
\text { Grossa, } \\
\text { Seqüência B }\end{array}$ & \begin{tabular}{|l|} 
Afl. corte estrada \\
ferro/Jaguariaiva \\
-Arapoti. \\
\end{tabular} & Conularia quichua & 1 & UNESP \\
\hline DZP-3515 & $\begin{array}{c}\text { Fm. Ponta } \\
\text { Grossa, } \\
\text { Següência B }\end{array}$ & \begin{tabular}{|l|} 
Afl. corte estrada \\
ferro/Jaguariaiva \\
-Arapoti. \\
\end{tabular} & Conularia quichua & 1 & UNESP \\
\hline DZP-3516 & $\begin{array}{c}\text { Fm. Ponta } \\
\text { Grossa, } \\
\text { Seqüência B }\end{array}$ & $\begin{array}{l}\text { Afl. corte estrada } \\
\text { ferro/Jaguariaiva } \\
\text {-Arapoti. } \\
\end{array}$ & Conularia quichua & 1 & UNESP \\
\hline DZP-3517 & $\begin{array}{c}\text { Fm. Ponta } \\
\text { Grossa, } \\
\text { Seqüência B }\end{array}$ & \begin{tabular}{|l|} 
Afl. corte estrada \\
ferro/Jaguariaiva \\
-Arapoti. \\
\end{tabular} & Conularia quichua & 1 & UNESP \\
\hline DZP-3609 & $\begin{array}{c}\text { Fm. Ponta } \\
\text { Grossa, } \\
\text { Seqüência B }\end{array}$ & $\begin{array}{l}\text { Afl. corte estrada } \\
\text { ferro/Jaguariaíva } \\
\text {-Arapoti. } \\
\end{array}$ & Conularia quichua & 1 & UNESP \\
\hline DZP-3610 & $\begin{array}{c}\text { Fm. Ponta } \\
\text { Grossa, } \\
\text { Seqüência B }\end{array}$ & $\begin{array}{l}\text { Afl. corte estrada } \\
\text { ferro/Jaguariaiva } \\
\text {-Arapoti. }\end{array}$ & Conularia quichua & 1 & UNESP \\
\hline $\begin{array}{c}\text { DZP-3611 } \\
a, b, c \\
\end{array}$ & $\begin{array}{c}\text { Fm. Ponta } \\
\text { Grossa, } \\
\text { Seqüência B }\end{array}$ & \begin{tabular}{|l|} 
Afl. corte estrada \\
ferro/Jaguariaiva \\
-Arapoti. \\
\end{tabular} & Conularia quichua & 3 & UNESP \\
\hline DZP-3612 & $\begin{array}{c}\text { Fm. Ponta } \\
\text { Grossa, } \\
\text { Seqüência B }\end{array}$ & $\begin{array}{l}\text { Afl. corte estrada } \\
\text { ferro/Jaguariaiva } \\
\text {-Arapoti. } \\
\end{array}$ & Conularia quichua & 1 & UNESP \\
\hline DZP-3613 & $\begin{array}{c}\text { Fm. Ponta } \\
\text { Grossa, } \\
\text { Seqüência B } \\
\end{array}$ & $\begin{array}{l}\text { Afl. corte estrada } \\
\text { ferro/Jaguariaiva } \\
\text {-Arapoti. } \\
\end{array}$ & Conularia quichua & 1 & UNESP \\
\hline DZP-3614 & $\begin{array}{l}\text { Fm. Ponta } \\
\text { Grossa, }\end{array}$ & $\begin{array}{l}\text { Afl. corte estrada } \\
\text { ferro/Jaguariaiva }\end{array}$ & Conularia quichua & 1 & UNESP \\
\hline
\end{tabular}




\begin{tabular}{|c|c|c|c|c|c|}
\hline & Seqüência B & -Arapoti. & & & \\
\hline DZP-3615 & $\begin{array}{c}\text { Fm. Ponta } \\
\text { Grossa, } \\
\text { Seqüência B }\end{array}$ & \begin{tabular}{|l|} 
Afl. corte estrada \\
ferro/Jaguariaiva \\
-Arapoti. \\
\end{tabular} & Conularia quichua & 1 & UNESP \\
\hline DZP-3616 & $\begin{array}{c}\text { Fm. Ponta } \\
\text { Grossa, } \\
\text { Seqüência B } \\
\end{array}$ & $\begin{array}{l}\text { Afl. corte estrada } \\
\text { ferro/Jaguariaiva } \\
\text {-Arapoti. }\end{array}$ & Conularia quichua & 1 & UNESP \\
\hline DZP-3617 & $\begin{array}{c}\text { Fm. Ponta } \\
\text { Grossa, } \\
\text { Seqüência B }\end{array}$ & $\begin{array}{l}\text { Afl. corte estrada } \\
\text { ferro/Jaguariaiva } \\
\text {-Arapoti. }\end{array}$ & Conularia quichua & 1 & UNESP \\
\hline DZP-3618 & $\begin{array}{c}\text { Fm. Ponta } \\
\text { Grossa, } \\
\text { Seqüência B }\end{array}$ & $\begin{array}{l}\text { Afl. corte estrada } \\
\text { ferro/Jaguariaiva } \\
\text {-Arapoti. }\end{array}$ & Conularia quichua & 1 & UNESP \\
\hline DZP-3620 & $\begin{array}{c}\text { Fm. Ponta } \\
\text { Grossa, } \\
\text { Seqüència B }\end{array}$ & \begin{tabular}{|l|} 
Afl. corte estrada \\
ferro/Jaguariaiva \\
-Arapoti.
\end{tabular} & Conularia quichua & 1 & UNESP \\
\hline $\begin{array}{c}\mathrm{DZP}-3621 \\
\mathrm{a}, \mathrm{b}\end{array}$ & $\begin{array}{c}\text { Fm. Ponta } \\
\text { Grossa, } \\
\text { Seqüência B } \\
\end{array}$ & \begin{tabular}{l|} 
Afl. corte estrada \\
ferro/Jaguariaiva \\
-Arapoti. \\
\end{tabular} & Conularia quichua & 2 & UNESP \\
\hline DZP-3622 & $\begin{array}{c}\text { Fm. Ponta } \\
\text { Grossa, } \\
\text { Seqüência B } \\
\end{array}$ & $\begin{array}{l}\text { Afl. corte estrada } \\
\text { ferro/Jaguariaiva } \\
\text {-Arapoti. }\end{array}$ & Indeterminada & 1 & UNESP \\
\hline DZP-3623 & $\begin{array}{c}\text { Fm. Ponta } \\
\text { Grossa, } \\
\text { Seqüência B } \\
\end{array}$ & \begin{tabular}{|l|} 
Afl. corte estrada \\
ferro/Jaguariaiva \\
-Arapoti. \\
\end{tabular} & Conularia quichua & 1 & UNESP \\
\hline $\begin{array}{c}\text { DZP-3624 } \\
a, b\end{array}$ & $\begin{array}{c}\text { Fm. Ponta } \\
\text { Grossa, } \\
\text { Seqüencia B } \\
\end{array}$ & $\begin{array}{l}\text { Afl. corte estrada } \\
\text { ferro/Jaguariaiva } \\
\text {-Arapoti. } \\
\end{array}$ & Conularia quichua & 2 & UNESP \\
\hline DZP-3625 & $\begin{array}{c}\text { Fm. Ponta } \\
\text { Grossa, } \\
\text { Seqüência B }\end{array}$ & $\begin{array}{l}\text { Afl. corte estrada } \\
\text { ferro/Jaguariaiva } \\
\text {-Arapoti. }\end{array}$ & Indeterminada & 1 & UNESP \\
\hline DZP-3626 & $\begin{array}{c}\text { Fm. Ponta } \\
\text { Grossa, } \\
\text { Seqüencia B }\end{array}$ & \begin{tabular}{l|} 
Afl. corte estrada \\
ferro/Jaguariaíva \\
-Arapoti. \\
\end{tabular} & Conularia quichua & 1. & UNESP \\
\hline DZP-3627 & $\begin{array}{c}\text { Fm. Ponta } \\
\text { Grossa, } \\
\text { Seqüência B }\end{array}$ & $\begin{array}{l}\text { Afl. corte estrada } \\
\text { ferro/Jaguariaiva } \\
\text {-Arapoti. } \\
\end{array}$ & Conularia quichua & 1 & UNESP \\
\hline DZP-3628 & $\begin{array}{c}\text { Fm. Ponta } \\
\text { Grossa, } \\
\text { Seqüencia B }\end{array}$ & \begin{tabular}{|l|} 
Afl. corte estrada \\
ferro/Jaguariaíva \\
-Arapoti. \\
\end{tabular} & Conularia quichua & 1 & UNESP \\
\hline DZP-3629 & $\begin{array}{c}\text { Fm. Ponta } \\
\text { Grossa, } \\
\text { Seqüência B }\end{array}$ & $\begin{array}{l}\text { Afl. corte estrada } \\
\text { ferro/Jaguariaiva } \\
\text {-Arapoti. } \\
\end{array}$ & Conularia quichua & 1 & UNESP \\
\hline DZP-3630 & $\begin{array}{c}\text { Fm. Ponta } \\
\text { Grossa, } \\
\text { Seqüencia B }\end{array}$ & $\begin{array}{l}\text { Afl. corte estrada } \\
\text { ferro/Jaguariaiva } \\
\text {-Arapoti. }\end{array}$ & Conularia quichua & 1 & UNESP \\
\hline DZP-3631 & $\begin{array}{c}\text { Fm. Ponta } \\
\text { Grossa, } \\
\text { Seqüência B }\end{array}$ & $\begin{array}{l}\text { Afl. corte estrada } \\
\text { ferro/Jaguariaíva } \\
\text {-Arapoti. }\end{array}$ & Conularia quichua & 1 & UNESP \\
\hline $\begin{array}{c}\mathrm{DZP}-3632 \\
\mathrm{a}, \mathrm{b} \\
\end{array}$ & $\begin{array}{c}\text { Fm. Ponta } \\
\text { Grossa, } \\
\text { Seqüência B }\end{array}$ & $\begin{array}{l}\text { Afl. corte estrada } \\
\text { ferro/Jaguariaiva } \\
\text {-Arapoti. }\end{array}$ & $\begin{array}{c}\text { Conularia quichua } \\
\text { Agrupamento }\end{array}$ & 2 & UNESP \\
\hline $\begin{array}{c}\mathrm{DZP}-3633 \\
\mathrm{a}, \mathrm{b}\end{array}$ & $\begin{array}{c}\text { Fm. Ponta } \\
\text { Grossa, } \\
\text { Seqüência B } \\
\end{array}$ & $\begin{array}{l}\text { Afl. corte estrada } \\
\text { ferro/Jaguariaiva } \\
\text {-Arapoti. }\end{array}$ & $\begin{array}{l}\text { Conularia quichua } \\
\text { Agrupamento }\end{array}$ & 2 & UNESP \\
\hline
\end{tabular}




\begin{tabular}{|c|c|c|c|c|c|}
\hline DZP-3634 & $\begin{array}{c}\text { Fm. Ponta } \\
\text { Grossa, } \\
\text { Seqüência B }\end{array}$ & $\begin{array}{l}\text { Afl. corte estrada } \\
\text { ferro/Jaguariaíva } \\
\text {-Arapoti. }\end{array}$ & Conularia quichua & 1 & UNESP \\
\hline DZP-3684 & $\begin{array}{c}\text { Fm. Ponta } \\
\text { Grossa, Ponta } \\
\text { Grossa }\end{array}$ & Curva I & Conularia quichua & 1 & UNESP \\
\hline DZP-3685 & $\begin{array}{c}\text { Fm. Ponta } \\
\text { Grossa, Ponta } \\
\text { Grossa } \\
\end{array}$ & Curva I & Indeterminada & 1 & UNESP \\
\hline $\begin{array}{c}\text { DZP-3686 } \\
\text { a, b, c }\end{array}$ & $\begin{array}{c}\text { Fm. Ponta } \\
\text { Grossa, Ponta } \\
\text { Grossa } \\
\end{array}$ & Curva II & $\begin{array}{c}\text { Conularia quichua } \\
\text { Agrupamento }\end{array}$ & 3 & UNESP \\
\hline DZP-3687 & $\begin{array}{c}\text { Fm. Ponta } \\
\text { Grossa, Ponta } \\
\text { Grossa }\end{array}$ & - & Conularia quichua & 1 & UNESP \\
\hline DZP-16814 & $\begin{array}{c}\text { Fm. Ponta } \\
\text { Grossa, } \\
\text { Seqüência B }\end{array}$ & \begin{tabular}{l|} 
Afl. corte estrada \\
ferro/Jaguariaiva \\
-Arapoti. \\
\end{tabular} & Conularia quichua & 1 & UNESP \\
\hline DZP-16815 & $\begin{array}{c}\text { Fm. Ponta } \\
\text { Grossa, } \\
\text { Seqüência B }\end{array}$ & $\begin{array}{l}\text { Afl. corte estrada } \\
\text { ferro/Jaguariaíva } \\
\text {-Arapoti. }\end{array}$ & Conularia quichua & 1 & UNESP \\
\hline DZP-16816 & $\begin{array}{c}\text { Fm. Ponta } \\
\text { Grossa, } \\
\text { Seqüencia B }\end{array}$ & $\begin{array}{l}\text { Afl. corte estrada } \\
\text { ferro/Jaguariaiva } \\
\text {-Arapoti. } \\
\end{array}$ & Indeterminada & 1 & UNESP \\
\hline DZP-16817 & $\begin{array}{c}\text { Fm. Ponta } \\
\text { Grossa, } \\
\text { Seqüencia B }\end{array}$ & $\begin{array}{l}\text { Afl. corte estrada } \\
\text { ferro/Jaguariaíva } \\
\text {-Arapoti. } \\
\end{array}$ & Indeterminada & 1 & UNESP \\
\hline DZP-16818 & $\begin{array}{c}\text { Fm. Ponta } \\
\text { Grossa, } \\
\text { Seqüência B }\end{array}$ & $\begin{array}{l}\text { Afl. corte estrada } \\
\text { ferro/Jaguariaiva } \\
\text {-Arapoti. }\end{array}$ & Conularia quichua & 1 & UNESP \\
\hline DZP-16819 & $\begin{array}{c}\text { Fm. Ponta } \\
\text { Grossa, } \\
\text { Seqüência B } \\
\end{array}$ & $\begin{array}{l}\text { Afl. corte estrada } \\
\text { ferro/Jaguariaiva } \\
\text {-Arapoti. }\end{array}$ & Conularia quichua & 1 & UNESP \\
\hline DZP-16820 & $\begin{array}{c}\text { Fm. Ponta } \\
\text { Grossa, } \\
\text { Seqüência B }\end{array}$ & $\begin{array}{l}\text { Afl. corte estrada } \\
\text { ferro/Jaguariaiva } \\
\text {-Arapoti. } \\
\end{array}$ & Conularia quichua & 1 & UNESP \\
\hline DZP-17036 & $\begin{array}{c}\text { Fm. Ponta } \\
\text { Grossa, } \\
\text { Seqüencia B }\end{array}$ & $\begin{array}{l}\text { Afl. corte estrada } \\
\text { ferro/Jaguariaiva } \\
\text {-Arapoti. } \\
\end{array}$ & Conularia quichua & 1 & UNESP \\
\hline DZP-17037 & $\begin{array}{c}\text { Fm. Ponta } \\
\text { Grossa, } \\
\text { Seqüencia B }\end{array}$ & $\begin{array}{l}\text { Afl. corte estrada } \\
\text { ferro/Jaguariaiva } \\
\text {-Arapoti. } \\
\end{array}$ & Conularia quichua & 1 & UNESP \\
\hline DZP- 17038 & $\begin{array}{c}\text { Fm. Ponta } \\
\text { Grossa, } \\
\text { Seqüencia B }\end{array}$ & \begin{tabular}{|l|} 
Afl. corte estrada \\
ferro/Jaguariaiva \\
-Arapoti. \\
\end{tabular} & Conularia quichua & 1 & UNESP \\
\hline DZP-17039 & $\begin{array}{c}\text { Fm. Ponta } \\
\text { Grossa, } \\
\text { Sequeencia B }\end{array}$ & $\begin{array}{l}\text { Afl. corte estrada } \\
\text { ferro/Jaguariaiva } \\
\text {-Arapoti. }\end{array}$ & Conularia quichua & 1 & UNESP \\
\hline DZP-17040 & $\begin{array}{c}\text { Fm. Ponta } \\
\text { Grossa, } \\
\text { Seqüência B }\end{array}$ & $\begin{array}{l}\text { Afl. corte estrada } \\
\text { ferro/Jaguariaiva } \\
\text {-Arapoti. }\end{array}$ & Conularia quichua & 1 & UNESP \\
\hline \multirow[t]{2}{*}{ DZP-17041 } & $\begin{array}{c}\text { Fm. Ponta } \\
\text { Grossa, } \\
\text { Seqüência B }\end{array}$ & $\begin{array}{l}\text { Afl. corte estrada } \\
\text { ferro/Jaguariaiva } \\
\text {-Arapoti. } \\
\end{array}$ & Conularia quichua & 1 & UNESP \\
\hline & Fm. Ponta & Afl. corte estrada & & & \\
\hline
\end{tabular}




\begin{tabular}{|c|c|c|c|c|c|}
\hline $\mathrm{DZP}-17042$ & $\begin{array}{c}\text { Grossa, } \\
\text { Seqüência B }\end{array}$ & $\begin{array}{l}\text { ferro/Jaguariaiva } \\
\text {-Arapoti. }\end{array}$ & Conularia quichua & 1 & UNESP \\
\hline DZP-17043 & $\begin{array}{c}\text { Fm. Ponta } \\
\text { Grossa, } \\
\text { Seqüência B }\end{array}$ & \begin{tabular}{|l|} 
Afl. corte estrada \\
ferro/Jaguariaiva \\
-Arapoti. \\
\end{tabular} & Conularia quichua & 1 & UNESP \\
\hline DZP-17044 & $\begin{array}{c}\text { Fm. Ponta } \\
\text { Grossa, } \\
\text { Seqüência B }\end{array}$ & $\begin{array}{l}\text { Afl. corte estrada } \\
\text { ferro/Jaguariaiva } \\
\text {-Arapoti. } \\
\end{array}$ & Conularia quichua & 1 & UNESP \\
\hline DZP-17045 & $\begin{array}{c}\text { Fm. Ponta } \\
\text { Grossa, } \\
\text { Seqüência B }\end{array}$ & $\begin{array}{l}\text { Afl. corte estrada } \\
\text { ferro/Jaguariaiva } \\
\text {-Arapoti. }\end{array}$ & Conularia quichua & 1 & UNESP \\
\hline DZP-17046 & $\begin{array}{c}\text { Fm. Ponta } \\
\text { Grossa, } \\
\text { Seqüência B }\end{array}$ & $\begin{array}{l}\text { Afl. corte estrada } \\
\text { ferro/Jaguariaiva } \\
\text {-Arapoti. }\end{array}$ & Conularia quichua & 1 & UNESP \\
\hline DZP-17047 & $\begin{array}{c}\text { Fm. Ponta } \\
\text { Grossa, } \\
\text { Seqüência B }\end{array}$ & $\begin{array}{l}\text { Afl. corte estrada } \\
\text { ferro/Jaguariaiva } \\
\text {-Arapoti. }\end{array}$ & Conularia quichua & 1 & UNESP \\
\hline DZP-17048 & $\begin{array}{c}\text { Fm. Ponta } \\
\text { Grossa, } \\
\text { Seqüência B }\end{array}$ & $\begin{array}{l}\text { Afl. corte estrada } \\
\text { ferro/Jaguariaiva } \\
\text {-Arapoti. }\end{array}$ & Conularia quichua & 1 & UNESP \\
\hline DZP-17049 & $\begin{array}{c}\text { Fm. Ponta } \\
\text { Grossa, } \\
\text { Seqüencia B }\end{array}$ & $\begin{array}{l}\text { Afl. corte estrada } \\
\text { ferro/Jaguariaiva } \\
\text {-Arapoti. } \\
\end{array}$ & Conularia quichua & 1 & UNESP \\
\hline DZP-17050 & $\begin{array}{c}\text { Fm. Ponta } \\
\text { Grossa, } \\
\text { Seqüência B }\end{array}$ & $\begin{array}{l}\text { Afl. corte estrada } \\
\text { ferro/Jaguariaiva } \\
\text {-Arapoti. }\end{array}$ & Conularia quichua & 1 & UNESP \\
\hline DZP 17051 & $\begin{array}{c}\text { Fm. Ponta } \\
\text { Grossa, } \\
\text { Seqüência B }\end{array}$ & $\begin{array}{l}\text { Afl. corte estrada } \\
\text { ferro/Jaguariaiva } \\
\text {-Arapoti. }\end{array}$ & Conularia quichua & 1 & UNESP \\
\hline DZP-17052 & $\begin{array}{c}\text { Fm. Ponta } \\
\text { Grossa, } \\
\text { Seqüencia B }\end{array}$ & \begin{tabular}{l|} 
Afl. corte estrada \\
ferro/Jaguariaiva \\
-Arapoti.
\end{tabular} & Conularia quichua & 1 & UNESP \\
\hline DZP-17053 & $\begin{array}{c}\text { Fm. Ponta } \\
\text { Grossa, } \\
\text { Seqüencia B }\end{array}$ & $\begin{array}{l}\text { Afl. corte estrada } \\
\text { ferro/Jaguariaiva } \\
\text {-Arapoti. } \\
\end{array}$ & Conularia quichua & 1 & UNESP \\
\hline DZP-17057 & $\begin{array}{c}\text { Fm. Ponta } \\
\text { Grossa, } \\
\text { Seqüencia B }\end{array}$ & $\begin{array}{l}\text { Afl. corte estrada } \\
\text { ferro/Jaguariaiva } \\
\text {-Arapoti. }\end{array}$ & Conularia quichua & 1 & UNESP \\
\hline DZP-17058 & $\begin{array}{c}\text { Fm. Ponta } \\
\text { Grossa, } \\
\text { Seqüencia B }\end{array}$ & \begin{tabular}{|l|} 
Afl. corte estrada \\
ferro/Jaguariaiva \\
-Arapoti. \\
\end{tabular} & Conularia quichua & 1 & UNESP \\
\hline $\mathrm{GP} / 1 \mathrm{E}-3177$ & $\begin{array}{c}\text { Fm. Ponta } \\
\text { Grossa, } \\
\text { Jaguariaiva }\end{array}$ & $\begin{array}{l}\text { Afl. corte estrada } \\
\text { ferro/Jaguariaiva } \\
\text {-Arapoti. }\end{array}$ & Conularia quichua & 1 & USP \\
\hline $\mathrm{GP} / 1 \mathrm{E}-3178$ & $\begin{array}{c}\text { Fm. Ponta } \\
\text { Grossa, } \\
\text { Jaguariaiva }\end{array}$ & $\begin{array}{l}\text { Afl. corte estrada } \\
\text { ferro/Jaguariaiva } \\
\text {-Arapoti. } \\
\end{array}$ & Conularia quichua & 1 & USP \\
\hline GP/1E-3191 & $\begin{array}{c}\text { Fm. Ponta } \\
\text { Grossa, } \\
\text { Jaguariaiva }\end{array}$ & $\begin{array}{l}\text { Afl. corte estrada } \\
\text { ferro/Jaguariaíva } \\
\text {-Arapoti. } \\
\end{array}$ & Conularia quichua & 1 & USP \\
\hline GP/1E-4914 & $\begin{array}{c}\text { Fm. Ponta } \\
\text { Grossa, } \\
\text { Seqüência B }\end{array}$ & \begin{tabular}{|l|} 
Afl. corte estrada \\
ferro/Jaguariaiva \\
-Arapoti. \\
\end{tabular} & Conularia quichua & 1 & USP \\
\hline $\mathrm{GP} / 3 \mathrm{E}-3569$ & $\begin{array}{l}\text { Fm. Ponta } \\
\text { Grossa, }\end{array}$ & $\begin{array}{l}\text { Afl. corte estrada } \\
\text { ferro/Jaguariaiva }\end{array}$ & Conularia quichua & 1 & USP \\
\hline
\end{tabular}




\begin{tabular}{|c|c|c|c|c|c|}
\hline & Jaguariaíva & -Arapoti. & & & \\
\hline GP/3E-4194 & $\begin{array}{c}\text { Fm. Ponta } \\
\text { Grossa, } \\
\text { Jaguariaiva }\end{array}$ & $\begin{array}{l}\text { Afl. corte estrada } \\
\text { ferro/Jaguariaíva } \\
\text {-Arapoti. }\end{array}$ & $\begin{array}{c}\text { Paraconularia } \\
\text { africana }\end{array}$ & 1 & USP \\
\hline $\mathrm{CuPg}-01$ & $\begin{array}{c}\text { Fm. Ponta } \\
\text { Grossa, } \\
\text { Jaguariaiva }\end{array}$ & $\begin{array}{l}\text { Afl. corte estrada } \\
\text { ferro/Jaguariaiva } \\
\text {-Arapoti. }\end{array}$ & $\begin{array}{c}\text { Paraconularia } \\
\text { africana }\end{array}$ & 1 & UNG \\
\hline CuPg-02 & $\begin{array}{c}\text { Fm. Ponta } \\
\text { Grossa, } \\
\text { Jaguariaiva }\end{array}$ & $\begin{array}{l}\text { Afl. corte estrada } \\
\text { ferro/Jaguariaiva } \\
\text {-Arapoti. }\end{array}$ & Conularia quichua & 1 & UNG \\
\hline CuPg-04 & $\begin{array}{c}\text { Fm. Ponta } \\
\text { Grossa, } \\
\text { Jaguariaíva }\end{array}$ & \begin{tabular}{|l|} 
Afl. corte estrada \\
ferro/Jaguariaiva \\
-Arapoti. \\
\end{tabular} & Conularia quichua & 1 & UNG \\
\hline CuPg-05 & $\begin{array}{c}\text { Fm. Ponta } \\
\text { Grossa, } \\
\text { Jaguariaiva }\end{array}$ & $\begin{array}{l}\text { Afl. corte estrada } \\
\text { ferro/Jaguariaiva } \\
\text {-Arapoti. }\end{array}$ & Conularia quichua & 1 & UNG \\
\hline CuPg-06 & $\begin{array}{c}\text { Fm. Ponta } \\
\text { Grossa, } \\
\text { Jaguariaíva }\end{array}$ & $\begin{array}{l}\text { Afl. corte estrada } \\
\text { ferro/Jaguariaiva } \\
\text {-Arapoti. }\end{array}$ & Indeterminada & 1 & UNG \\
\hline CuPg-09 & $\begin{array}{c}\text { Fm. Ponta } \\
\text { Grossa, } \\
\text { Jaguariaiva }\end{array}$ & $\begin{array}{l}\text { Afl. corte estrada } \\
\text { ferro/Jaguariaíva } \\
\text {-Arapoti. }\end{array}$ & Conularia quichua & 1 & UNG \\
\hline CuPg-10 & $\begin{array}{c}\text { Fm. Ponta } \\
\text { Grossa, } \\
\text { Jaguariaiva }\end{array}$ & $\begin{array}{l}\text { Afl. corte estrada } \\
\text { ferro/Jaguariaiva } \\
\text {-Arapoti. }\end{array}$ & Conularia quichua & 1 & UNG \\
\hline CuPg-11 & $\begin{array}{c}\text { Fm. Ponta } \\
\text { Grossa, } \\
\text { Seqüência B }\end{array}$ & $\begin{array}{l}\text { Afl. corte estrada } \\
\text { ferro/Jaguariaiva } \\
\text {-Arapoti. } \\
\end{array}$ & Indeterminada & 1 & UNG \\
\hline $\mathrm{CuPg}-12$ & $\begin{array}{c}\text { Fm. Ponta } \\
\text { Grossa, } \\
\text { Jaguariaiva }\end{array}$ & $\begin{array}{l}\text { Afl. corte estrada } \\
\text { ferro/Jaguariaiva } \\
\text {-Arapoti. }\end{array}$ & Conularia quichua & 1 & UNG \\
\hline CuPg-14 & $\begin{array}{c}\text { Fm. Ponta } \\
\text { Grossa, } \\
\text { Jaguariaiva }\end{array}$ & $\begin{array}{l}\text { Afl. corte estrada } \\
\text { ferro/Jaguariaiva } \\
\text {-Arapoti. }\end{array}$ & Conularia quichua & 1 & UNG \\
\hline D-058 & $\begin{array}{c}\text { Fm. Ponta } \\
\text { Grossa, Ponta } \\
\text { Grossa }\end{array}$ & Curva I & Conularia quichua & 1 & UEPG \\
\hline
\end{tabular}

